\title{
miR-149 Suppresses Breast Cancer Metastasis by Blocking Paracrine Interactions with Macrophages
}

\author{
Von der Fakultät Energie-, Verfahrens- und Biotechnik der \\ Universität Stuttgart zur Erlangung der Würde eines \\ Doktors der Naturwissenschaften (Dr. rer. nat.) genehmigte \\ Abhandlung
}

Vorgelegt von

\section{Ismael Sánchez-González}

aus Mexiko-Stadt, Mexiko

\author{
Hauptberichter: Prof. Dr. Monilola Olayioye \\ Mitberichter: Prof. Dr. Thomas Kufer \\ Tag der mündlichen Prüfung: 11.11.2020
}

Institut für Zellbiologie und Immunologie

Universität Stuttgart

2020 



\section{Eidesstattliche Erklärung}

Hiermit erkläre ich, Ismael Sánchez-González, dass ich dies vorliegende Arbeit selbständig angefertigt habe. Es wurden nur die in der Arbeit ausdrücklich benannten Quellen und Hilfsmittel benutzt. Wörtlich oder sinngemäß übernommenes Gedankengut habe ich als solches kenntlich gemacht.

I hereby assure that I performed this work independently without further help or other materials than stated.

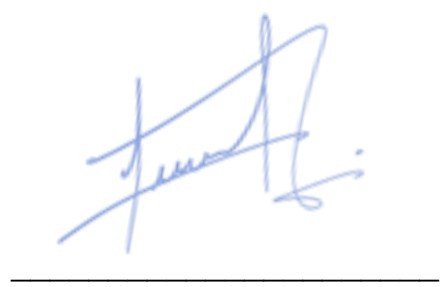

Ismael Sánchez-González

5th October 2020, Stuttgart 



\section{Table of Content}

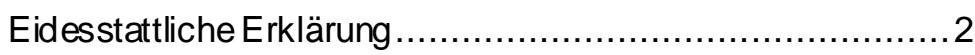

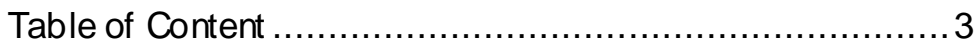

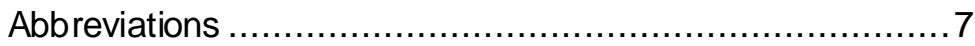

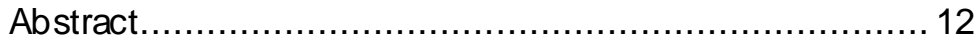

Zusammenfassung ................................................ 15

1. Introduction ..................................................... 18

$1.1 \quad$ Breast cancer ......................................... 18

1.1.1 Triple-negative breast cancer ..................... 19

1.2 Tumor microenvironment.................................2 21

1.2.1 Origins of macrophages ........................... 24

1.2.2 M1/M2 polarization ................................ 26

1.2.3 Tumor associated macrophages................. 29

1.2.3.1 TAMs and cancer cell invasion................29

1.2.3.2 TAMs and angiogenesis........................ 32

1.2.3.3 TAMs and immune suppression ............... 33

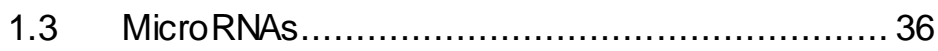

1.3.1 MicroRNA biogenesis.............................. 37

1.3.2 Mechanism of action of miRNAs ................. 40

1.3.3 MiRNAs in cancer.................................... 42 
1.4 Aim of the thesis.

2.Material and Methods................................................ 48

$2.1 \quad$ Materials ..................................................... 48

2.1.1 Equipment...................................... 48

2.1.2 Chemicals and consumables..................... 49

2.1.3 Buffers and solutions ..............................5 53

2.1.4 Cell culture............................................ 56

2.1.5 Oligonucleotides.................................... 57

2.1.6 Plasmids and vectors..............................59

2.1.7 Antibodies ........................................ 59

2.1.8 Kits and enzymes................................ 60

2.1.9 Animals........................................... 62

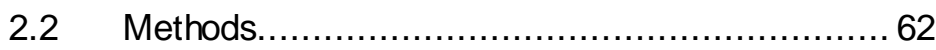

2.2.1 Cell culture and transfection.......................62

2.2.1.1 Cell lines......................................... 62

2.2.1.2 Primary human monocyte isolation and primary human macrophage differentiation ..............64

2.2.2 RNA isolation and quantitative PCR ............ 64

2.2.3 Vectors and cloning ................................. 65

2.2.4 Luciferase reporter assay .......................... 65

2.2.5 Transwell co-cultures................................ 66 
2.2.6 Three-Dimensional tumor spheroid co-culture

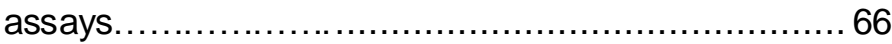

2.2.7 Migration, invasion, and proliferation assays..67

2.2.8 Cell lysis, immunoprecipitation, and western

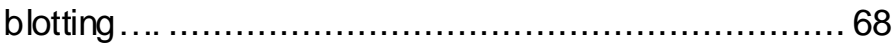

2.2.9 ELISA assays ..................................... 69

2.2.10 Animal experiments ................................69

2.2.11 Tissue immunostaining ............................. 69

2.2.12 miRNA target prediction, $\mathrm{KM}$ plot and correlation analyses............................................. 70

2.2.13 Statistical analysis ................................. 71

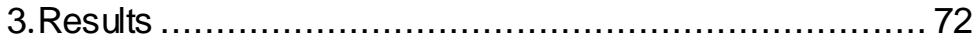

3.1 MiR-149 and survival of TNBC patients............... 72

3.2 MiR-149 overexpression in MDA-MB-231 sphero ids impairs THP-1 macrophage recruitment ........................ 77

3.3 CSF1 is a direct target of miR-149 .................... 80

3.4 MiR-149 suppresses CSF1-dependent communication between breast cancer cells and THP-1 macrophages. 83

3.5 MiR-149 impairs paracrine signal crosstalk of MDAMB-231 cells with THP-1 cells ................................. 87

3.6 MiR-149 suppresses EGFR ligand production by and M2 polarization of primary human macrophages.......90 


\subsection{Characterization of MDA-MB-231 cells stably}

expressing miR-149 ........................................... 93

3.8 MiR-149 inhibits macrophage recruitment and lung metastasis of breast cancer cells in vivo........................ 95

3.9 MiR-149 is epigenetically silenced in TNBC....... 100

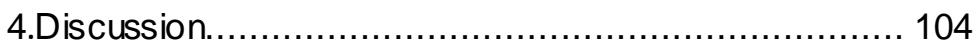

4.1 MiR-149 as a prog nostic marker in lymph nodepositive TNBC.................................................... 106

4.2 MiR-149 regulates macrophage recruitment and M2polarization by targeting CSF1 ................................ 107

4.3 MiR-149 regulates the EGF/CSF1 crosstalk between breast cancercells and macrophages

4.4 MiR-149 is epigenetically silenced in TNBC....... 117

4.5 Conclusions and outlook............................... 119

List of Figures.................................................... 122

List of Tables........................................................ 124

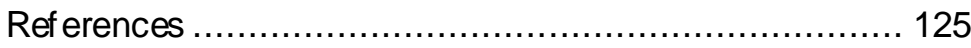

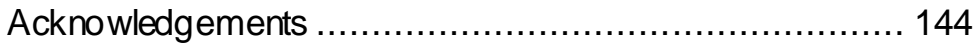

Curriculum vitae................................................. 146

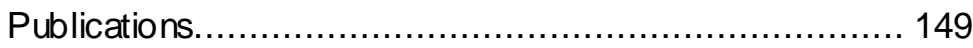

Conference presentations....................................... 150 


\section{Abbreviations}

$\%$

${ }^{\circ} \mathrm{C}$

$\mu \mathrm{g}$

$\mu \mathrm{L}$

$\mu \mathrm{m}$

$\mu \mathrm{M}$

2-ME

A

$A b$

AGO

APS

AREG

ARG1

ATP

AZA

bp

BSA

C

CAF

CCL

C. elegans

cDNA

$\mathrm{CM}$

$\mathrm{CO}_{2}$

$\mathrm{cpm}$

$\mathrm{Cq}$

CSF1

CTLA-4

DGCR8

DCM percent (per hundred)

degree Celsius

microgram

microliter

micrometer

micromolar

2-mercaptoethanol

Adenosine

Antibody

argonaute protein

ammonium persulfate

Amphiregulin

Arginase-1

Adenosine triphosphate

5-aza-2'-deoxycytidine

Base pairs

Bovine serum albumin

Cytosine

cancer-associated fibroblast

C-C motif chemokine ligand

caenorhabditis elegans

complementary deoxyribonucleic acid

conditioned medium

carbon dioxide

counts per million

quantification cycle

colony-stimulating factor-1

cytotoxic T-lymphocyte associated antigen-4

DiGeorge critical region 8

double conditioned medium 


\begin{tabular}{|c|c|}
\hline DMEM & Dulbecco's Modified Eagle Medium \\
\hline DMSO & dimethyl sulfoxide \\
\hline DNA & deoxyribonucleic acid \\
\hline DNMT & DNA methyltransferases \\
\hline dNTP & deoxynucleotide triphosphate \\
\hline $\mathrm{DTT}$ & Dithiothreitol \\
\hline EDTA & ethylenediaminetetraacetic acid \\
\hline EGF & epidermal growth factor \\
\hline EGFR & epidermal growth factor receptor \\
\hline ER & estrogen receptor \\
\hline ER & endoplasmic reticulum \\
\hline FACS & fluorescence activated cell sorting \\
\hline FCS & fetal calf serum \\
\hline FGF & fibroblast growth factor \\
\hline$g$ & gravitational acceleration \\
\hline G & Guanine \\
\hline GAP & GTPase activating protein \\
\hline GAPDH & glyceraldehyde-3-Phosphate dehydrogenase \\
\hline GDI & guanosine nucleotide dissociation inhibitors \\
\hline GLUT1 & gluco se transporter-1 \\
\hline GO & gene ontology \\
\hline $\mathrm{h}$ & hour \\
\hline HIF & hypoxia-inducible transcription factor \\
\hline HEK293 & human embryonic kidney cells 293 \\
\hline HER2 & $\begin{array}{l}\text { human epidermal growth factor receptor } 2 \\
\text { (ErbB2) }\end{array}$ \\
\hline HMGB1 & High mobility group box 1 \\
\hline HRP & horseradish peroxidase \\
\hline hsa & homo sapiens \\
\hline hsa-miR & homo sapiens microRNA \\
\hline IDO & indoleamine 2,3-dioxygenase \\
\hline IF & Immunof luorescence \\
\hline $\mathrm{IL}$ & Interleukin \\
\hline
\end{tabular}




\begin{tabular}{|c|c|}
\hline $\begin{array}{l}\text { IFNy } \\
\text { IV }\end{array}$ & $\begin{array}{l}\text { Interferon gamma } \\
\text { intravenous }\end{array}$ \\
\hline kDa & kilo Dalton \\
\hline LN & lymph node \\
\hline $\mathrm{mA}$ & Milliampere \\
\hline mfe & minimum free energy \\
\hline $\mathrm{mg}$ & Milligram \\
\hline miR- & mature miRNA \\
\hline miRISC & microRNA induced silencing complex \\
\hline miRNA & microRNA \\
\hline $\mathrm{ml}$ & milliliter \\
\hline $\mathrm{mM}$ & Millimolar \\
\hline MMP & matrix metallopeptidases \\
\hline mRNA & messenger ribonucleic acid \\
\hline MRC1 & mannose receptor C-type 1 \\
\hline mut & mutated \\
\hline MW & molecular weight \\
\hline ncRNA & non-protein-coding RNA \\
\hline NK & Natural killer \\
\hline n.s. & non significant \\
\hline $\mathrm{Na}_{3} \mathrm{VO}_{4}$ & sodium orthovanadate \\
\hline NaDoc & sodium deoxycholate \\
\hline $\mathrm{NaF}$ & sodium fluoride \\
\hline $\mathrm{ng}$ & Nanogram \\
\hline nt & Nucleotide \\
\hline OD & optical density \\
\hline PBS & phosphate buffered saline \\
\hline PBMCs & peripheral blood mononuclear cells \\
\hline PCR & polymerase chain reaction \\
\hline PDBu & phorbol 12, 13-Dibutyrate \\
\hline PD-L1 & programmed death ligand 1 \\
\hline PFA & paraf ormaldehyde \\
\hline $\mathrm{pH}$ & potential of hydrogen \\
\hline
\end{tabular}


PMSF Phenylmethylsulfonylfluorid

PPIA peptidyl-prolyl cis-trans isomerase

pre-miRNA precursor microRNA

pri-miRNA primary microRNA

PTPRO protein tyrosine phosphatase receptor-type $O$

qRT-PCR quantitative real time polymerase chain reaction

RIPA radio immuno precipitation assay

RISC RNA induced silencing complex

RNA ribonucleic acid

RNA pol II RNA polymerase II

RNAi

RNA interference

RNase Ribonuclease

rpm

rotations per minute

RPMI Roswell Park Memorial Institute medium 1640

RT room temperature

SCID severe combined immunodeficient

SDS sodium dodecyl sulfate

SDS- $\quad$ SDS- polyacrylamide gel electrophoresis

PAGE

SEM standard error of the mean

SEMA4D semaphorin-4D

siRNA small interfering RNA

STAT3 signal transducer and activator of transcription 3

$T$ thymine

TAE tris-acetate-EDTA

TAM tumor associated macrophage

TCGA the cancer genome atlas

TEMED N,N,N',N'-Tetramethylethylendiamin

TGFB transforming growth factor- $B$

TME tumor microenvironment

TNBC triple-negative breast cancer

TNFa tumor necrosis factor alpha 


$\begin{array}{ll}\text { Tregs } & \text { regulatory T-cells } \\ \text { Tris } & \text { tris-(hydroxylmethyl)-amino methane } \\ \text { Tyr } & \text { tyrosine } \\ \text { U } & \text { uracil } \\ \text { UTR } & \text { untranslated region } \\ \text { VAV1 } & \text { Vav Guanine Nucleotide Exchange Factor } 1 \\ \text { VEGF } & \text { vascular endothelial growth factor } \\ \text { v/v } & \text { volume/volume } \\ \text { w/v } & \text { weight/volume } \\ \text { WB } & \text { western blot } \\ \text { wt } & \text { wild type }\end{array}$




\section{Abstract}

Triple-negative breast cancer (TNBC) constitutes $20 \%$ of all breast cancer cases. TNBC is defined by the lack of estrogen and progesterone receptors, and HER2 overexpression and is characterized by its frequent recurrence and high metastatic potential. The crosstalk between cancer cells and the surrounding tumor microenvironment (TME) plays a crucial role in fostering or restraining tumor progression and metastasis. Tumor-associated macrophages (TAMs) are the predominant cellular component of the TME in several solid-cancer entities, including mammary tumors. In response to microenvironmental stimuli, TAMs polarize towards tumoricidal M1 or tumorpromoting M2 activated cells. In breast cancer, malignant cells recruit and educate macrophages into an M2 phenotype that supports the metastatic spread of cancer cells. Breast cancer progression and metastasis are driven by the epidermal growth factor (EGF) and colony stimulatory factor 1 (CSF1) positive paracrine loop established between macrophages and cancer cells. However, the molecular mechanisms involved in establishing and maintaining these signaling loops are still poorly understood. Dysregulation of microRNAs (miRNAs), a class of short non-coding RNAs that regulate gene expression at the post-transcriptional level, has been implicated in tumor progression by remodeling the TME composition and inducing its transition into a tumor-supportive state. Considering the critical role of the TME in promoting tumor progression, a 
deeper understanding of the role of miRNAs in TME modulation is fundamental for developing more efficient therapies.

This thesis focuses on understanding whether miR-149 downregulation in TNBC is involved in the modulation of TAMs, which may result in a suitable TME required for cancer cell invasion and subsequent metastasis. Here, CSF1 was validated as a direct target of miR-149. In silico analysis of TCGA clinical data demonstrated that in lymph node-positive TNBC tissues low miR-149 expression correlated with high CSF1 expression and M2-macrophage infiltration as well with reduced patient survival. Functional analyses using 3D cocultures and Transwell assays demonstrated that by directly targeting CSF1, miR-149 overexpression in TNBC cell lines inhibited the interaction between macrophages and the tumor cells. In macrophages co-cultured with MDA-MB-231 cells expressing miR-149 the expression levels of two EGF receptor ligands, EGF and amphiregulin, were strongly reduced, resulting in reduced EGF receptor activation in the cancer cells. Moreover, using an in vivo mouse model, lung metastases developing from orthotopic MDA-MB-231 tumors were reduced by $75 \%$ by the ectopic miR-149 expression, and this was associated with impaired M2-macrophage infiltration of the primary tumors. Furthermore, the inhibition of DNAmethyltransferases in TNBC cell lines showed that miR-149 expression is epigenetically silenced by DNA methylation mechanisms. 
Taken together, the experimental studies performed in this thesis suggest that in TNBC miR-149 downregulation functionally contributes to breast tumor progression by recruiting macrophages to the tumor and facilitating CSF1 and EGF receptor crosstalk between cancer cells and macrophages. 


\section{Zusammenfassung}

Triple-negativer Brustkrebs (TNBC) macht 20\% aller Brustkrebsfälle aus. TNBC wird definiert durch das Fehlen von Östrogen- und Progesteronrezeptoren sowie durch eine HER2Überexpression und zeichnet sich durch ein häufiges Wiederauf treten und ein hohes Metastasierungspotenzial aus. Das Zusammenwirken von Krebszellen und der umliegenden Tumormikroumgebung (TME) spielt eine entscheidende Rolle bei der Förderung oder Eindämmung der Tumorprogression und Metastasierung. Tumorassoziierte Makrophagen (TAMs) sind die vorherrschende zelluläre Komponente der TME in mehreren soliden Krebsentitäten, einschließlich Mammatumoren. Als Reaktion auf Mikroumweltstimuli polarisieren TAMs in Richtung tumorizider M1- oder tumorfördernder M2-aktivierter Zellen. Bei Brustkrebs rekrutieren bösartige Zellen Makrophagen und bilden diese zu einem M2-Phänotyp aus, der die metastatische Ausbreitung von Krebszellen unterstützt. Brustkrebsprogression und Metastasierung werden durch den epidermalen Wachstumsfaktor (EGF) und den positiven parakrinen Regelkreis des Kolonie-stimulierenden Faktors 1 (CSF1) angetrieben, der zwischen Makrophagen und Krebszellen gebildet wird. Die molekularen Mechanismen, die bei der Etablierung und Aufrechterhaltung dieser Signalschleifen eine Rolle spielen, sind jedoch noch wenig verstanden. Man 
vermutet, dass die Dysregulation von Mikro-RNAs (miRNAs), einer Klasse kurzer nicht-kodierender RNAs, die die Genexpression auf posttranskriptionaler Ebene regulieren, eine Rolle in der Tumorprogression spielt, wodurch die TMEZusammensetzung verändert und der Übergang in einen tumorunterstützenden Zustand induziert wird. In Anbetracht der entscheidenden Rolle der TME bei der Förderung der Tumorprogression ist ein tieferes Verständnis der Rolle der miRNAs bei der TME-Modulation grundlegend für die Entwicklung effizienterer Therapien.

In der vorliegenden Arbeit wurde untersucht, ob die miR-149Deregulation bei TNBC an der Modulation der TAMs beteiligt ist, was zu einer geeigneten TME führen kann, die für die Invasion von Krebszellen und die nachfolgende Metastasienung erforderlich ist. Hierbei wurde CSF1 als ein direktes Ziel von miR-149 validiert. Die In-silico-Analyse klinischer TCGA-Daten zeigte, dass in lymphknotenpositiven TNBC-Geweben eine niedrige miR-149-Expression mit einer hohen CSF1Expression und einer M2-Makrophagen-Infiltration sowie mit einer verminderten Überlebensrate der Patienten korrelierte. Funktionelle Analysen unter Verwendung von 3D-Kokulturen und Transwell-Assays zeigten, dass die miR-149Überexpression in TNBC-Zelllinien die Interaktion zwischen Makrophagen und Tumorzellen hemmte, indem sie direkt auf CSF1 abzielte. In Makrophagen, die mit MDA-MB-231-Zellen kokultiviert wurden, die miR-149 exprimieren, war das 
Expressionsniveaus von zwei EGF-Rezeptorliganden, EGF und Amphiregulin, stark reduziert, was zu einer verminderten EGFRezeptoraktivierung in den Krebszellenführte. Darüber hinaus wurden in einem in vivo-Mausmodell die Lungenmetastasen, die sich aus orthotopen MDA-MB-231-Tumoren entwickelten, durch die ektopische miR-149-Expression um 75\% reduziert, was mit einer gestörten M2-Makrophagen-Infiltration der Primärtumoren assoziiert war. Darüber hinaus zeigte die Hemmung von DNA-Methyltransferasen in TNBC-Zelllinien, dass die miR-149-Expression durch DNAMethylierungsmechanismen epigenetisch stillgelegt wird.

Zusammengefasst deuten die in dieser Arbeit durchgeführten experimentellen Studien darauf hin, dass bei TNBC die miR149-Dysregulation funktionell zur Brusttumorprogression beiträgt, indem sie Makrophagen zum Tumor rekrutiert und die Wechselwirkung durch CSF1- und EGF-Rezeptoren zwischen Krebszellen und Makrophagen erleichtert. 


\section{Introduction}

\section{$1.1 \quad$ Breast cancer}

Cancer is a generic term that refers to over 200 different disease entities that can affect any part of the body. Despite the significant advances in the study, diagnosis, and treatment of cancer, cancer burden continues to grow worldwide, accounting for 18.1 million new cases and 9.6 million deaths in 2018, making cancer the second leading cause of death globally (Bray et al. 2018). Cancer arises from the transformation of nomal cells into tumor cells in a complex multistep process and its causation is multifactorial, ranging from mutations that accumulate over time in diverse genes that control cell proliferation to environmental factors (Wu et al. 2018).

Breast cancer is the most common malignancy in women in the western world; one in eight women will have breast cancer at some point in their life (Cronin et al. 2018). In 2018, the breast cancer incidence was estimated at 2.1 million new cases, representing $24.2 \%$ of all cancers in women; additionally, 626,679 women with breast cancer died (Bray et al. 2018). Furthermore, breast cancer has a bro ad clinical and molecular heterogeneity and several classifications have been developed to group tumors accordingly. Currently, clinical practice frequently uses a surrogate classification of five subtypes based on histology and immunohistochemistry expression of key proteins: estrogen receptor $(E R)$, progesterone receptor $(P R)$, 
human epidermal growth factor receptor 2 (HER2) and the proliferation marker Ki67 (Harbeck et al. 2019); giving rise to Luminal A-like (Strongly ER+ and PR+; HER2-; low Ki67), Luminal B-like HER2- (ER+ but ER and PR expression lower than in luminal A-like; high Ki67), HER2-enriched (ER-, PR-, HER2+; high Ki67), Luminal B-like HER2+ (ER+ but lower ER and PR expression than luminal A-like; HER2+; high Ki67) and triple-negative (ER-, PR-, HER2-; high Ki67) breast cancer.

\subsubsection{Triple-negative breast cancer}

Triple-negative breast cancer (TNBC), constitutes $20 \%$ of all breast cancer cases and in comparison to other breast cancer subtypes TNBC is associated with poorer outcome, higher early recurrence (within 2-3 years of first presentation) and metastatic potential (Hurvitz and Finn 2009; Di Cosimo and Baselga 2010), which reflects the intrinsic aggressiveness and the lack of recognized molecular targets for the treatment of this disease.

Cytotoxic chemotherapy is the standard therapeutic approach for TNBC in both the early (cancer that is contained in the breast) and advanced-stages (metastatic cancer) of the disease. Studies have shown that approximately $30-40 \%$ of patients with early-stage TNBC treated with standard neoadjuvant chemotherapy regimens have an increase in both overall survival and disease-free survival (Woodward et al. 
2006), however, less than $30 \%$ of women with advanced/metastatic TNBC survive 5 years after diagnosis with a median overall survival of 2-3 years (Cardoso et al. 2018; Bianchini et al. 2016). Therefore, a better understanding of the mechanisms regulating TNBC progression towards metastasis is increasing ly becoming a vital factor to boost the therapeutic opportunities for TNBC patients.

Metastasis is a multistep process during tumor progression and represents the main cause of death in cancer patients, yet this complex process is still poorly understood. For metastasis to occur, cancer cells follow a stepwise sequence of events starting with local invasion, intravasation, survival in the circulation, followed by extravasation and colonization of the target organ (Nguyen, Bos, and Massagué 2009). In the past decades, an extensive number of activating oncogenic mutations and inactivating mutations in tumor suppressor genes required for cancer development and progression has been described. However, it has become clear that these mutations are not sufficient to develop a fully malignant phenotype in cancer cells and that the surrounding microenvironment provides the required stimuli for cancer cell viability, growth, and invasiveness. Cancer cells grow in a complex and dynamic stroma consisting of various cell types, matrix proteins, and soluble factors.

Although the understanding of the key role that the microenvironment plays in metastasis formation dates back to 
the end of the $19^{\text {th }}$ century, the crosstalk between cancer cells with their microenvironment has received much attention in the past decade, as these interactions were found to result in the reprogramming of the surrounding non-malignant cells that ultimately determine whether the primary tumor is eradicated or metastasizes.

\subsection{Tumor microenvironment}

In 1889, Stephen Paget proposed the 'seed and soil' theory, after examining the autopsy records from 735 patients with breast cancer (Paget 1889). This theory suggested that cancer cells (seed) grow preferentially in the context of a congenial and supportive microenvironment (soil). Since then, a growing body of evidence has supported the notion that the intricate balance of interactions between cancer cells and the tumor microenvironment (TME) plays crucial roles in regulating tumor progression and metastasis (De Palma, Biziato, and Petrova 2017; Mantovani and Sica 2010).

The TME is composed of a heterogeneous population of cancer cells; diverse tissue-resident and recruited host cells, such as endothelial cells, adipocytes, fibroblasts, and numerous immune cells including $B$ and Tcells of the adaptive and natural killer cells, neutrophils, dendritic cells and macrophages of the innate immune system; and the secreted products of thesecells (Joyce and Pollard 2009; Hinshaw and Shevde 2019), (Fig. 1). 
Notably, the TME significantly modulates the malignancy of tumors and its composition continuously evolves over the course of cancer progression in response to secreted factors and oncogenic signals from growing tumors (Greten and Grivennikov 2019). For example, in breast and pancreas cancer, cancer-associated fibroblasts (CAFs) promote cancer progression by secreting interleukin (IL)-6 and IL-8 that maintain a small subset of cancer cells within tumors with capabilities of self-renewal and differentiation termed cancer stem cells (Su et al. 2018). Furthermore, CAFs secrete diverse growth factors, such as hepatocyte growth factor (HGF), fibroblast growth factor (FGFs) and insulin-like growth factor 1 (IGF1), which are mitogenic for malignant cells. In ovarian cancer, adipocytes promote tumor growth by providing fatty acids as fuel for the cancer cells (Nieman et al. 2011). The formation of new blood vessels within the tumor, necessary for tumor growth and development, is in part the result of the stimulation of endothelial cells by the proangiogenic factors IL8 and vascular end othelial growth factor (VEGF) secreted by cancer cells (Carmeliet and Jain 2011). Multiple studies in solid tumors have associated the infiltration of $T$ lymphocytes, particularly of CD8+ memory $T$ cells, with a good patient prognosis as these cells efficiently kill tumor cells (Fridman, Pagès, and Sautès-fridman 2012; Anderson, Stromnes, and Greenberg 2018). However, the crosstalk established between cancer cells and the proximal immune cells may result in an 
immunosuppressive environment that blocks the anti-tumor immune response.

Currently, as an alternative to the classical approach of targeting cancer cell-intrinsic factors, to which tumors develop resistance, strategies supporting immune system re-activation within the TME are gaining great attention (Cassetta and Pollard 2018a). Among the most promising therapeutic approaches to achieve this, is to prevent $\mathrm{T}$ cell exhaustion and to re-engage $\mathrm{T}$ cells in anti-tumor functions by blocking inhibitory immune checkpoints expressed by tumors, such as Cytotoxic TLymphocyte Associated Antigen-4 (CTLA-4) and Programmed Death-1 (PD-1) (Leach, Krummel, and Allison 1996; Freeman et al. 2000). However, only about $25 \%$ of cancer patients respond to these immune checkpoint blockade therapies (D. S. Chen and Mellman 2017), suggesting that a broader view of cancer immunity and novel targets in the TME are required. Herein, tumor associated macrophages (TAMs), the prevailing immune cell in several solid cancer entities, including mammary tumors (Obeid et al. 2013), are of special interest as these cells along with their secreted factors on the one hand, modulate the immunologic state of cancer by suppressing or promoting antitumor immunity, and on the other hand, directly stimulate or inhibit cancer cell proliferation, angiogenesis and metastasis. 


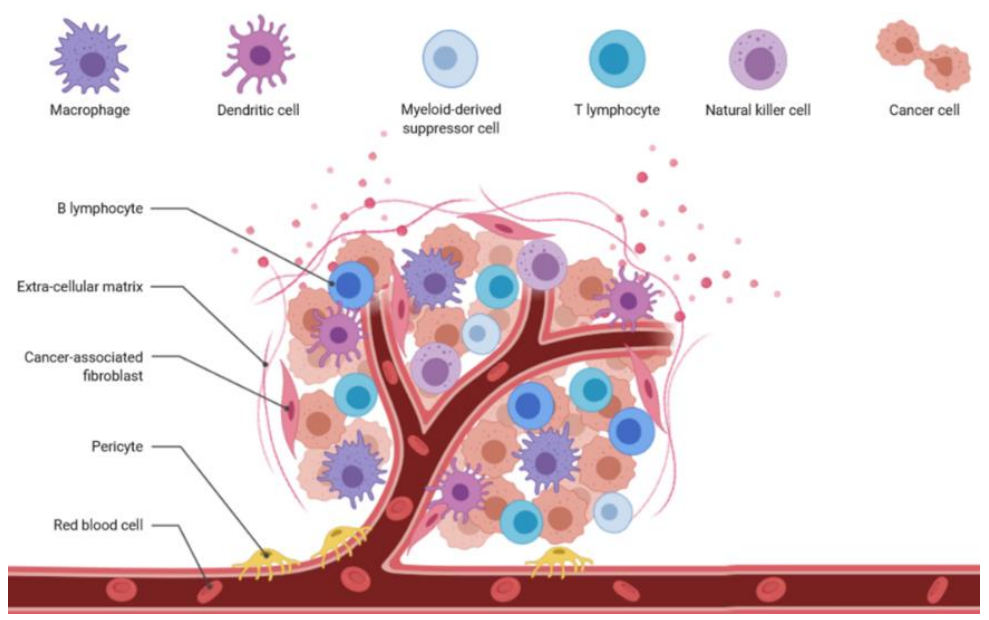

Figure 1. Role of the tumor microenvironment. The TME is made up of various cellular and soluble components, including fibroblasts, end othelial cells, pericytes, ECM, immune cells, and cancer cells and their secreted factors. Cancer cells can shape their microenvironment by secreting diverse factors that recnit and/or reprogram the surrounding cells. Tumor progression or elimination depends on the TME composition and on the paracrine interactions of cancer cells with their microenvironment.

\subsubsection{Origins of macrophages}

In 1882, macrophages were first described by Elia Metchnikoff after observing that pinning starfish larvae with small thoms of a tangerine tree, the thorns were surrounded by phagocytic cells able to respond to foreign particles and infection (Teti G. 2015). Macrophages are highly heterogenic innate immune cells found throughout every tissue in the body, where they 
participate in a wide range of essential functional roles duning development, homeostasis, tissue-repair, immunity to pathogens as well as in pathological conditions (Wynn, Chawla, and Pollard 2013; Gordon and Martinez-Pomares 2017). Macrophages can arise from different developmental pathways. A vast proportion of tissue-residentmacrophages originate from embryonic precursors present in the yolk sac or fetal liver that seed tissues in the prenatal and perinatal periods (Ginhoux and Guilliams 2016). The majority of these tissue-resident macrophages maintain themselves indefinitely throughout adulthood in a colony-stimulating factor-1 (CSF1)-dependent manner that is produced by the tissue stroma (Epelman, Lavine, and Randolph 2014). CSF1 is a key growth factor that via its receptor CSF1R, controls macrophage proliferation and survival (Hashimoto et al. 2013) and in its absence almost all macrophages are dramatically depleted in mice (Cecchini et al. 1994). After birth, tissue-resident macrophages can be augmented through the recruitment and differentiation of circulating monocytes derived from hematopoietic stem cells (HSCs), a process that is mainly induced during inflammation (Gordon and Martinez-Pomares 2017). Furthermore, circulatory monocytes are not homogeneous and are broadly classified as classical/inflammatory (Ly6c ${ }^{\text {high }}$ in mouse and CD14 ${ }^{\text {high }}$ in human) and nonclassicalpatrolling (Ly6c ${ }^{\text {low }}$ in mouse and CD14 ${ }^{\text {low }}$ in human) subsets (Guilliams, Mildner, and Yona 2018). Nonclassical monocytes "patrol" the vasculature, in part via their $\beta 2$ integrin, lymphocyte function-associated antigen-1 
(LFA-1) and maintain the integrity vascular end othelial cells by clearing damaged endothelial cells (Auffray et al. 2007), whereas in case of inflammation, classical monocytes are rapidly recruited to sites of infection or injury and differentiate into macrophages (Chao Shi 2011). Interestingly, macrophages across tissues (for example, spleen, lung, liver, b rain) display a considerable gene expression diversity and exhibit a remarkable plasticity. This plasticity allows them to execute a wide range of roles, including defending against foreign pathogens and regulating wound healing and tissue homeostasis, therefore, the phenotypic plasticity makes macrophages attractive therapeutic targets to address multiple diseases (Poh and Ernst 2018). Macrophages change and adopt their appropriate functional phenotype in response to soluble cues derived from the local microenvironment through a process defined as polarization.

\subsubsection{M1/M2 polarization}

In tissues, macrophages undergo diverse forms of functional reprogramming in response to different signals. This high plasticity allows them to adjust to local microenvironmental signals and respond with distinct activities according to the physiological context rapidly and efficiently. Macrophages are conventionally classified into two groups, referred as "classical" M1 and "alternatively" M2 subtypes. Although the M1/M2 paradigm is a simplified classification, it provides a useful 
framework in the analysis and understanding of macrophage responses. An integrative action of diverse regulatory cells, signaling molecules, and transcription factors is involved in coordinating and controlling macrophage activation and polarization. Exposure to pro-inflammatory stimuli like interferon Y (IFNY), tumor necrosis factor $\alpha$ (TNF $\alpha$ ), pathogen-associated molecular patterns (e.g. lipopolysaccharide and other microbial ligands) and danger-associated molecular patterns (e.g. HMGB1, DNA), induce a predominance in NF-KB, STAT1 and IRF3 transcription factors that polarize macrophages toward the classical M1 subtype (N. Wang, Liang, and Zen 2014; Mosser 2008; Italiani and Boraschi2014). M1 macrophages have a proinf lammatory phenotype, are highly endocytic and possess the ability to present tumor antigens to initiate $T$ cell immunity as they express major histocompatibility complex (MHC) class II molecules (Biswas and Mantovani 2010). Furthermore, M1 macrophages induce the elimination of invading pathogens and tumor cells through the production of superoxide/nitrogen free radicals and pro-immunogenic cytokines such as IL-1, IL-2, IL6 and IL-12 among others. For instance, M1 TAMs secrete: IFNy (Ong et al. 2012), required to enable cy totoxic CD8+T-cell functions against cancer; IL-18 and IL-12 that enhance the maturation and cytotoxic activity of NK cells (Osaki et al. 1999; Molgora et al. 2017); and macrophage migration inhibitor factor which augments the phagocytic and tumoricidal activity of macrophages (Pozzi 1992; Onodera et al. 1997). 
In contrast, anti-inflammatory cytokines such as IL-4, IL-10, IL13, transforming growth factor- $B$ (TGFB), glucocorticoids, immune complexes and CSF1, mainly activate the transcription factors STAT3, STAT6, IRF4 and c-Maf required to drive macrophages towards the M2 polarization (Fleetwood et al. 2007; Martinez and Gordon 2014; N. Wang, Liang, and Zen 2014). M2 macrophages express the mannose receptor C-type 1 (MRC1, also known as CD206) and CD163 on their cell surf ace and secrete anti-inflammatory mediators such as IL-4, IL-10, and growth factors like TGFß, therefore, they are highly endocytic and are involved in promoting cell proliferation, tissue repair and parasite immunity. However, in diseases like cancer M2 macrophages stimulate tumor growth, angiogenesis and metastasis (Martinez and Gordon 2014; Gordon and MartinezPomares 2017).

Importantly, both M1 and M2 macrophages can be reversibly reprogrammed by the appropriate local microenvironment stimuli (Stout et al. 2005). This dynamic fine-tuning balance plays an important role during inflammation and its resolution process. Consequently, M1/M2 dysregulation may lead to diseases/pathogenesis, ranging from autoimmune disorders, inflammatory chronic diseases to tumor progression. 


\subsubsection{Tumor associated macrophages}

TAMs are the major constituent of the tumor stroma in various solid tumors including prostate, bladder, colon, and breast cancer (Obeid et al. 2013; Mantovani et al. 2017) and in some cases like in breast cancer, macrophages represent up to $50 \%$ of the tumormass (Laoui et al. 2014). Notably, the role of TAMs in cancer largely depends on their location and M1/M2 activation state. Although in some cases, such as colorectal cancer, TAMs are predominantly skewed towards a classical M1 phenotype and represent a good prognosis factor as they exert anti-tumor activities (Edin et al. 2012), in most cancers TAMs typically have an M2 phenotype and numerous clinical studies in breast, gastric, thyroid, lung, liver and glioblastoma cancer patients have reported that high inf iltration densities of M2-TAMs correlate with advanced-stages of disease and poor survival rates (J. Yang et al. 2015; Gwak et al. 2015). Overall, M2 TAMs promote tumor progression to malignancy and to date, the tumor-promoting mechanisms of TAMs include suppression of the immune system, promotion of tumor angiogenes is and escape of cancer cells from the primary tumor to distant organs (Fig. 2).

\subsubsection{TAMs and cancer cell invasion}

Invasion of tumor cells into the surrounding connective tissue and blood vessels is a key step in the metastatic spread of breast tumors. In a groundbreaking paper of 2001, Lin and 
colleagues established for the first time a link between macrophages and tumor progression. Their study showed that macrophage depletion through Csf1 genetic ablation in the polyoma middle T (PyMT) model of breast cancer did not affect primary tumor growth, but inhibited tumor progression and metastasis. In contrast, CSF1 overexpression accelerated tumor progression and increased lung metastasis, effects that were associated with an enhanced infiltration of macrophages into the primary tumor (B. E. Y. Lin et al. 2001). These results highlighted that mammary tumor growth and the progression to malignancy are independent processes and that malignancy progression depends on CSF1. Afterwards, the tumorpromoting functions of macrophages were demonstrated across several solid tumors and a strong association between macrophage infiltration and poor patient survival has been identified in breast, gastric, thyroid and glioblastoma cancers (DeNardo et al. 2011; Shabo et al. 2008; Q. wen Zhang et al. 2012; Hambardzumyan, Gutmann, and Kettenmann 2015). Although the role of CSF1 in tumor progression has been well established, little is known about the molecular mechanisms underlying CSF1 overexpression in cancer cells.

TAMs are differentiated and recruited to tumors in response to diverse tumor-derived chemotactic factors, including CSF1 and chemokines such as $\mathrm{C}-\mathrm{C}$ motif chemokine ligand (CCL)-2, CCL-5, CCL-11, CCL-20 and CXCL-12 (Joyce and Pollard 2009; Argyle and Kitamura 2018). In addition, some of these 
factors can activatesignaling networks that induce macrophage polarization towards specific phenotypes. CSF1 in particular, the major lineage regulator for macrophages, is abundantly expressed in TNBC and, via its receptor CSF1R, regulates macrophage survival, migration, and differentiation, and induces a tumor-promoting M2 phenotype (Laoui et al. 2014). Remarkably, clinical studies in breast cancer patients have shown that CSF1 is overexpressed in more than $70 \%$ of cases and the extent of expression correlates with high tumor grade and poor prognosis (Kacinski 1995). Similar findings were observed in ovarian, endometrial, prostate and hepatocellular cancer (E. Y. Lin et al. 2002; Groblewska et al. 2007; Smith et al. 1995; Zhu et al. 2008). Intravital multiphoton imaging of xenograft mouse models has shown that macrophages are required for primary breast tumor invasion (Harney et al. 2015). Cancer cells guidance by macrophages towards vessels is dependent on a positive EGF/CSF1 paracrine loop established between macrophages and cancer cells as follows: breast cancer cells express epidermal growth factor receptor (EGFR) and secrete CSF1, which recruits macrophages and induces them to secrete factors such as epidermal growth factor (EGF), that in turn promotes cancer cell proliferation and the formation of actin-rich protrusions specialized for matrix degradation termed invadopodia, eventually leading to intravasation of breast cancer cells (Condeelis and Pollard 2006). Although paracrine CSF1 and EGF receptor interactions critically contribute to breast tumor progression, the molecular 
mechanisms involved in establishing and maintaining these signaling loops are still poorly understood.

\subsubsection{TAMs and angiogenesis}

The increase of blood vessels in the primary tumor is required for oxygen and nutrients delivery. This process referred as angiogenesis, represents a crucial step during the transition to malignancy. In 2006, using a transgenic mouse susceptible to mammary cancer with a genetic ablation of Csf1, Lin reported that the angiog enic process was regulated by macrophages in the primary tumor (E. Y. Lin et al. 2006). Several studies demonstrated that TAMs tend to accumulate in hypoxic areas and this correlates with higher metastasis and poor survival in breast, endometrial and cervical cancer (Leek 1996; M. Yang et al. 2018). More recent evidence shows that a specific subset of TAMs that express the angiopoietin receptor TIE2 are responsible for blood vessel formation (L. Chen et al. 2016). Hypoxia is the major driver of angiogenesis and in response to hypoxic conditions, TAMs upregulate hypoxia-inducible transcription factors (HIFs) 1 and 2 that induce the expression of angiogenic factors such as VEGF-A, glucose transporter-1 (GLUT1) and matrix metallopeptidases (MMP)-7 (Burke et al. 2003). In addition, the secretion of VEGF-C, TGFB, TNFa, fibroblast growth factor 2 (FGF2), WNT7B, IL-8 by TAMs contributes to the angiogenic process by recruiting and activating endothelial cells, fibroblasts or pericytes that further 
support the formation of vascular networks in the TME (Cassetta and Pollard 2018b).

\subsubsection{TAMs and immune suppression}

TAMs actively contribute to establish and maintain an immunosuppressive TME via cell-cell and humoral mechanisms. For example, in melanoma, ovarian and hepatocellular carcinoma patients, hypoxia and cytokines such as IL-10 induce high expression levels of programmed deathligand 1 (PD-L1) in both, monocytes and TAMs (Kuang et al. 2009; H. Lin et al. 2018). PD-L1 is an immunosuppressive, negative checkpoint regulator that upon binding to PD1 receptor expressed in T-cells, inhibits T-cell function and leads to T-cell anergy. B7-H4 is another negative checkpoint protein expressed by TAMs in liver and ovarian cancer. Although its receptor on T-cells is still unknown, studies have demonstrated that $\mathrm{B} 7-\mathrm{H} 4$ suppresses IL-2 production and T-cell proliferation and induces CD8+ T-cell exhaustion (Kryczek et al. 2006; Ceeraz, Nowak, and Noelle 2013). Additionally, in lung cancer and glioblastoma it has been shown that TAMs can express additional inhibitory molecules from the non-classical MHC class I, including HLA-G and HLA-E, that interact with the inhibitory receptor CD94/NKG2A in NK cells (Morandi and Pistoia 2014). TAMs also induce immunosuppression by recruiting regulatory immune cells to the TME. Specifically, by secreting diverse chemokines such as CCL5, CCL7 and 
CCL22, TAMs attract regulatory T-cells (Tregs), which in tum suppresses the anti-tumor activity of T, B, NK and dendritic cells via humoral and cell-cell contact mechanisms (Tanaka and Sakaguchi 2017). Tregs activity is further supported by cytokines secreted by TAMs, such as IL-10 and TGFB which directly inhibit cytotoxic CD8+ T-cells and at the same time support Tregs induction (Mougiakakos et al. 2010).

Taken together, these findings suggest that the intricate balance of interactions between cancer cells and the tumor microenvironment, with especial attention to macrophages, dictates the disease course of breast cancer by controlling tumor progression and metastasis. In this context, recent evidence has highlighted that the gene expression regulatory role of microRNAs during tumor progression is not limited to cancer cells but also implicated in the interaction with the tumor microenvironment and its transition into a cancer-associated state (N. Yang et al. 2018). Thus, microRNAs emerge as potent regulators of the crosstalk between cancer and stroma cells and as attractive targets with potential implications as novel prognostic biomarkers with therapeutic significance duning tumor progression. 


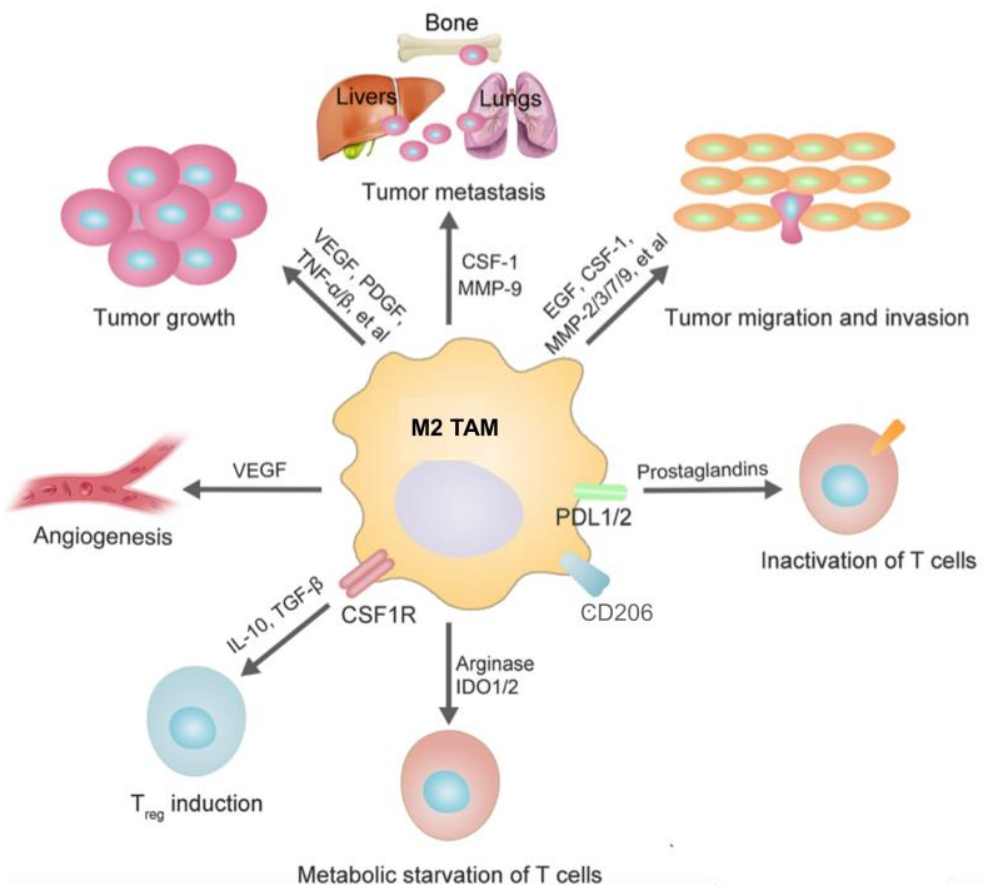

Figure 2. M2 Tumor-associated macrophages in cancer. M2 Tumor-associated macrophages promote tumor progression by secreting numerous cytokines, chemokines, and growth factors, among others, that induce suppression of the immune system, promotion of tumor angiogenesis and escape of cancer cells from the primary tumor to distant organs. Figure modified from Chen et al., 2019. 


\subsection{MicroRNAs}

The fact that only a small portion ( 1.5\%) of the human genome codes for proteins, but at least $80 \%$ of mammalian genomic DNA is actively transcribed (Hon et al. 2017; Dunham et al. 2012), prompted the question whether the non-protein-coding transcripts besides ribosomal RNAs (rRNAs) and transfer RNAs, are transcriptional "junk" or have further functions. Interestingly, the non-protein-coding RNA (ncRNA) genes proportion of an animal genome positively correlates with its biological complexity (Liu, Mattick, and Taft 2013), indicating that a large number of aspects of complex organisms emerge from non-protein-coding regions. Over the last decade, a growing number of ncRNAs have been assigned to roles in gene regulation. Among these, a class of small non coding RNAs called microRNAs (miRNAs) have received increased attention as they are crucial for no rmal development, physiology and in disease (Esteller 2011; Morris and Mattick 2014).

MiRNAs are small non-coding and single-stranded RNAs of 1724 nucleotides in length that regulate gene expression at the post-transcriptional level (Bartel 2009; Ambros 2004). In 1993, Lee and colleagues described in Caenorhabditis elegans the first miRNA, lin-4, as an RNA that controls the temporal developmental events in $C$. elegans larvae by negatively regulating the levels of LIN-14 protein via an antisense RNARNA interaction (Wightman, Ha, and Ruvkun 1993). Subsequently, it was shown that miRNAs representa numerous 
class of small RNAs expressed in almost all eukaryotes and the fact that plenty of them are conserved across many organisms (Griffiths-Jones et al. 2008), highlights their regulatory potential. To date, the primary public repository and online resource for microRNA sequences and annotation, miRBase, reports that the human genome contains 1917 annotated hairpin precursors, and 2654 mature miRNA sequences (Alles et al. 2019; Griffiths-Jones et al. 2008; Kozomara et al. 2019) MiRNAs are predicted to regulate $\sim 30 \%$ of all protein-coding genes and have been implicated in various biological processes and pathways such as development, cell proliferation, differentiation, apoptosis, signal transduction, metabolism and morphogenesis, and in diseases including cancer (Filipowicz, Bhattacharyya, and Sonenberg 2008; Ambros 2004). Therefore, the study of miRNAs has potential implications in basic research and in the discovery of novel biomarkers and therapeutic targets.

\subsubsection{MicroRNA biogenesis}

MiRNAs are encoded in the genome as individual genes, as clusters containing several miRNAs or in introns of host genes. Clustered miRNAs are transcribed together as polycistronic transcripts, which are processed to the individual mature miRNAs (Treiber, Treiber, and Meister 2019). Most miRNAs genes are transcribed by RNA polymerase II as capped and polyadenylated primary miRNAs (pri-miRNAs). The 20-25 
nucleotides of the mature miRNA are embedded in the stem of a hairpin found on the pri-miRNA. A typical pri-miRNA consists of a stem of 33-35 bp, a terminal loop and single-stranded RNA segments at both the $5^{\prime}$ and $3^{\prime}$ sides (Ha and Kim 2014). The biogenesis of miRNA is classified into canonical and noncanonical pathways, with the canonical being the dominant pathway by which miRNAs are processed (Fig. 3). The canonical pathway starts when pri-miRNAs are processed to single hairpins termed precursor miRNAs (pre-miRNAs) by a nuclear protein complex called microprocessor. The microprocessor is a heterotrimeric complex that comprises one RNase III enzyme Drosha, and two DiGeorge critical region 8 (DGCR8) molecules. The DGCR8 dimer binds to the UGUG motifs contained in the stem and apical loop regions of the primiRNA hairpin whereas Drosha interacts with the UG motifs found at the basal end of the pri-miRNA stem and restricts the leng th of the dsRNA from the basal junction to the cleavage site to $11 \mathrm{bp}$ (Frank, Sonenberg, and Nagar 2010).

The non-canonical pathway differs at this step in that pre-mi RNAs are generated by mRNA splicing machinery, circumventing the requirement for Drosha-mediated digestion in the nucleus. Nevertheless, the pre-mi RNAs resulting from both pathways are exported to the cytoplasm via the nuclear export protein exportin-5 where the pre-miRNA is further processed by a second RNase Ill enzyme, Dicer (Z. Li and Rana 2014). In this reaction, Dicer binds simultaneously to the $5^{\prime}$-phosphorylated 
and 3 '-end, allowing the pre-miRNA to extend along the protein and facilitating Dicer to act as a 'molecular ruler' that measures the distance from both pre-miRNA termini to the cleavage site adjacent to the terminal loop (MacRae et al. 2006). This cleavage liberates a mature double-stranded RNA and with the assistance of the HSC70/HSP90 chaperones, the RNA duplex is loaded into Argonaute (AGO) family proteins in an ATP dependent manner to form a functional ribonucleoprotein complex called the RNA-induced silencing complex (RISC) (Iwasaki et al. 2010). To note, the directionality of the miRNA strand determines the name of the mature miRNA form. The $5 p$ strand arises from the $5^{\prime}$ end of the pre-miRNA hairpin while the $3 p$ strand originates from the $3^{\prime}$ end (O'Brien et al. 2018). Later on, AGO2 unwinds the RNA duplex and one strand of the mature miRNA is retained (guide strand) to form the miRNAinduced silencing complex (miRISC), while the other one strand is degraded (passenger strand) (Kobayashi and Tomari 2016; Kwak and Tomari 2012). Although the molecular mechanisms underlying unwinding and strand removal are not yet fully understood, it is proposed that the selection of the $5 p$ or $3 p$ strand is given to the less stably paired $5^{\prime}$ end (Khvorova, Reynolds, and Jayasena 2003) and AGO2 is reported to prefer adenosine $(A)$ or uridine $(U)$ as the 5 '-terminal nucleotide (Frank, Sonenberg, and Nagar 2010). 


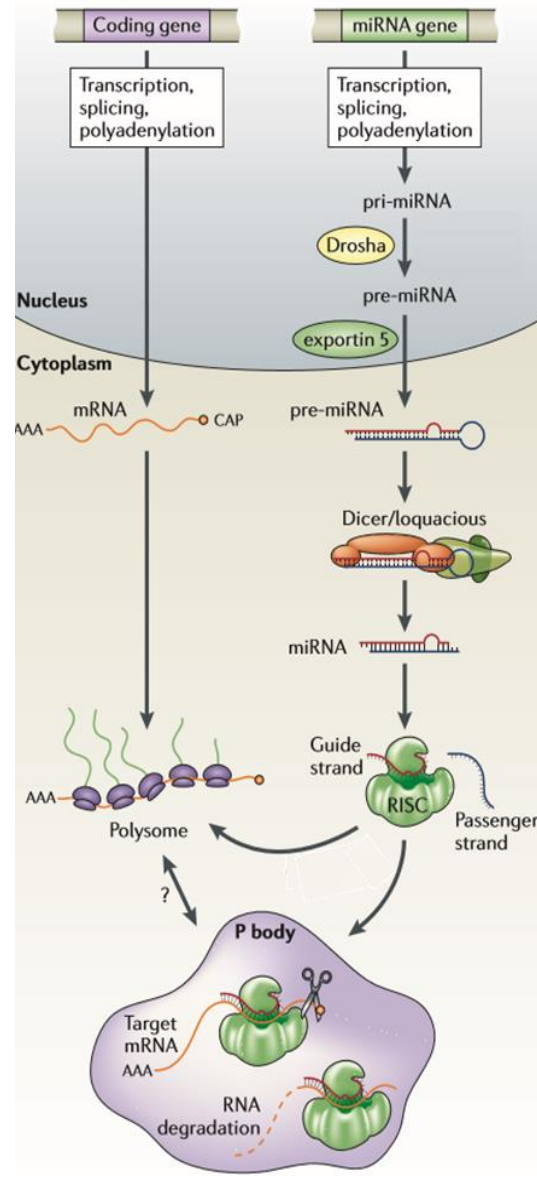

Figure $3 . \quad$ MicroRNA biogenesis and mechanism of action. MicroRNAs are encoded as monocistronic, polycistronic, or intronic genes and are initially transcribed as primary miRNA (pri-miRNA) by the RNA polymerase II. The microprocessor complex consisting of a DiGeorge critical region 8 (DGCR8) and Drosha processes the primiRNA into a precursor miRNA pre-miRNA. Exportin 5 exports pre-miRNA into the cytoplasm, where they are cleaved by Dicer into a miRNA duplex. After miRNA unwinding, the guide miRNA strand is loaded into the Argonaute (AGO) resulting in the formation of the RNA-induced silencing complex (RISC). MiRNAs loaded into the RISC complex can now interact with a complementary mRNA, which results in mRNA degradation or translational repression. This figure was modified from Kosik, 2006.

\subsubsection{Mechanism of action of miRNAs}

MiRNAs loaded into the RISC complex, induce gene silencing by two mechanisms:mRNA decay and translational repression. Most studies have shown that miRISC generally binds to 
complementary sequences located in the $3^{\prime}$-UTR of their target mRNA, yet less commonly, some reports have demonstrated it can also bind in other mRNA regions including the $5^{\prime}$-UTR (J. Zhang et al. 2018) and in the coding sequence (Forman, Legesse-Miller, and Coller 2008). The strongest target-site recognition required for miRISC binding to mRNA is located between nucleotides 2 and 7 , at the $5^{\prime}$-end of the mature miRNA (Z. Li and Rana 2014). The miRNA-mRNA interaction already prevents $m R N A$ translation, but is later enhanced by the AGO protein after recruiting TNRC6AC that sequesters the cytoplasmic polyadenylate-binding protein 1 (PABPC1) and by interfering with the function of eukaryotic initiation factor $4 A$ (elF4A), both factors required for translation initiation (Gebert and MacRae 2019; Trabucchi 2019). Furthermore, TNRC6AC also recruits two deadenylase complexes, CCR4-NOT and PAN2-PAN3 complexes (Iwakawa and Tomari 2015), and subsequently mRNA decapping factors, overall making the mRNA susceptible to rapid degradation by $5^{\prime}-3^{\prime}$ exoribonuclease 1 (XRN1) (Gebert and MacRae 2019).

Depending on the cell type, miRISC complexes bound to their target mRNAs have been reported to localize in various subcellular compartments such as the endoplasmic reticulum (Barman and Bhattacharyya 2015), processing (P)-bodies (Nishi et al. 2015), the trans-Golgi network (Translational and Cells 2017) and the nucleus (Miao et al. 2016) among others. This location seems to correlate with mRNA fate, for example, 
in the endoplasmic reticulum miRISC seems to regulate translation of mRNA destined for Golgi, whereas miRISC in Pbodies is mainly involved with mRNAs targeted for degradation (Akgül and Erdogan 2018). However, more studies are required to elucidate the miRISC roles throughout the cell as well as to better understand the dynamic changes of the miRISC localization as part of mRNA regulation.

\subsubsection{MiRNAs in cancer}

The first investigation establishing an association between miRNAs and tumor biology came from molecular studies characterizing the 13q14 deletion in human chronic lymphocytic leukemia (CLL), which resulted in the loss or downregulation of miR-15a and miR-16-1 in 60\% of CLL patients (Calin et al. 2002). Further analyses showed that miR-15 and miR-16 act as tumor suppressors by targeting the antiapoptotic BCL2 oncogene which is overexpressed in the malignant nondividing B cells of CLL (Calin et al. 2008).

In the following years, miRNA profiling analyses in normal and tumor tissues have revealed that miRNAs are aberrantly expressed in cancer and its signatures could be useful for tumor classification and prognosis (lorio et al. 2005; Mattie et al. 2006). MiRNAs are dysregulated by a variety of mechanisms, including polymorphisms, amplification/deletion of miRNA genes, altered transcriptional control of miRNAs, defects in the 
miRNA biogenesis machinery and by epigenetic mechanisms (Peng and Croce 2016; Ben-Hamo and Efroni 2015). Weber et al. found that almost $50 \%$ of human miRNAs were associated with $\mathrm{CpG}$ Islands, suggesting that miRNAs were susceptible to epigenetic alterations (Weber et al. 2007). The epigenetic mechanisms most widely studied are DNA hypermethylation and post-translational modifications of histones. DNA methylation is the major modification of eukaryotic genomes associated to downregulation of gene expression. This process involves the covalent binding of a methyl group to the cytosine bases located in CpG dinucleotides by a family of DNA methyltransferases (DNMTs), of which three catalytically active DNMTs have been identified in mammals: DNMT1, DNMT3a, and DNMT3b (Syeda et al. 2020; Humphries, Wang, and Yang 2019). In addition to DNA methylation, histones which are proteins that associate with DNA and help condense it into chromatin, can also be methylated. The most common histone methylation occurs in lysine residues and in contrast to gene silencing induced by DNA methylation, histone methylation can exert both silencing and activation on gene expression and it will depend on the degree and position of methylation. For instance, methylation at $\mathrm{H} 3 \mathrm{~K} 4, \mathrm{~K} 36$ and $\mathrm{K} 79$ induces gene activation, whereas methylation at $\mathrm{H} 3 \mathrm{~K} 9, \mathrm{H} 3 \mathrm{~K} 27$ and $\mathrm{H} 4 \mathrm{~K} 20$ is associated with transcriptional repression (Humphries, Wang, and Yang 2019). 
Multiple dysregulated miRNAs have been described in cancer and miRNA dysregulation has become a central role in tumorigenesis and tumor progression. Although certain upregulated miRNAs have been characterized to possess transforming potential, there are other miRNAs with inherent tumor suppressive activity that are downregulated in cancer cells (Farazi et al. 2013; Rupaimo ole and Slack 2017). Among them, miR-149 has a differential expression depending on the cancer type. For example, in nasopharyngeal cancer and melanoma miR-149 is upregulated, whereas in most solid cancers including breast cancer miR-149 has been reported to be downregulated ( $\mathrm{He}$ et al. 2018). Furthermore, in the genetically-defined basal-like breast cancer subtype, miR-149 downregulation has been reported as part of the basal-like specific miRNA signature (Enerly et al. 2011). Typically, most basal-like subtype cases are also characterized as TNBC since basal-like cancers often lack receptors for estrogen, progesterone, and HER2 (Alluri and Newman 2015). Our group, as well as others, have reported that miR-149 expression levels in TNBC are strongly downregulated, inversely correlating with higher tumor grade and that miR-149 regulates signaling molecules downstream of integrin receptors. For instance, miR149 expression suppresses migration and invasion of TNBC cells by regulating integrin signaling through the targeting of the Ras-related GTPases Rap 1a/b and the Arf GTPase-activating protein GIT1, as shown by experiments performed with the 
TNBC cell line MDA-MB231 (Chan et al. 2014; Bischoff et al. 2014).

Recent studies have shown that miRNA dysregulation in cancer cells can also affect tumor progression by shaping the TME composition. For example, nasopharyngeal carcinoma-derived exosomes containing the miR-24, miR-891, miR-106a, miR-20a and miR-1908 have been found to impair T-cell proliferation, differentiation and secretion of inflammatory cytokines required for anti-tumor response (Ye et al. 2014). Furthermore, a study by Yin, et al., revealed that in breast, non-small-cell lung and pancreas cancer, miR-214 is highly secreted in exosomes and promotes regulatory T-cells expansion by targeting PTEN in CD4+ T-cells, leading to host immune suppression and rapid tumor growth (Yin et al. 2014).

The fact that the miRNA regulatory network affects tumor progression not only by modulating gene expression in cancer cells but also by actively influencing the crosstalk between these cells and the TME, highlights the need to enhance our knowledge of the function of miRNAs in the TME that will allow the development and improvement of therapeutics. 


\subsection{Aim of the thesis}

Cancer research has tended to focus on tumor-cell-intrinsic factors required for cancer development and progression. In recent years, increasing attention has been paid to the multiple signals derived from the TME as accumulated evidence has shown that the TME plays a crucial role in fostering or restraining tumor progression and metastasis. In breast cancer, TAMs are the predominant cellular component of the TME and are associated with poor prognosis. miRNAs are short noncoding RNAs often described as master regulators as they are crucial in the regulation of gene expression in a myriad of biological processes and thus, miRNA dysregulation has been implicated in the development of numerous diseases, including cancer. The regulatory role of microRNAs is not only limited to cancer cells but is also involved in the crosstalk between cancer cells and the TME and its transition into a tumor-supportive state. Considering the critical role of the TME in determining the fate of tumor progression, a comprehensive understanding of the role of miRNAs in TME remodeling is fundamental for developing more efficient therapies.

The main objective of this project was to understand whether miR-149 dysregulation in TNBC is involved in the modulation of the tumor-promoting roles of TAMs, which may result in a TME that favors breast cancer cell invasion and thus, subsequent metastasis. In particular, by using biochemical assays I aimed 
to validate predicted targets of miR-149 that could be relevant in the communication of breast cancer cells with the TME. Furthermore, using novel 3D cocultures, Transwell assays, and an in vivo model I aimed to uncover the functional crosstalk between TNBC cells and TAMs in dependence of miR-149. 


\section{Material and Methods}

\section{$2.1 \quad$ Materials}

\subsubsection{Equipment}

\section{Table 1: List of equipment used in this thesis}

\begin{tabular}{|c|c|}
\hline Equipment & Company \\
\hline $\mathrm{CASY}^{\circledR}$ cell counter & Roche, Basel, Switzerland \\
\hline CFX96 Touch ${ }^{\mathrm{TM}}$ & $\begin{array}{l}\text { Bio-Rad Laboratories } \\
\text { GmbH, München, } \\
\text { Germany }\end{array}$ \\
\hline $\begin{array}{l}\text { Cell Observer Spinning Disk } \\
\text { microscope }\end{array}$ & $\begin{array}{l}\text { Carl Zeiss Microlmaging } \\
\text { GmbH, Jena, Germany }\end{array}$ \\
\hline $\begin{array}{l}\text { Beckman Coulter Centrifuge } \\
\text { Avanti J-30l (Rotor J20) }\end{array}$ & $\begin{array}{l}\text { Beckman Coulter, Krefeld, } \\
\text { Germany }\end{array}$ \\
\hline $\begin{array}{l}\text { Beckman Coulter Centrifuge } \\
\text { J2-MC Centrif uge (Rotor J20) }\end{array}$ & $\begin{array}{l}\text { Beckman Coulter, Krefeld, } \\
\text { Germany }\end{array}$ \\
\hline $\begin{array}{l}\text { Curix } 60 \text { processor (western } \\
\text { blot device) }\end{array}$ & Agfa, Düsseldorf \\
\hline Cytomics FC-500 & $\begin{array}{l}\text { Beckman Coulter, Krefeld, } \\
\text { Germany }\end{array}$ \\
\hline $\begin{array}{l}\text { Electroblotter: Semi Dry Blotter } \\
\text { PEGASUS }\end{array}$ & Phase, Lübeck, Germany \\
\hline Eppendorf Centrifuge 5415D & $\begin{array}{l}\text { Eppendorf, Hamburg, } \\
\text { Germany }\end{array}$ \\
\hline $\begin{array}{l}\text { Eppendorf Research }(0,5- \\
10 \mu l)(\text { multichannel pipette) }\end{array}$ & $\begin{array}{l}\text { Eppendorf, Hamburg, } \\
\text { Germany }\end{array}$ \\
\hline $\begin{array}{l}\text { Eppendorf Xplorer }{ }^{\circledR}(2-200 \\
\mu \mathrm{l} / 50-1250 \mu \mathrm{l}) \text { (electronic } \\
\text { multichannel pipette) }\end{array}$ & $\begin{array}{l}\text { Eppendorf, Hamburg, } \\
\text { Germany }\end{array}$ \\
\hline
\end{tabular}




\begin{tabular}{|c|c|}
\hline $\begin{array}{l}\text { EVOS fl (fluorescence } \\
\text { microscope) }\end{array}$ & $\begin{array}{l}\text { peQLab, Erlangen, } \\
\text { Germany }\end{array}$ \\
\hline $\begin{array}{l}\text { Hettich Centrifuge Rotanta } 460 \\
\text { R (Rotor 5699) }\end{array}$ & $\begin{array}{l}\text { Hettich Lab Technologie, } \\
\text { Tuttlingen, German }\end{array}$ \\
\hline iBlot® Gel Transfer Device & $\begin{array}{l}\text { Life technologies, } \\
\text { Carlsbad, CA, USA }\end{array}$ \\
\hline $\begin{array}{l}\text { Inf inite } 200 M \text { (fluorescent } 96- \\
\text { well plate reader) }\end{array}$ & Tecan, Crailsheim \\
\hline $\begin{array}{l}\text { NanoDropß ND-1000 } \\
\text { (Spectrophotometer) }\end{array}$ & $\begin{array}{l}\text { ThermoFisher Scientific, } \\
\text { Waltham, MA, USA }\end{array}$ \\
\hline Neubauer counting chamber & $\begin{array}{l}\text { Multimed, Kirchheim, } \\
\text { Germany }\end{array}$ \\
\hline Quantitative PCR Cfx96 & Biorad, Munich, Germany \\
\hline $\begin{array}{l}\text { Pipettes }(1-20 \mu \mathrm{l} / 20-200 \\
\mu \mathrm{l} / 200-1000 \mu \mathrm{l})\end{array}$ & $\begin{array}{l}\text { Eppendorf, Hamburg, } \\
\text { Germany }\end{array}$ \\
\hline Thermoshaker MKR 13 & HLC BioTech, Bovenden \\
\hline Vortex Genie 2 & $\begin{array}{l}\text { Scientific Industries, } \\
\text { Bohemia, USA }\end{array}$ \\
\hline $\begin{array}{l}\text { XCell4 SureLock }{ }^{\mathrm{TM}} \text { Midi-Cell } \\
\text { (electrophoresis chamber) }\end{array}$ & $\begin{array}{l}\text { Life technologies, } \\
\text { Carlsbad, CA, USA }\end{array}$ \\
\hline $\begin{array}{l}\text { xCELLig ence device (RTCA } \\
\text { DP) }\end{array}$ & Roche, Basel, Switzerland \\
\hline
\end{tabular}

\subsubsection{Chemicals and consumables}

Table 2: List of chemicals used in this thesis

\begin{tabular}{|l|l|}
\hline Chemical & Company \\
\hline Agar & $\begin{array}{l}\text { Carl Roth GmBH \& Co., } \\
\text { Karlsruhe, Germany }\end{array}$ \\
\hline Agarose & $\begin{array}{l}\text { Carl Roth GmBH \& Co., } \\
\text { Karlsruhe, Germany }\end{array}$ \\
\hline
\end{tabular}




\begin{tabular}{|l|l|}
\hline $\begin{array}{l}\text { Acrylamide (Rotiphorese Gel } \\
30)\end{array}$ & $\begin{array}{l}\text { Carl Roth GmBH \& Co., } \\
\text { Karlsruhe, Germany }\end{array}$ \\
\hline Ammonium persulfate (APS) & $\begin{array}{l}\text { Carl Roth GmBH \& Co., } \\
\text { Karlsruhe, Germany }\end{array}$ \\
\hline$\beta$-Mercaptoethanol & $\begin{array}{l}\text { Sigma-Aldrich, Tauf kirchen, } \\
\text { Germany }\end{array}$ \\
\hline Blocking reagent & $\begin{array}{l}\text { Roche Diagnostics, Basel, } \\
\text { Switzerland }\end{array}$ \\
\hline $\begin{array}{l}\text { Bovine Serum Albumin } \\
\text { (BSA) }\end{array}$ & $\begin{array}{l}\text { Sigma-Aldrich, Taufkirchen, } \\
\text { Germany }\end{array}$ \\
\hline $\begin{array}{l}\text { CellTracker } \\
\text { CMRA Orange }\end{array}$ & $\begin{array}{l}\text { Life Technologies, Carlsbad, } \\
\text { CA; USA }\end{array}$ \\
\hline $\begin{array}{l}\text { CellTracker } \\
\text { CMFDA Green }\end{array}$ & $\begin{array}{l}\text { Life Technologies, Carlsbad, } \\
\text { CA; USA }\end{array}$ \\
\hline $\begin{array}{l}\text { Complete protease inhibitor } \\
\text { cocktail }\end{array}$ & $\begin{array}{l}\text { Roche, Mannheim, } \\
\text { Germany }\end{array}$ \\
\hline Crystal violet & Merck, Darmstadt, Germany \\
\hline $\begin{array}{l}\text { 4',6-diamidino-2- } \\
\text { phenylindole (DAPI) }\end{array}$ & $\begin{array}{l}\text { Sigma-Aldrich, Taufkirchen, } \\
\text { Germany }\end{array}$ \\
\hline Dimethyl sulfoxide (DMSO) & $\begin{array}{l}\text { Carl-Roth GmBH \& Co., } \\
\text { Karlsruhe, Germany }\end{array}$ \\
\hline Dithiothreitol (DTT) & $\begin{array}{l}\text { Carl-Roth GmBH \& Co., } \\
\text { Karlsruhe, Germany }\end{array}$ \\
\hline DNAorange & $\begin{array}{l}\text { Sigma-Aldrich, Taufkirchen, } \\
\text { Germany }\end{array}$ \\
\hline Ethylenediaminetetraacetic \\
acid (EDTA) & $\begin{array}{l}\text { Carl-Roth GmbH \& Co., } \\
\text { Karlsruhe, Germany }\end{array}$ \\
\hline Ethanol & VWR, Darmstadt, Germany \\
\hline Ethidium bromide & $\begin{array}{l}\text { Roche Diagnostics, Basel, } \\
\text { Switzerland }\end{array}$ \\
\hline Fluoromount-G & $\begin{array}{l}\text { Southern Biotechnology, } \\
\text { Birmingham, UK }\end{array}$ \\
\hline
\end{tabular}




\begin{tabular}{|c|c|}
\hline Gene Ruler 1 kb Ladder & $\begin{array}{l}\text { MBIFermentas, St. Leon- } \\
\text { Rot, Germany }\end{array}$ \\
\hline Goat serum & $\begin{array}{l}\text { Invitrogen, Karlsruhe, } \\
\text { Germany }\end{array}$ \\
\hline$\beta$-Glycerophosphate & $\begin{array}{l}\text { Sigma-Aldrich, St.Louis, } \\
\text { USA }\end{array}$ \\
\hline Glycine & $\begin{array}{l}\text { Carl-Roth GmbH \& Co., } \\
\text { Karlsruhe, Germany }\end{array}$ \\
\hline Isopropanol & $\begin{array}{l}\text { Carl Roth GmbH \& Co., } \\
\text { Karlsruhe, Germany }\end{array}$ \\
\hline Methanol & $\begin{array}{l}\text { Carl-Roth GmbH \& Co., } \\
\text { Karlsruhe, Germany }\end{array}$ \\
\hline Magnesium chloride $\left(\mathrm{MgCl}_{2}\right)$ & $\begin{array}{l}\text { Carl-Roth GmbH \& Co., } \\
\text { Karlsruhe, Germany }\end{array}$ \\
\hline $\begin{array}{l}\text { "PageRuler" prestained } \\
\text { protein ladder }\end{array}$ & $\begin{array}{l}\text { Thermo Scientific, Waltham, } \\
\text { USA }\end{array}$ \\
\hline $\begin{array}{l}\text { Phenylmethylsulfonyl } \\
\text { fluoride (PMSF) }\end{array}$ & $\begin{array}{l}\text { Sigma-Aldrich, Tauf kirchen, } \\
\text { Germany }\end{array}$ \\
\hline Potassium chloride (KCl) & $\begin{array}{l}\text { Carl-Roth GmbH \& Co., } \\
\text { Karlsruhe, Germany }\end{array}$ \\
\hline Sodium azide (NaN3) & $\begin{array}{l}\text { Sigma-Aldrich, Taufkirchen, } \\
\text { Germany }\end{array}$ \\
\hline Sodium chloride $(\mathrm{NaCl})$ & $\begin{array}{l}\text { Carl Roth GmbH, Karlsruhe, } \\
\text { Germany }\end{array}$ \\
\hline Sodium fluoride (NaF) & $\begin{array}{l}\text { Carl Roth GmbH \& Co., } \\
\text { Karlsruhe, Germany }\end{array}$ \\
\hline $\begin{array}{l}\text { Sodium dodecyl sulfate } \\
\text { (SDS) }\end{array}$ & $\begin{array}{l}\text { Carl Roth GmbH \& Co., } \\
\text { Karlsruhe, Germany }\end{array}$ \\
\hline Sodium hydroxide $(\mathrm{NaOH})$ & $\begin{array}{l}\text { Carl Roth GmbH \& Co., } \\
\text { Karlsruhe, Germany }\end{array}$ \\
\hline $\begin{array}{l}\text { Sodium dihydrogen } \\
\text { phosphate }\left(\mathrm{Na}_{2} \mathrm{HPO}_{4}\right)\end{array}$ & $\begin{array}{l}\text { Carl Roth GmBH \& Co., } \\
\text { Karlsruhe, Germany }\end{array}$ \\
\hline
\end{tabular}




\begin{tabular}{|l|l|}
\hline $\begin{array}{l}\text { Sodium orthovanadate } \\
\mathrm{Na}_{3} \mathrm{VO}_{4}\end{array}$ & $\begin{array}{l}\text { Sigma-Aldrich, Taufkirchen, } \\
\text { Germany }\end{array}$ \\
\hline $\begin{array}{l}\text { Tetramethyldiethyldiamine } \\
\text { (TEMED) }\end{array}$ & $\begin{array}{l}\text { Carl Roth GmbH \& Co., } \\
\text { Karlsruhe, Germany }\end{array}$ \\
\hline $\begin{array}{l}\text { Thiozolylblue tetrazolium } \\
\text { bromide (MTT) }\end{array}$ & $\begin{array}{l}\text { Sigma-Aldrich, Taufkirchen, } \\
\text { Germany }\end{array}$ \\
\hline Thimerosal & $\begin{array}{l}\text { Carl Roth GmbH \& Co., } \\
\text { Karlsruhe, Germany }\end{array}$ \\
\hline $\begin{array}{l}\text { Tris-(hydroxymethyl)- } \\
\text { aminomethane (Tris) }\end{array}$ & $\begin{array}{l}\text { Carl Roth GmbH \& Co., } \\
\text { Karlsruhe, Germany }\end{array}$ \\
\hline Triton X-100 & $\begin{array}{l}\text { Carl Roth GmbH \& Co., } \\
\text { Karlsruhe, Germany }\end{array}$ \\
\hline Tween-20 & $\begin{array}{l}\text { Carl Roth GmbH \& Co., } \\
\text { Karlsruhe, Germany }\end{array}$ \\
\hline
\end{tabular}

\section{Table 3: List of consumables used in this thesis}

\begin{tabular}{|l|l|}
\hline Consumable & Company \\
\hline $\begin{array}{l}\text { Cell culture flasks, plates, } \\
\text { dishes, falcon tubes, } \\
\text { pipette tips and cryo vials }\end{array}$ & $\begin{array}{l}\text { Greiner, Frickenhausen, } \\
\text { Germany }\end{array}$ \\
\hline $\begin{array}{l}\text { Costar® Stripette }{ }^{\circledR} \text { Serological } \\
\text { Pipets }(2 \mathrm{ml}, 5 \mathrm{ml}, 10 \mathrm{ml}, 25 \\
\mathrm{ml}, 50 \mathrm{ml})\end{array}$ & $\begin{array}{l}\text { Corning Inco rporated, } \\
\text { Corning, NY, USA }\end{array}$ \\
\hline $\begin{array}{l}\text { Eppendorf Tubes and Safe- } \\
\text { Lock Tubes }(1.5 \mu \mathrm{l} / 2 \mu \mathrm{l})\end{array}$ & $\begin{array}{l}\text { Eppendorf, Hamburg, } \\
\text { Germany }\end{array}$ \\
\hline $\begin{array}{l}\text { epT.I.P.S. Reloads } 50- \\
1250 \mu \mathrm{l}\end{array}$ & $\begin{array}{l}\text { Eppendorf, Hamburg, } \\
\text { Germany }\end{array}$ \\
\hline $\begin{array}{l}\text { Glass coverslips } 18 \mathrm{~mm} \times \\
18 \mathrm{~mm}\end{array}$ & $\begin{array}{l}\text { Carl Roth GmbH Co, } \\
\text { Karlsruhe, Germany }\end{array}$ \\
\hline GravityTRAP TM ULA plates & $\begin{array}{l}\text { InSphero, Waldshut, } \\
\text { Germany }\end{array}$ \\
\hline
\end{tabular}




\begin{tabular}{|c|c|}
\hline $\begin{array}{l}\text { iBlot }{ }^{\circledR} \text { Gel Transfer Stacks } \\
\text { Nitrocellulose, Regular }\end{array}$ & $\begin{array}{l}\text { Life technologies, } \\
\text { Carlsbad, CA, USA }\end{array}$ \\
\hline $\begin{array}{l}\text { Microseal }^{\circledR} \text { ‘B' Film (PCR } \\
\text { Sealers) }\end{array}$ & $\begin{array}{l}\text { Bio-Rad Laboratories, } \\
\text { Hercules, CA, USA }\end{array}$ \\
\hline $\begin{array}{l}\text { Multiplate }^{\mathrm{TM}} \text { PCR Plates } \\
\text { (MLL9651) }\end{array}$ & $\begin{array}{l}\text { Bio-Rad Laboratories, } \\
\text { Hercules, CA, USA }\end{array}$ \\
\hline $\begin{array}{l}\text { NuPAGE } \AA \text { Novex® 4-12\% Bis- } \\
\text { Tris Midi Protein Gels }\end{array}$ & $\begin{array}{l}\text { Life Technologies, } \\
\text { Carlsbad, CA; USA }\end{array}$ \\
\hline $\begin{array}{l}\text { Transwells ( } 24 \text {-well plate plus } \\
\text { inserts) for cell migration } \\
\text { assays, }(0.8 \mu \mathrm{m} \text { pore size })\end{array}$ & $\begin{array}{l}\text { Costar/Vitaris AG, Baar, } \\
\text { Germany }\end{array}$ \\
\hline $\begin{array}{l}\text { Transwells (6-well plate plus } \\
\text { inserts) for coculture assays, } \\
(0.4 \mu \mathrm{m} \text { pore size) }\end{array}$ & $\begin{array}{l}\text { Costar/Vitaris AG, Baar, } \\
\text { Germany }\end{array}$ \\
\hline $\begin{array}{l}\text { Roti@-PVDF } \\
\text { transfermembrane }\end{array}$ & $\begin{array}{l}\text { Carl Roth GmbH \& Co., } \\
\text { Karlsruhe, Germany }\end{array}$ \\
\hline $\begin{array}{l}\text { Whatman } \AA \text { cellulose } \\
\text { chromatography papers } 3 \mathrm{~mm}\end{array}$ & $\begin{array}{l}\text { Schleicher \& Schuell, } \\
\text { Dassel, Germany }\end{array}$ \\
\hline X-ray films & CEA, Strangnas, Sweden \\
\hline
\end{tabular}

\subsubsection{Buffers and solutions}

Table 4: List of buffers and solutions used in this thesis
\begin{tabular}{|l|l|}
\hline Buffer & Recipe \\
\hline Acrylamide running & $8 \%$ and $15 \%(\mathrm{v} / \mathrm{v})$ acrylamide, 375 \\
gel solution & $\mathrm{mM}$ Tris $\mathrm{pH} 8.8,0.1 \%$ SDS, 0.1\% \\
& ammonium persulfate, 0.06\% \\
& $\mathrm{N}, \mathrm{N}, \mathrm{N}, \mathrm{N}-$ \\
tetramethylethylenediamine \\
\hline Acrylamide stacking & $5 \%(\mathrm{v} / \mathrm{v})$ acrylamide, 130 mM Tris \\
gel solution & $\mathrm{pH} 6.8,0.1 \%(\mathrm{w} / \mathrm{v})$ SDS, \\
& $0.1 \%$ ammonium persulfate, \\
\hline
\end{tabular}




\begin{tabular}{|c|c|}
\hline & $\begin{array}{l}0.1 \% \mathrm{~N}, \mathrm{~N}, \mathrm{~N}, \mathrm{~N} \text { tetramethyl- } \\
\text { ethylenediamine }\end{array}$ \\
\hline Blocking solution (IF) & $\begin{array}{l}5 \%(v / v) \text { goat serum, } 0.1 \%(v / v) \\
\text { Tween } 20 \text { in PBS }\end{array}$ \\
\hline $\begin{array}{l}\text { Blocking solution } \\
\text { (WB) }\end{array}$ & $\begin{array}{l}0.5 \%(\mathrm{v} / \mathrm{v}) \text { blocking reagent, } 0.05 \% \\
(\mathrm{v} / \mathrm{v}) \text { Tween } 20, \\
0.01 \%(\mathrm{v} / \mathrm{v}) \text { Thimerosal in PBS }\end{array}$ \\
\hline Blotting buffer & $\begin{array}{l}200 \mathrm{mM} \text { glycine, } 25 \mathrm{mM} \text { Tris base, } \\
20 \%(\mathrm{v} / \mathrm{v}) \text { methanol }\end{array}$ \\
\hline Firefly substrate & $\begin{array}{l}470 \mu \mathrm{M} \text { D-lucif erin, } 530 \mu \mathrm{M} \text { ATP, } \\
270 \mu \mathrm{M} \text { Co A, } 33 \mathrm{mM} \text { DTT, } 20 \mathrm{mM} \\
\text { tricine, } 2.67 \mathrm{mM} \mathrm{MgSO}_{4}, 0.1 \mathrm{mM} \\
\text { EDTA (pH 7.8) }\end{array}$ \\
\hline $\begin{array}{l}\text { Laemmli protein } \\
\text { sample buffer }(5 x)\end{array}$ & $\begin{array}{l}400 \mathrm{mM} \text { Tris, } \mathrm{pH} 6.8,500 \mathrm{mM} \\
\text { dithio threitol, } 50 \%(\mathrm{v} / \mathrm{v}) \text { glycerol, } \\
10 \%(\mathrm{w} / \mathrm{v}) \mathrm{SDS}, 0.2 \%(\mathrm{w} / \mathrm{v}) \\
\text { bromophenol blue }\end{array}$ \\
\hline $\begin{array}{l}\text { NuPAGE® MES SDS } \\
\text { Running Buffer }(20 \times) \\
\text { and NuPAGE® } \\
\text { Antioxidant }\end{array}$ & $\begin{array}{l}\text { Life Technologies, Carlsbad, CA, } \\
\text { USA }\end{array}$ \\
\hline $\begin{array}{l}1 \% \text { NEB lysis buffer / } \\
1 \% \text { TEB lysis buffer }\end{array}$ & $\begin{array}{l}50 \mathrm{mM} \text { Tris (pH 7.5), } 150 \mathrm{mM} \\
\mathrm{NaCl}, 1 \% \text { (v/v) NP-40 / 1\% Triton } \\
\mathrm{X}-100,1 \mathrm{mM} \text { EDTA, } 1 \mathrm{mM} \\
\mathrm{Na3VO} 4,10 \mathrm{mM} \text { sodium fluoride, } \\
0.5 \mathrm{mM} \mathrm{PMSF}, 20 \mathrm{mM} \beta- \\
\text { glycerophosphate and Complete } \\
\text { protease inhibitors in ddH2O }\end{array}$ \\
\hline $\begin{array}{l}\text { Passive lysis buffer } \\
\text { (for Luciferase } \\
\text { reporter assays) }\end{array}$ & Promega, Mannheim \\
\hline $\begin{array}{l}\text { Permeabilization } \\
\text { solution (IF) }\end{array}$ & $0.2 \%(v / v)$ Triton $X-100$ in PBS \\
\hline
\end{tabular}




\begin{tabular}{|c|c|}
\hline PFA & $4 \%(w / v)$ in PBS \\
\hline $\begin{array}{l}\text { Phosphate Buffered } \\
\text { Saline (PBS) }\end{array}$ & $\begin{array}{l}140 \mathrm{mM} \mathrm{NaCl}, 2.7 \mathrm{mM} \mathrm{KCl}, 8 \mathrm{mM} \\
\mathrm{Na}_{2} \mathrm{HPO}_{4}, 1.5 \mathrm{mM} \mathrm{KH}_{2} \mathrm{PO}_{4}\end{array}$ \\
\hline PBS-Tween (PBS-T) & $0.05 \%(\mathrm{v} / \mathrm{v})$ Tween 20 in PBS \\
\hline $\begin{array}{l}\text { Propidium iodide }(\mathrm{Pl}) \\
\text { staining solution }\end{array}$ & $\begin{array}{l}\mathrm{PI}(50 \mu \mathrm{g} / \mu \mathrm{l}), \mathrm{RNaseA}(20 \mathrm{pg} / \mu \mathrm{l}) \text { in } \\
\mathrm{PBS}\end{array}$ \\
\hline RIPA lysis buffer & $\begin{array}{l}50 \mathrm{mM} \text { Tris (pH 7.5), } 150 \mathrm{mM} \\
\text { NaCl, } 1 \% \mathrm{NP}_{4} 0,0.5 \% \text { sodium } \\
\text { deoxycholate, } 0.1 \% \text { SDS, } 1 \mathrm{mM} \\
\text { sodium orthovanadate, } 10 \mathrm{mM} \\
\text { sodium fluoride, } 20 \mathrm{mM} \text { B- } \\
\text { glycerophosphate, Complete } \\
\text { Protease Inhibitor Cocktail }(1: 25)\end{array}$ \\
\hline $\begin{array}{l}\text { Renilla substrate } \\
\text { solution }\end{array}$ & $\begin{array}{l}0.7 \text { coelenterazine, } 2.2 \mathrm{mM} \\
\mathrm{Na}_{2} \mathrm{EDTA}, 0.44 \mathrm{mg} / \mathrm{ml} \text {, bovine } \\
\text { serum albumin, } 1.1 \mathrm{M} \mathrm{NaCl} \text {, } \\
1.3 \mathrm{mM} \mathrm{NaN}_{3}, 0.22 \mathrm{M} \text { potassium } \\
\text { phosphate buffer (pH 5.0) }\end{array}$ \\
\hline SDS running buffer & $\begin{array}{l}25 \mathrm{mM} \text { Tris } \mathrm{pH} 8.8,192 \mathrm{mM} \\
\text { glycine, } 0.1 \% \text { SDS }\end{array}$ \\
\hline $\begin{array}{l}\text { Separating gel } \\
\text { solution }\end{array}$ & $\begin{array}{l}8 \% \text { and } 10 \%(v / v) \text { acrylamide, } 375 \\
\mathrm{mM} \text { Tris } \mathrm{pH} 8.8,0.1 \%(\mathrm{w} / \mathrm{v}) \text { SDS, } \\
0.1 \% \text { APS }, 0.06 \% \text { TEMED in } \\
\mathrm{ddH} 2 \mathrm{O}\end{array}$ \\
\hline $\begin{array}{l}\text { S1 resuspension } \\
\text { buffer }\end{array}$ & $\begin{array}{l}50 \mathrm{Mm} \text { Tris Ph 8.0, } 10 \mathrm{Mm} \text { EDTA, } \\
0.1 \mathrm{mg} / \mathrm{ml} \text { RnaseA in ddH2O }\end{array}$ \\
\hline S2 lysis buffer & $\begin{array}{l}200 \mathrm{mM} \mathrm{NaCl}, 1 \%(\mathrm{w} / \mathrm{v}) \mathrm{SDS} \text { in } \\
\mathrm{dd} \mathrm{H} 2 \mathrm{O}\end{array}$ \\
\hline $\begin{array}{l}\text { S3 neutralization } \\
\text { buffer }\end{array}$ & $2.8 \mathrm{M} \mathrm{CH} 3 \mathrm{CO} 2 \mathrm{~K}$ in ddH2O, pH 5.1 \\
\hline $\begin{array}{l}\text { Tris-Acetat-EDTA } \\
\text { (TAE) buffer }\end{array}$ & $\begin{array}{l}40 \mathrm{mM} \text { Tris-acetate, } 1 \mathrm{mM} \text { EDTA, } \\
\mathrm{pH} 8.3\end{array}$ \\
\hline
\end{tabular}




\subsubsection{Cell culture}

Table 5: List of cell lines and primary human cells used in this thesis

\begin{tabular}{|l|l|}
\hline Cell lines & Source \\
\hline BT549 & CLS, Heidelberg, Germany \\
\hline HEK293T & $\begin{array}{l}\text { American Type Culture Collection (ATCC), } \\
\text { Manassas, VA, USA }\end{array}$ \\
\hline Hs578T & $\begin{array}{l}\text { Bernhard Lüscher (RWTH Aachen } \\
\text { University, Germany) }\end{array}$ \\
\hline MDA-MB-231 & CLS, Heidelberg, Germany \\
\hline THP-1 & DSMZ, Braunschweig, Germany \\
\hline PBMCs & $\begin{array}{l}\text { Isolated from buffy coats of healthy donors } \\
\text { provided by the Blutzentrale Kinikum, } \\
\text { Katharinenhospital Stuttgart, Germany }\end{array}$ \\
\hline
\end{tabular}

Table 6: List of cell culture reagents used in this thesis

\begin{tabular}{|c|c|}
\hline Cell culture reagents & Company \\
\hline Accutase & $\begin{array}{l}\text { Sigma-Aldrich, München, } \\
\text { Germany Fetal }\end{array}$ \\
\hline Collagen $\mathrm{R}$ solution & $\begin{array}{l}\text { Serva, Heidelberg, } \\
\text { Germany }\end{array}$ \\
\hline Fetal calf serum (FCS) & $\begin{array}{l}\text { PAA, Laboratories, } \\
\text { Pasching, Austria }\end{array}$ \\
\hline G418 & $\begin{array}{l}\text { Life Technologies, } \\
\text { Carlsbad, CA, USA }\end{array}$ \\
\hline $\begin{array}{l}\text { Lipofectamine } \AA \text { RNAiMAX } \\
\text { Transfection Reagent }\end{array}$ & $\begin{array}{l}\text { Life Technologies, } \\
\text { Carlsbad, CA, USA }\end{array}$ \\
\hline $\begin{array}{l}\text { Lipofectamine }{ }^{\circledR} \text { LTX with } \\
\text { Plus }^{\text {TM Reag }} \text { Rent }\end{array}$ & $\begin{array}{l}\text { Life Technologies, } \\
\text { Carlsbad, CA, USA }\end{array}$ \\
\hline $\begin{array}{l}\text { Matrigel }{ }^{\mathrm{TM}} \text { Basement } \\
\text { Membrane Matrix }\end{array}$ & $\begin{array}{l}\text { BD Bioscience, Franklin } \\
\text { Lakes, NJ, USA }\end{array}$ \\
\hline
\end{tabular}




\begin{tabular}{|l|l|}
\hline RPMI 1640 & $\begin{array}{l}\text { Invitrogen, Karlsruhe, } \\
\text { Germany }\end{array}$ \\
\hline $\begin{array}{l}\text { MEM non-essential amino } \\
\text { acids solution }(100 \times)\end{array}$ & $\begin{array}{l}\text { Life Technologies, } \\
\text { Carlsbad, CA, USA }\end{array}$ \\
\hline siRNA buffer & $\begin{array}{l}\text { Thermo Fisher Scientific, } \\
\text { Dreieich, Germany }\end{array}$ \\
\hline Trypsin/EDTA $(10 x)$ & $\begin{array}{l}\text { Life Technologies, } \\
\text { Carlsbad, CA, USA }\end{array}$ \\
\hline
\end{tabular}

\subsubsection{Oligonucleotides}

\section{Table 7: List of oligonucleotides used in this thesis}

\begin{tabular}{|l|l|}
\hline \multicolumn{2}{|l|}{ MiR-149 cloning } \\
\hline hsa-miR-149 & F:5'- \\
& TGCTGTCTGGCTCCGTGTCTTCACTCC \\
& CGTGCTTGTCCGAGGAGGGAGG \\
& GAGGGACGGGGGCTGTGC-3' \\
& R:5'- \\
& CCTGGCACAGCCCCCGTCCCTCCCTC \\
& CCTCCTCGGACAAGCACGGGAG \\
& TGAAGACACGGAGCCAGAC-3' \\
\hline miR-Control & F:5'- \\
& GAAATGACTGCGCGTGGAGACGTTा \\
& GGCCACTGACTGACGTCTCC \\
& ACGCAGTACATT-3' \\
& R: 5'- \\
& AAATGTACTGCGTGGAGACGTCAGTCA \\
& GTGGCCAAAACGTCTCCAC \\
GCGCAGTACATTC-3' \\
\hline Deletion of miR-149 binding regions in the CSF-1 3'- \\
UTR \\
\hline CSF-1 3'-UTR & F: 5'- \\
& T1TCTAGAGAGCTCCTGCCTGCCA-3' \\
& R: 5'- \\
& TITCTAGAAGGCTGGAGAGTGGAGGA \\
& C-3' \\
\hline
\end{tabular}




\begin{tabular}{|c|c|}
\hline CSF1-del1 & $\begin{array}{l}\text { F: 5'-GGACCAGAGCGCTGGGGCCC-3' } \\
\text { R: 5'-GGGCCCCAGCGCTCTGGTCC-3' }\end{array}$ \\
\hline CSF1-del2 & $\begin{array}{l}\text { F: 5'- } \\
\text { CCCTTGACTGAATGAGAAGGATGCTCC } \\
\text { CCATGCTGCC-3' } \\
\text { R: 5'- } \\
\text { GGCAGCATGGGGAGCATCCTTCTCATT } \\
\text { CAGTCAAGGG-3' }\end{array}$ \\
\hline CSF1-del3 & $\begin{array}{l}\text { F: 5'- } \\
\text { GCCCCCGTCCATCCATCATCCGTCCG } \\
\text { TCCTCC-3' } \\
\text { R: 5'- } \\
\text { GGAGGACGGACGGATGATGGATGGAC } \\
\text { GGGGGC-3' }\end{array}$ \\
\hline \multicolumn{2}{|l|}{ qRT-PCR } \\
\hline EGF & $\begin{array}{l}\text { F: 5'-GAGTCGAGCAGAGATGTGAGG-3' } \\
\text { R: 5'-TTGGTTGATTGACCCATCTG-3' }\end{array}$ \\
\hline AREG & $\begin{array}{l}\text { F: 5'-GTCTCCACTCGCTCTTCCAA-3' } \\
\text { R: 5'-TAATGGCCTGAGCCGAGTATC-3' }\end{array}$ \\
\hline ARG1 & $\begin{array}{l}\text { 5'-GTGGAAACTTGCATGGACAAC-3' } \\
\text { 5'-AATCCTGGCACATCGGGAATC-3' }\end{array}$ \\
\hline MRC1 & $\begin{array}{l}\text { F: 5'-TTTGTCAACTTGAGTCCCTTCAC-3' } \\
\text { R: 5'-TCCCGCTACACTGTTITCAC-3' }\end{array}$ \\
\hline EGFR & $\begin{array}{l}\text { F: 5'-GGGTTGCTATCACTCTCTATGC-3' } \\
\text { R: 5'-TICTGTCTGTTGCCGTAGT-3' }\end{array}$ \\
\hline SEM4D & $\begin{array}{l}\text { F: 5'-AAGCAGCATGAGGTGTATTGG-3' } \\
\text { R: 5'-AGTTGAGGCACTCTGTCTGTT-3' }\end{array}$ \\
\hline VAV1 & $\begin{array}{l}\text { F: 5'- } \\
\text { TCTGCCCAAGATGGAGGTGTTCA-3' } \\
\text { R: 5'- } \\
\text { TICGTGAGCTCCACAATGTCTCCA-3' }\end{array}$ \\
\hline PTPRO & $\begin{array}{l}\text { F: 5'-GGGATGCTTCACCTGCTTA-3' } \\
\text { R: 5'-ACCATTGAGACGGCTATGAAC-3' }\end{array}$ \\
\hline PPIA & QT00052311, Qiagen \\
\hline GAPDH & QT01192646, Qiagen \\
\hline CSF1 & QT00035224, Qiagen \\
\hline
\end{tabular}




\begin{tabular}{|l|l|}
\hline RNU6B & RT:001093, TM:001093, Life technologies \\
\hline $\begin{array}{l}\text { hsa-miR-149- } \\
\text { pp }\end{array}$ & RT: 002255 TM: 002255, Life technologies \\
\hline
\end{tabular}

\subsubsection{Plasmids and vectors}

Table 8: List of plasmids and vectors used in this thesis

\begin{tabular}{|l|l|}
\hline Plasmid & Source \\
\hline $\begin{array}{l}\text { pcDNA6.2- } \\
\text { GW/EmGFP-miRNA }\end{array}$ & Thermo Scientific, Waltham, USA \\
\hline $\begin{array}{l}\text { pGL3-Luciferase } \\
\text { plasmid }\end{array}$ & Promega, Madison, WI, USA \\
\hline
\end{tabular}

\subsubsection{Antibodies}

Table 9: List of primary antibodies used in this thesis

\begin{tabular}{|l|l|l|l|}
\hline Antibody & Species & Dilution & Source \\
\hline $\begin{array}{l}\text { anti-CD206 } \\
\text { (polyclonal) }\end{array}$ & rabbit & $\begin{array}{l}1: 100 \\
(\mathrm{IF})\end{array}$ & $\begin{array}{l}\text { Abcam, } \\
\text { Cambridge, UK }\end{array}$ \\
\hline $\begin{array}{l}\text { anti-CSF1R } \\
\text { (D309X) }\end{array}$ & rabbit & $\begin{array}{l}1: 200 \\
(\mathrm{IP})\end{array}$ & $\begin{array}{l}\text { Cell Signaling, } \\
\text { Danvers, MA, USA }\end{array}$ \\
\hline $\begin{array}{l}\text { anti- F4/80 } \\
\text { (BM8) }\end{array}$ & rat & $\begin{array}{l}1: 100 \\
(\mathrm{IF})\end{array}$ & $\begin{array}{l}\text { Thermo Scientific, } \\
\text { Waltham, USA }\end{array}$ \\
\hline $\begin{array}{l}\text { anti- Phospho- } \\
\text { EGFR (D7A5) }\end{array}$ & rabbit & $\begin{array}{l}1: 2000 \\
\text { (WB) }\end{array}$ & $\begin{array}{l}\text { Cell Signaling, } \\
\text { Danvers, MA, USA }\end{array}$ \\
\hline $\begin{array}{l}\text { anti- } \\
\text { Phosphotyrosine } \\
\text { (mAb P-Tyr-100) }\end{array}$ & mouse & $\begin{array}{l}1: 1000 \\
\text { (WB) }\end{array}$ & $\begin{array}{l}\text { Cell Signaling, } \\
\text { Danvers, MA, USA }\end{array}$ \\
\hline $\begin{array}{l}\text { anti - Vimentin } \\
\text { (SP20) }\end{array}$ & rabbit & $\begin{array}{l}1: 100 \\
(\mathrm{IF})\end{array}$ & $\begin{array}{l}\text { Thermo Scientific, } \\
\text { Waltham, USA }\end{array}$ \\
\hline
\end{tabular}




\begin{tabular}{|l|l|l|l|}
\hline $\begin{array}{l}\text { anti- } \alpha \text {-tubulin } \\
\text { mAb }\end{array}$ & mouse & $\begin{array}{l}1: 5000 \\
(\text { WB })\end{array}$ & $\begin{array}{l}\text { Sigma-Aldrich, St } \\
\text { Louis, MO, USA }\end{array}$ \\
\hline
\end{tabular}

Table 10: List of secondary antibodies used in this thesis

\begin{tabular}{|l|l|l|l|}
\hline Antibody: & Species & Dilution & Company \\
\hline $\begin{array}{l}\text { Alexa Fluor } \\
\text { 48 }\end{array}$ & goat & $\begin{array}{l}1: 500 \\
(\text { IF })\end{array}$ & $\begin{array}{l}\text { Invitrogen, } \\
\text { Karlsruhe, } \\
\text { Germany }\end{array}$ \\
\hline $\begin{array}{l}\text { Alexa Fluor } \\
546 \text { anti-mouse }\end{array}$ & goat & $\begin{array}{l}1: 500 \\
(\mathrm{IF})\end{array}$ & $\begin{array}{l}\text { Invitrogen, } \\
\text { Karlsruhe, } \\
\text { Germany }\end{array}$ \\
\hline $\begin{array}{l}\text { Alexa Fluor } \\
633 \text { anti-rabbit }\end{array}$ & goat & $\begin{array}{l}1: 500 \\
(\mathrm{IF})\end{array}$ & $\begin{array}{l}\text { Invitrogen, } \\
\text { Karlsruhe, } \\
\text { Germany }\end{array}$ \\
\hline $\begin{array}{l}\text { HRP-anti- } \\
\text { mouse lg G }\end{array}$ & sheep & $\begin{array}{l}1: 10000 \\
(\mathrm{WB})\end{array}$ & $\begin{array}{l}\text { GE Healthcare, } \\
\text { Munich, Germany }\end{array}$ \\
\hline $\begin{array}{l}\text { HRP-anti-rabbit } \\
\text { lgG }\end{array}$ & donkey & $\begin{array}{l}1: 10000 \\
(\mathrm{WB})\end{array}$ & $\begin{array}{l}\text { GE Healthcare, } \\
\text { Munich, Germany }\end{array}$ \\
\hline
\end{tabular}

\subsubsection{Kits and enzymes}

Table 11: List of kits and enzymes used in this thesis

\begin{tabular}{|l|l|}
\hline Kit and enzymes & Company \\
\hline $\begin{array}{l}\text { BLOCK-iTTM Pol II miR RNAi } \\
\text { Expression }\end{array}$ & $\begin{array}{l}\text { Life Technologies, } \\
\text { Carlsbad, CA, USA }\end{array}$ \\
\hline CD14 Mirco Beads (human) & $\begin{array}{l}\text { Miltenyi Biotec GmbH, } \\
\text { Bergisch Gladbach, } \\
\text { Germany }\end{array}$ \\
\hline DC Protein Assay & Bio-Rad, Hercules, \\
& USA \\
\hline
\end{tabular}




\begin{tabular}{|c|c|}
\hline $\begin{array}{l}\text { DyNAmo ColorFlash Probe qPCR } \\
\text { Kit }\end{array}$ & $\begin{array}{l}\text { Thermo Scientific, } \\
\text { Fremont, MA, USA }\end{array}$ \\
\hline mirVana $^{\mathrm{TM}}$ miRNA Isolation Kit & $\begin{array}{l}\text { Life Technologies, } \\
\text { Carlsbad, CA, USA }\end{array}$ \\
\hline $\begin{array}{l}\text { Power SYBRâ Green RNA-to- } \\
\text { СT }^{\text {тм }} \text { 1-Step Kit }\end{array}$ & $\begin{array}{l}\text { Thermo Fisher } \\
\text { Scientific, Dreiech, } \\
\text { Germany }\end{array}$ \\
\hline $\begin{array}{l}\text { PureLink® HiPure Plasmid } \\
\text { Midiprep Kit }\end{array}$ & $\begin{array}{l}\text { Life Technologies, } \\
\text { Carlsbad, CA, USA }\end{array}$ \\
\hline $\begin{array}{l}\text { PureLink® Quick Gel Extraction } \\
\text { Kit }\end{array}$ & $\begin{array}{l}\text { Life Technologies, } \\
\text { Carlsbad, CA, USA }\end{array}$ \\
\hline $\begin{array}{l}\text { QuikChange site-directed PCR } \\
\text { mutagenesis Kit }\end{array}$ & $\begin{array}{l}\text { Stratagene, La Jolla, } \\
\text { CA, USA }\end{array}$ \\
\hline QuantiTect® Primer Assay & $\begin{array}{l}\text { Qiagen, Venlo, } \\
\text { Netherlands }\end{array}$ \\
\hline RNAse A & $\begin{array}{l}\text { Life Technologies, } \\
\text { Carlsbad, CA, USA }\end{array}$ \\
\hline RNeasyâ Plus Mini Kit & $\begin{array}{l}\text { Qiagen, Hilden, } \\
\text { Germany }\end{array}$ \\
\hline $\begin{array}{l}\text { SuperSignal® West Pico } \\
\text { Chemiluminescent Substrate }\end{array}$ & $\begin{array}{l}\text { Thermo Scientific, } \\
\text { Fremont, MA, USA }\end{array}$ \\
\hline $\begin{array}{l}\text { SuperSignal® West Dura } \\
\text { Extended Duration Substrate }\end{array}$ & $\begin{array}{l}\text { Thermo Scientific, } \\
\text { Fremont, MA, USA }\end{array}$ \\
\hline $\begin{array}{l}\text { TaqMan® MicroRNA Reverse } \\
\text { Transcription Kit }\end{array}$ & $\begin{array}{l}\text { Life Technologies, } \\
\text { Carlsbad, CA, USA }\end{array}$ \\
\hline TaqMan® Small RNA Assays & $\begin{array}{l}\text { Life Technologies, } \\
\text { Carlsbad, CA, USA }\end{array}$ \\
\hline
\end{tabular}




\subsubsection{Animals}

Six-weeks-old female SCID mice were obtained from Janvier Laboratories Saint Berthevin, France. Animal care and experiments were performed in accordance with federal guidelines and were approved by the institutional ethical committee, the university and state autho rities and conducted under the authority of the Project License 35-9185.81/0367.

\subsection{Methods}

\subsubsection{Cell culture and transfection}

\subsubsection{Cell lines}

The cell lines MDA-MB-231 and BT-549 were obtained from CLS (Heidelberg, Germany), Hs578T from Dr. Bernhard Lüscher (RWTH Aachen, Germany), and THP-1 from DSMZ (Braunschweig, Germany). All cell lines were tested negative for mycoplasma (Lonza, LT07-318) and authenticated (Multiplexion $\mathrm{GmbH}$, Germany). Cell lines were cultured in RPMI-1640 (Life Technologies, Carlsbad, CA, USA) supplemented with 10\% FCS (PAA Laboratories, Cölbe, Germany) at $37^{\circ} \mathrm{C}, 5 \% \mathrm{CO}_{2}$, and $90 \%$ humidity. THP-1 cells were differentiated by treatment with $25 \mathrm{nM}$ phorbol 12,13dibutyrate $(\mathrm{PDBu})$ for $48 \mathrm{~h}$, followed by a $24 \mathrm{~h}$ rest period in 
fresh media. Transient transfections of miRNA mimics or siRNAs were performed at final concentrations of $5 \mathrm{nM}$ and 10 nM, respectively, using RNAiMax (Life Technologies). HsamiR-149-5p mimic (miR-149, cat\# AM17000), miRNA-negative control\#1 (miR-con), silencer Select siRNAs targeting CSF1 (cat\# 4392420) and the negative control (cat\# 4390843) were obtained from Life Technologies. Plasmid transfection was performed using Lipofectamine LTX with Plus Reagent (Life Technologies). For stable cell lines, MDA-MB-231 cells were transfected with pcDNA6.2-GW/EmGFP-miRNA vectors and selected with $1 \mu \mathrm{g} / \mathrm{ml}$ Blasticidin S (Life Technologies Carlsbad, CA, USA) for 2 weeks. GFP-positive cells were enriched by fluorescence activated sorting (BD Bioscience, FACS Aria III) and miR-149 overexpression was then confirmed by qPCR. Conditioned medium (CM) was obtained by exchanging the medium on MDA-MB-231 cells ( $80 \%$ confluency) with $3 \mathrm{~mL}$ of fresh growth medium containing $10 \%$ FCS. After $24 \mathrm{~h}$, the cell culture supernatant was collected, centrifuged and used immediately. Doubly conditioned medium (DCM) was obtained by first incubating $1 \times 10^{6}$ THP-1 MФs with CM $(2.5 \mathrm{~mL})$ derived from MDA-MB-231 cells for $24 \mathrm{~h}$, followed by medium exchange (RPMI plus $10 \% \mathrm{FCS}, 2.5 \mathrm{~mL}$ ) and collection of the cell culture supernatant af ter $24 \mathrm{~h}$. At the time of CM/DCM collection, the cells were counted to ensure conditioning of the medium by comparable cell numbers. 


\subsubsection{Primary human monocyte isolation and primary human macrophage \\ differentiation}

Buffy coats were obtained from healthy donors (provided by the Katherinenhospital, Stuttgart, Germany) and peripheral blood mononuclear cells (PBMCs) were isolated by centrifugation in Ficoll (PromoCell, Heidelberg, Germany), followed by positive selection with anti-CD14 magnetic beads (Miltenyi Biotec, Auburn, CA) according to the manufacturer's instructions. For human primary macrophage differentiation (hMФ), CD14positive monocytes were cultured in RPMI containing $20 \%$ human serum (Zentrum für Klinische Transfusionsmedizin, Tübingen, Germany) at $37^{\circ} \mathrm{C}, 5 \% \mathrm{CO}_{2}$, and $90 \%$ humidity for at least 10 days with medium exchange every 3-4 days as previously described (Linder et al. 2002).

\subsubsection{RNA isolation and quantitative PCR}

Total RNA was isolated from cells using the RNeasy plus Kit (Qiagen). 100 ng RNA were used for the real-time PCR reaction using the QuantiTect SYBR Green RT-PCR Kit (Qiagen). qRTPCR was performed with a Cfx96 device (Bio-Rad) using a Power SYBR Green RNA-to-Ct 1-Step kit (Applied Biosystems). For miRNA expression analysis, reverse transcription and qPCR of miR-149 and RNU6B were performed with TaqMan microRNA Assays (Life Technologies). Changes in the relative expression levels were determined using the $2^{-\Delta \Delta C t}$ method 
(Bio-Rad CFX Manager software 3.1). Primers are listed in Table S1.

\subsubsection{Vectors and cloning}

Genomic DNA from MCF-7 cells was used as a template to amplify a $779 \mathrm{bp}$ fragment of the 3'UTR of CSF-1 (nucleotides 23342-24118, ref. seq. NG_030008.1) and cloned into the pGL3-Luciferase plasmid (Promega, Madison, WI) via the Xbal site. The sequences involved in miR-149 seed region binding, as identified by microrna.org (del1: AGCCAG, del2: GAGGCCAG, del3: GAGCCAG), were deleted by Quikchange site-directed mutagenesis using the primers listed in Table S1. For stable miRNA expression, the BLOCK-iT ${ }^{\mathrm{TM}}$ Pol II miR RNAiExpression Vector Kit (K4936-00, Life Technologies) was used. Single-stranded DNA oligonucleotides encoding hsamiR-149 were designed as shown in Table $S 1$ and annealed to generate a double-stranded oligonucleotide for cloning into the linearized pcDNA6.2-GW/EmGFP-miR vector. The miR-control vector was contained in the kit. All plasmids generated were validated by sequencing (GATC Biotech AG, Konstanz, Germany).

\subsubsection{Luciferase reporter assay}

$3 \times 10^{4} \mathrm{HEK} 293 \mathrm{~T}$ cells perwell were seeded into 96-well plates. The next day, cells were transfected with $10 \mathrm{ng}$ pGL3-firefly luciferase plasmids (wt/mut) together with $10 \mathrm{ng} p R L$-Renilla 
luciferaseplasmid and $50 \mathrm{nM}$ miR-con or miR-149 mimics using Lipofectamine 2000 (Invitrogen). Two days later, cells were lysed with passive lysis buffer (Promega). The activities of the luciferases were measured by sequential substrate addition as described by Dyer et al. (Dyer et al. 2000) and detection at 562 $\mathrm{nm}$ with the multimode reader Infinite ${ }^{\circledR} 200$ PRO (Tecan, Männedorf, Switzerland). Firefly luciferase activities were normalized to those of Renilla luciferase activities in each sample. Experiments were done with at least triplicate samples.

\subsubsection{Transwell co-cultures}

For co-cultures with primary human macrophages, $1 \times 10^{6}$ MDA-MB-231 cells were seeded in $1 \mathrm{~mL}$ RPMl containing $10 \%$ human serum into the upper Transwell chamber $(0.4 \mu \mathrm{m}$ pore size; Greiner Bio-One, Germany) and allowed to adhere overnight. The next day, $1 \times 10^{6} \mathrm{hM} \Phi$ in $1 \mathrm{~mL}$ RPMI containing $10 \%$ human serum were seed ed into the lower well and the coculture was incubated for $24 \mathrm{~h}$. Transwell co-cultures of THP-1 and MDA-MB-231 cells were performed as described by Stewart D. et al. (Stewart et al. 2012).

\subsubsection{Three-Dimensional tumor spheroid co- culture assays}

MDA-MB-231 cells were labelled with CellTracker Green (Invitrogen, Carlsbad, CA) and seeded in GravityTRAPTM ULA 
plates (InSphero, Waldshut, Germany) in RPMI containing 10\% FCS and 2.5\% matrigel. After $72 \mathrm{~h}$, single spheroids were harvested and seeded in RPMI containing 2.5\% matrigel on top of collagen R bed ( $1 \mathrm{mg} / \mathrm{mL}$, Serva, Heidelberg, Germany) containing $1.6 \times 10^{4} \mathrm{THP}-1 \mathrm{M \Phi}$ labelled with CellTracker Orange (Invitrogen). Z-stack images of the spheroids (at $5 \mu \mathrm{m}$ intervals and optical slices starting at the bottom of the spheroid) were acquired on a Zeiss Cell Observer Spinning Disk microscope equipped with a Plan-Apochromat 10x/0.45 and an Axiocam 503 mono camera. 3D-spheroid reconstruction was done with Zen blue 2.3 software.

\subsubsection{Migration, invasion, and proliferation assays}

For migration, $5 \times 10^{4}$ cells were seeded in medium containing $0.5 \%$ FCS into Transwells ( $8 \mu \mathrm{m}$ pore size, Costar) and allowed

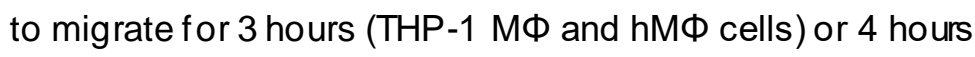
(MDA-MB-231). For invasion, Transwells were coated on the upper side with $50 \mu \mathrm{L}$ growth factor-reduced Matrigel (BD Biosciences) diluted 1:20 in medium containing $0.5 \%$ FCS, followed by seeding of MDA-MB-231 cells $\left(5 \times 10^{4}\right)$ in medium containing $0.5 \%$ FCS and overnight incubation. Cells on the underside of the membranes were fixed, stained with crystal violet, and six independent fields at a 10x magnification were quantified. For proliferation, $1 \times 10^{3}$ cells were plated into 96well plates and cell proliferation was assessed every $24 \mathrm{~h}$ for 4 
days by CellTiter-Glo $\AA^{\circ}$ Luminescent Cell Viability Assay (Promega).

\subsubsection{Cell lysis, immunoprecipitation, and western blotting}

Cells were lysed in RIPA buffer containing $50 \mathrm{mM}$ Tris, $\mathrm{pH} 7.5$, $150 \mathrm{mM} \mathrm{NaCl}, 1 \% \mathrm{NP}-40,0.25 \%$ deoxycholate, $0.1 \%$ SDS, 1 $\mathrm{mM} \mathrm{Na} \mathrm{VO}_{4}, 10 \mathrm{mM} \mathrm{NaF}, 0.5 \mathrm{mM}$ PMSF, $20 \mathrm{mM} \beta-$ glycerophosphate, and Complete protease inhibitors (Roche Diagnostics Basel, Switzerland). Lysates were clarified by centrifugation at $16,000 \times \mathrm{g}$ for 10 minutes. For immunoprecipitation, cells were lysed in TEB buffer ( $50 \mathrm{mM}$ Tris $\mathrm{pH}$ 7.5, $150 \mathrm{mM} \mathrm{NaCl}, 10 \mathrm{mM} \mathrm{NaF}, 20 \mathrm{mM} \beta$ glycerophosphate, $1 \mathrm{mM}$ EDTA, Complete protease inhibitors, $1 \mathrm{mM} \mathrm{Na}_{3} \mathrm{VO}_{4}, 0.5 \mathrm{mM}$ PMSF) plus $1 \%$ Triton X-100, and equal amounts of protein were incubated with CSF1R-specific antibodies for $3 \mathrm{~h}$ at $4{ }^{\circ} \mathrm{C}$, followed by incubation with protein $\mathrm{G}$ agarose (KLP) at $4^{\circ} \mathrm{C}$ for $2 \mathrm{~h}$ and 3 washes with TEB buffer containing $0.1 \%$ Triton $X-100$. Proteins were separated by SDS-PAGE and transferred to nitrocellulose membrane using the iBlot Gel Transfer Device (Life Technologies, Carlsbad, CA, USA). Membranes were blocked with $0.5 \%$ blocking buffer (0.5\% blocking reagent (Roche, Basel, Schweiz) in PBS containing $0.1 \%$ Tween-20 (PBS-T)) and then incubated with primary antibodies in blocking buffer. After washing with PBS$\mathrm{T}$, membranes were incubated with horseradish peroxidase- 
conjugated secondary antibodies in blocking buffer. After washing with PBS-T, proteins were visualized using an enhanced chemiluminescence detection system (Thermo Fischer, Waltham, MA). See Table S2 for details on primary and secondary antibodies.

\subsubsection{ELISA assays}

The concentration of CSF1 in the conditioned medium of TNBC cell lines was measured with the human CSF1 ELISA Kit \#EHCSF1 (Thermo Scientific) according to the manufacturer's instructions.

\subsubsection{Animal experiments}

$2 \times 10^{6}$ MDA-MB-231 cells were implanted into the fourth mammary fat pad of 8-week-old female SCID mice (Janvier Labs, France). Tumor growth was determined three times per week with a digital Vernier caliper and tumor volume was calculated as follows: tumor volume $=0.5 \times$ (length $\times$ (width) ${ }^{2}$ ). Mice were sacrificed after $6 \quad 1 / 2$ weeks. Animal care and experiments were conducted based on protocols approved by Institutional Animal Care and Use Committee and state authorities.

\subsubsection{Tissue immunostaining}

Primary tumors and lungs were isolated, snap-frozen in optimal cutting temperature (OCT) medium (Sakura Finetek) and $8 \mu \mathrm{m}$ 
(tumors) or $12 \mu \mathrm{m}$ (lungs) sections were prepared. Blocking was performed with $5 \%$ goat serum for $1 \mathrm{~h}$. Tissues were incubated at $4^{\circ} \mathrm{C}$ overnight with p rimary antibodies (Table S2), followed by three washing steps with $1 \times$ TBS (0.05 M Trizma base and 0.15 $\mathrm{M}$ sodium chloride, $\mathrm{pH}$ 7.6). Tissues were incubated with Alexa Fluor 546 or 633 conjugated secondary antibodies for $1 \mathrm{~h}$ at room temperature, nuclei were counterstained with DAPI and samples were mounted in Fluoromount G (Southern Biotech, Birmingham, $A L)$. Imaging was performed on a Zeiss Cell Observer Spinning Disk microscope equipped with a PlanApochromat 20x/0.8 for tumor or with a Plan-Apochromat $10 x / 0.45$ for lung sections and an Axiocam 503 mono camera. F4/80- CD206-, and vimentin-positive areas were quantified by ImageJ (v1.49s).

\subsubsection{2 miRNA target prediction, KM plot and correlation analyses}

Gene expression from breast cancer tumors and matched normal probes were obtained from the cancer genome atlas (TCGA) as raw counts (Rahman et al. 2015). Libraries were normalized and count values converted to counts per million (cpm) values using edgeR. TNBC samples were selected according to the combined negative status of the variables PR_Status/HER2_Final_Status/ER_Status. Lymph node metastasized and non-metastasized samples were distinguished according to the pathologic_N variable N1/N2/N3 and N0, respectively. Survival data of the BRCA patients was 
obtained from Oncolnc (Anaya 2016). Kaplan-Meier curves and survival significance was calculated using the $R$ library survival in version 2.44. Target genes of miR-149 were predicted through the miRWalk2.0 database (Dweep and Gretz 2015). Genes were selected as miR-149 targets, if such an interaction was predicted in the 3'-UTR region by at least 6 out of 12 databases with a $p$-value $<0.05$. Functional enrichment for biological processes within the Gene Ontology (Gene Ontology Consortium 2000; Blake et al. 2015) was calculated via a conditional hypergeometric test of the target genes as implemented in the R GOstats library. Predictions of miRNA duplex secondary structures and minimum free energy values were obtained from the RNAhybrid Web service (Rehmsmeier 2006).

\subsubsection{Statistical analysis}

Unless stated otherwise, all data represent the mean of 3 experiments $\pm S D$. Statistical significance was analyzed by $t$ test and one-way ANOVA followed by Tukey's post-test (GraphPad Prism version 4.03). P-values below 0.05 were considered significant $\left({ }^{*} p<0.05 ;{ }^{* *} p<0.01 ;{ }^{* * *} p<0.001\right), p$ $>0.05=$ ns, not significant. 


\section{Results}

\subsection{MiR-149 and survival of TNBC patients}

Aberrant exp ression of a single miRNA can deleteriously disturb the expression of multiple genes, leading to several profound pathological conditions, including cancer. Thus, miRNA expression levels have demonstrated clinical significance as potential biomarkers to diagnose and monitor cancer disease (Rupaimoole and Slack 2017). In order to identify if miR-149 expression could serve as a prognostic marker in TNBC, our collaborators Melanie Boerries and Hauke Busch, analyzed the overall survival of 987 breast cancer patients from the cancer genome atlas with respect to lymph node metastasis, triplenegative breast cancer (TNBC) status and expression strength of miR-149 (Fig. 4). An additive Cox proportional hazards regression model on these variables clearly indicates significantly poorer survival in the presence of lymph node metastasis $\left(H R=2.30, p=1.1^{*} 10^{-6}\right)$, TNBC positive cancer $(H R=$ $1.81, p=0.027)$ and low expression of $m i R-149(H R=1.59, p=$ $0.013)$.

To further elucidate the functional role of miR-149 in breast cancer, our collaborators predicted putative target genes of miR-149 through miRWalk2.0 (Dweep and Gretz 2015), a database for predicted and validated miRNA-target interactions. Genes were selected as target genes, if an interaction was predicted in the 3'-UTR region by at least 6 out of 12 databases 
with a $p$-value $<0.05$. This resulted in 2644 unique target genes. It has been suggested that miRNAs preferentially target groups of functionally related mRNAs (Ben-Hamo and Efroni 2015). In the following this idea was used to narrow down the number of putative miR-149 targets in a two-step process. First, conditional hypergeometric analysis was used to test for significantly enriched Gene Ontology (GO) terms. This revealed an enrichment of $474 \mathrm{GO}$ terms ( $p$-value $<0.05$ ), which were mainly related to cell morphogenesis, development, differentiation, cell-cell adhesion, migration and immune system development. Next, we searched for overrepresented genes within the enriched GO terms. Out of the 2644 predicted targets, $30 \%$ did not belong to any GO term, but $5 \%$ (96 genes) of the predicted targets belonged to 45 or more terms. It can be hypothesized that the latter target genes are biologically most meaningful due to the simultaneous regulation of genes in the same pathway through miR-149. Importantly, the expression of only five of these genes (CSF1, VAV1, SEMA4D, EGFR and PRTPO) was significantly anti-correlated with that of miR-149 in the lymph node-positive TNBC tissue samples. 
TNBC-

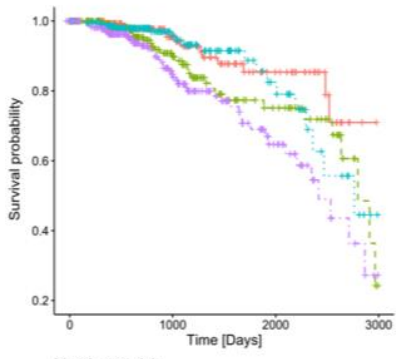

Number at risk
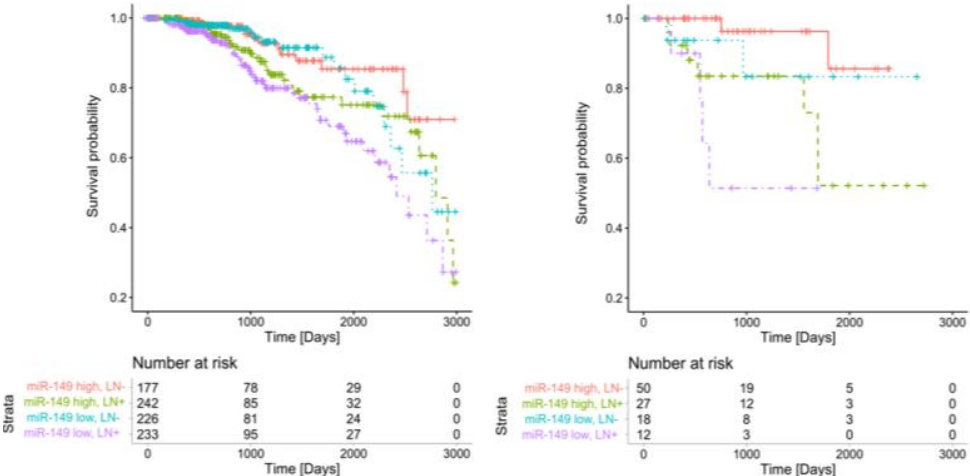

Number at risk

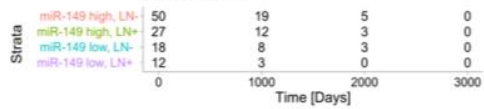

Endpoint Subgroup

miR-149 low 987

TNBC+

LN+

\begin{tabular}{lll}
$\mathrm{HR}$ & $\mathrm{Cl}$ & $\mathrm{P}$ \\
\hline $1.59(1.10-2.30)$ & 0.013
\end{tabular}

$1.81 \quad(1.07-3.08) \quad 0.027$

$2.30(1.55-3.40) \quad<.001$

Figure 4: Low miR-149 expression in lymph node-positive TNBC patients correlates with poor prognosis. KaplanMeier curves for the survival of breast cancer patients from the TCGA. Line colors refer to the combination of tumor traits: high/low miR-149 expression, lymph node metastasis ( $(\mathrm{LN}+/-)$ and triple negative tumor subtype (TNBC +/-). Forest tree plot of hazard ratio $(\mathrm{HR})$ with $95 \%$ conf idence interval $(\mathrm{Cl})$ and $\mathrm{p}$ values denote the significance for different survival of the individual variables based on a Cox proportional hazards regression model. Strata were high/low miR-149 expression, lymph node metastasis ( $\mathrm{LN}+/-$ ) and classification into TNBC +/based on the reported expression of progesterone/estrogen receptor and HER2 status.

Next, to evaluate the possibility of miR-49 regulating any of these five genes, I performed a transfection of the TNBC cell 
line MDA-MB-231 with miR-149 mimics followed by RT-qPCR analysis. These tests revealed suppression of semaphorin $4 \mathrm{D}$ (SEMA4D) and CSF1 transcript levels by miR-149, whereas no regulation was observed for the guanine nucleotide exchange factor VAV1 and EGFR, and protein tyrosine phosphatase receptor-type O (PTPRO) was not expressed (Figure 5A). CSF1 and SEMA4D play important roles in tumor-stroma interactions, with CSF1 stimulating macrophage survival, recruitment and differentiation (Laoui et al. 2014) and SEMA4D stimulating ang iogenesis by binding to plexin-B1 receptors on endothelial cells (Basile et al. 2004). To explore in silico the possibility of miR-149 expression regulating cancer cell interactions with macrophages or endothelial cells our collaborators performed a cell enrichment analysis based on the bulk gene expression of the tumor samples (Aran, $\mathrm{Hu}$, and Butte 2017). Intriguingly, among the immune cells, monocytes and macrophages were strongly and significantly anticorrelated with miR-149 expression, whereas endothelial cell abundance was less prominently and significantly regulated with respect to miR-149 expression (Figure 5B). Considering the association of low miR-149 levels with higher macrophage presence particularly in lymph node-positive patients (Fig. 5C), it was decided to focus on the regulation of TNBC-macrophage interactions by miR-149. 
A
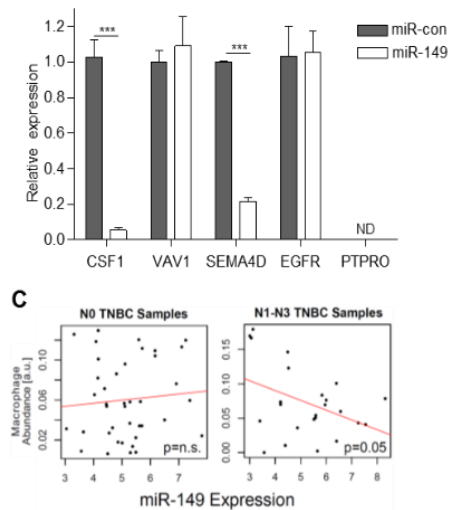

B

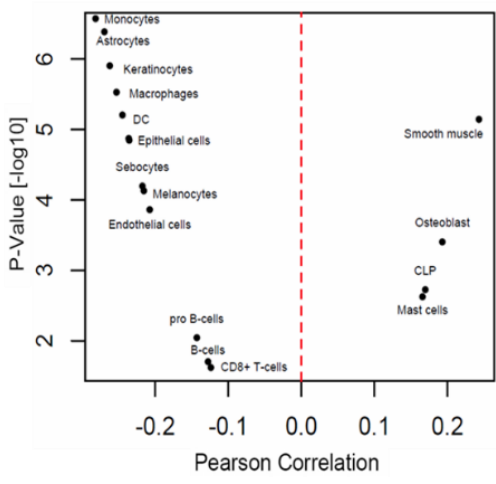

Figure 5: Low miR-149 expression in lymph node-positive TNBC tissues correlates with macrophage infiltration. (A) MDA-MB-231 cells were transiently transfected with miR-con or miR-149 mimics. Three days post-transfection, RNA was extracted, and the relative transcript levels of the indicated genes were determined by qRT-PCR. PPIA and ACTB were used as reference genes. Data is presented as mean $\pm S D, n=3$ $\left({ }^{* * *} p \leq 0.001\right.$; unpaired two-tailed Student's t-test). (B) The scatter plot depicts the Pearson correlation coefficient between miR-149 abundance and cell-enrichment scores versus the asso ciated cell-enrichmentp-value significance. (C) Correlation of the predicted macrophage abundance and miR-149 expression in lymph node-negative (left) and lymph nodepositive tumor samples (right). The line indicates a linear regression to the data points of the tumor samples. 


\subsection{MiR-149 overexpression in MDA-MB-231 spheroids impairs THP-1 macrophage recruitment}

To investigate if miR-149 expression in breast cancer cells regulates the interaction with macrophages, I established a 3D co-culture migration assay in which breast cancer cellspheroids in matrigel-containing serum-free medium were placed on top of a collagen bed containing THP-1 macrophages (Figure 6A).

A

MDA-MB 231

(miR-con/miR-149)

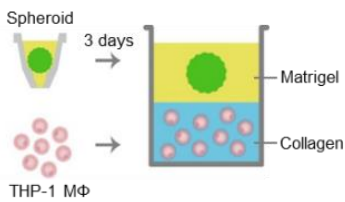

B

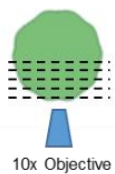

C

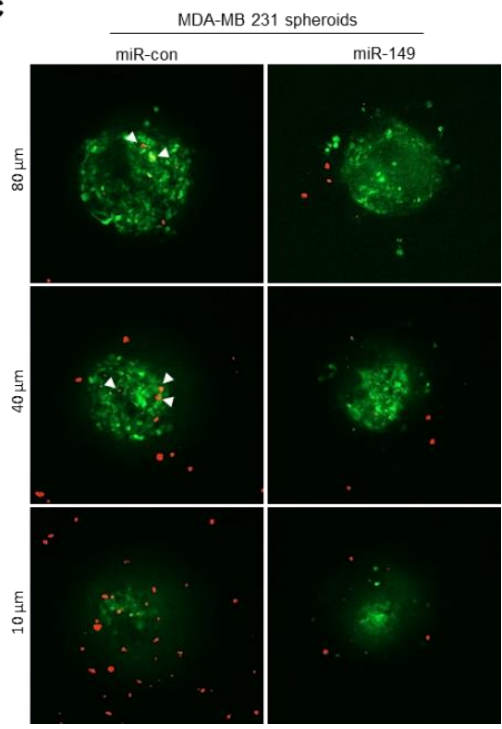

Figure 6: Model of macrophage migration towards TNBC spheroids in 3D co-cultures. A) Scheme of the workflow: MDA-MB-231 cells were transiently transfected with miR-con or miR-149 mimics, labelled with CellTracker Green and seeded in a Gravity TRAP plate for spheroid formation. After three days, spheroids were harvested and seeded in matrigel-containing 
medium on top of a collagen bed containing THP-1 cells differentiated by phorbol ester (PDBu) treatment (THP-1 MФ) and labelled with CellTracker Orange. (B) At day 0 and 3 of the co-culture, the spheroid contained in the top layer was imaged with a spinning disk confocal microscope (30 Z-stacks, $5 \mu \mathrm{m}$ intervals). (C) Representative images of three different Z-stacks positions of the spheroids analyzed in co-cultures. White arrows indicate infiltrating macrophages.

MDA-MB-231 cells produce CSF1 and are known to readily attract macrophages (12). Spheroids were generated by culturing MDA-MB-231 cells transfected with control miRNA (miR-con) or miR-149 and labeled with a green CellTracker dye in GravityTrap plates for $48 \mathrm{~h}$. As a model for macrophages THP-1 cells were used, a monocytic leukemia cell line that differentiates into CD11b-positive macrophages (THP-1 MФ) in response to phorbol ester (PDBu) treatment $(34,35)$. After three days of co-culture, THP-1 MФ (labeled in red) had efficiently migrated into the top spheroid-containing layer, with a subset of THP-1 MФ also found to infiltrate the control spheroids (Figure $6 \mathrm{~A}$ and $\mathrm{C})$. Compared to the control, the number of THP-1 MФ attracted by MDA-MB-231 spheroids transfected with miR-149 mimics was significantly reduced (Figure $7 A$ and $B$ ). 
A

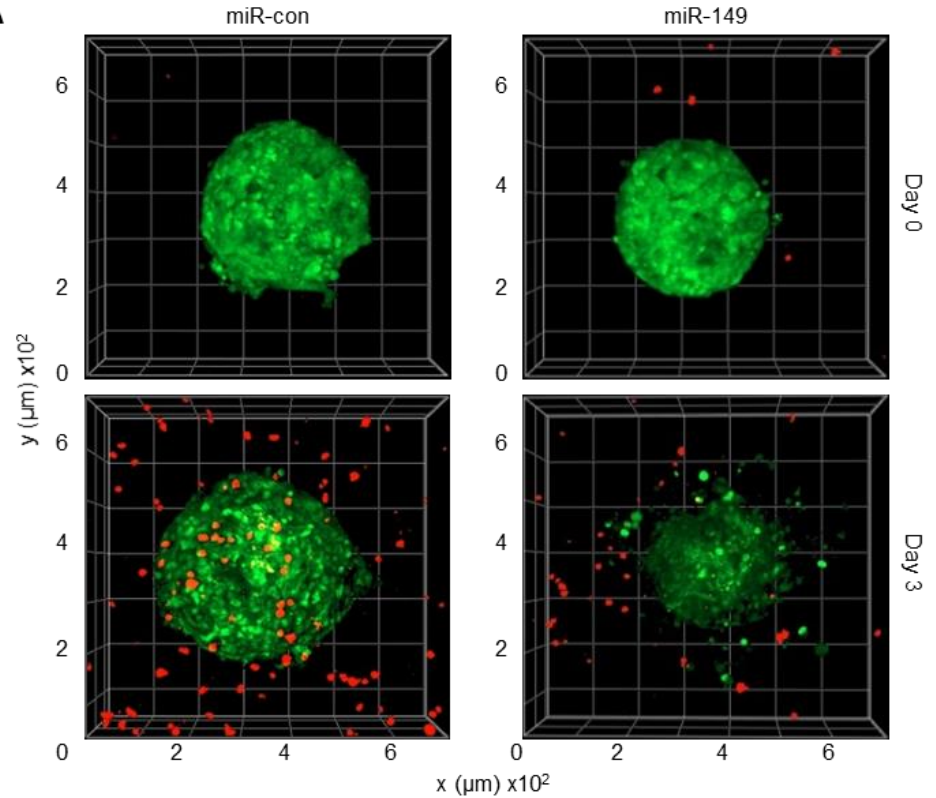

B

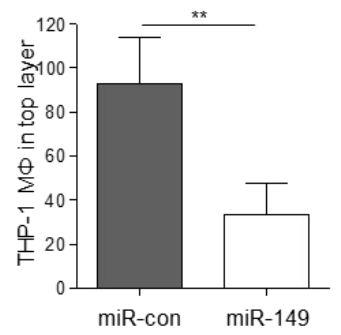

C

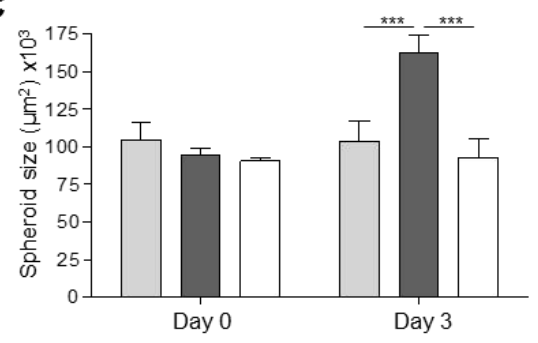

$\square$ Spheroid

$\square$ Spheroid miR-con + THP-1 MФ $\square$ Spheroid miR-149 + THP-1 MФ

Figure 7: miR-149 reduces THP-1 macrophage recruitment to MDA-MB-231 spheroids. (A) 3D reconstruction of spheroids analyzed in Figure 6. (B) The total number of THP-1 MФ in the individual Z-stacks of the top layer was quantified and $(C)$ the spheroid size was determined by analysis of the cross-section area of the most distal Z-stack using the ZEN software. Data is 
presented as mean \pm SD; 12 spheroids per condition from three independent experiments $\left({ }^{* * *} p \leq 0.001,{ }^{* *} p \leq 0.01\right.$; unpaired two-tailed Student's t-test (C) and one-way ANOVA (D)).

It was further observed that the co-culture with THP-1 MФ stimulated the growth of MDA-MB-231 spheroids expressing miR-con when compared to that of spheroids in monoculture, whereas no increase in size was observed in co-cultured MDAMB-231 spheroids expressing miR-149 (Figure 7C). Of note, neither miR-con nor miR-149 mimics af fected proliferation, as spheroids at day 0 were comparable in size to their nontransfected counterparts (Figure 7A, left). This is in line with previous observations on the proliferation rates of MDA-MB-231 cells not being affected by miR-149 (21). Taken together, these findings suggest that the presence of miR-149 in breast cancer cells inhibits macrophage recruitment and macrophage-induced tumor cell proliferation.

\subsection{CSF1 is a direct target of miR-149}

The 3'-UTR of CSF1 contains three miR-149 binding sites that are conserved across species (Figure 8A, left). To analyze the potential of miR-149 hybridization with the 3'-UTR of CSF1, I first modelled the possible miRNA-mRNA duplex secondary structures with their respective minimum free energy ( $\mathrm{mfe}$ ). Analyses of the predicted structures showed stable thermodynamic interactions with $\mathrm{mfe}$ values of $-18 \mathrm{kcal} / \mathrm{mol}$, - 
$16.2 \mathrm{kcal} / \mathrm{mol}$ and $-15.3 \mathrm{kcal} / \mathrm{mol}$ for each binding site, respectively (Figure $8 \mathrm{~A}$, right).
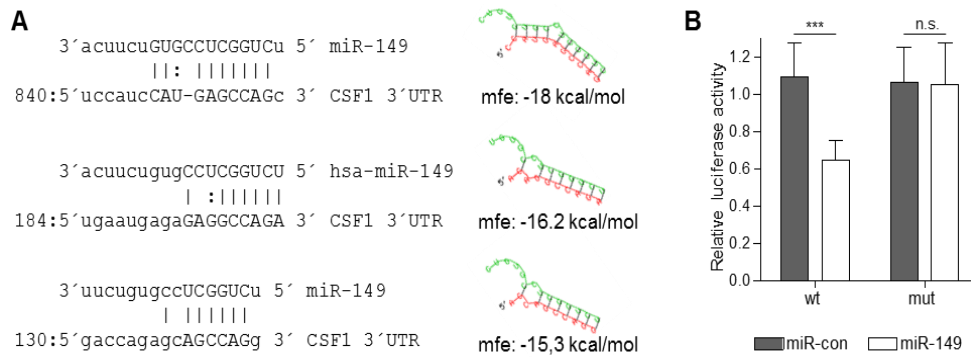

Figure 8: miR-149 directly targets CSF1. (A) Predicted binding sites of miR-149 within the $3^{\prime}$-UTR of the CSF1 mRNA according to microRNA.org. The minimum free energy (mfe) required for RNA hybridization was predicted by RNAhybrid sof tware. (B) HEK293T cells were co-transfected with wild-type (wt) or mutant (mut) CSF1 3'-UTR reporter constructs along with miR-con or miR-149 mimics. Three days post-transfection, cells were lysed, and luciferase activity was measured. Data is presented as mean $\pm S D, n=3$. $\left({ }^{* * *} p \leq 0.001\right.$; unpaired twotailored Student's t-test).

Afterwards, luciferase reporter gene assays were performed to validate CSF1 as a miR-149 target. To this end, wild type (wt) and mutated (mut) 3'-UTR sequences of the CSF1 gene were cloned downstream of the luciferase gene in the pGL3 reporter vector. HEK293T cells were transfected with these constructs along with miR-con or miR-149 and luciferase activity was 
measured three days later. Whereas luciferase activity was strongly reduced by miR-149 mimics in the case of the wt construct, upon deletion of the three predicted miR-149 binding sites (mut), miR-149 was no longer able to suppress luciferase activity (Figure 8B). Furthermore, compared to miR-con, miR149 mimics significantly downregulated CSF1 transcript levels in three different TNBC cell lines (Figure 9A), translating into significantly reduced CSF1 protein amounts in the cell culture supernatant as measured by ELISA (Figure 9B). These experiments confirm the direct regulation of the CSF $1 \mathrm{mRNA}$ by miR-149. The clinical relevance of this regulation is underscored by the inverse correlation of CSF1 and the macrophage markers CD163 and CD68 with miR-149 particularly in lymph node-positive compared to lymph nodenegative TNBC tissues (Figure 9C).
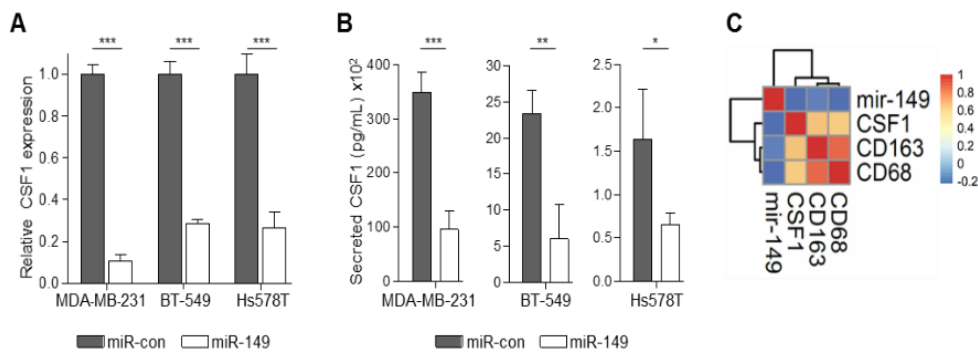

Figure 9: $\mathrm{miR}$-149 regulates CSF1 expression and inversely correlates with CSF1 expression in TNBC tissues. (A, B) TNBC cell lines were transiently transfected with miR-con or miR-149 mimics. Three days post-transfection, (A) CSF1 transcript levels were determined by qRT-PCR (Peptidy lprolyl 
isomerase $\mathrm{A}$ (PPIA) and actin beta were used as reference genes) or (B) conditioned medium was generated and levels of secreted CSF1 protein were quantified by ELISA. Data is presented as mean $\pm S D, n=3$. $\left({ }^{* * *} p \leq 0.001\right.$; unpaired twotailored Student's t-test). (C) Pearson correlation between mir149, CSF1, and the macrophage markers CD68 and CD163 in TNBC samples. Data were taken from the TCGA database.

\subsection{MiR-149 suppresses CSF1-dependent communication between breast cancer cells and THP-1 macrophages}

To address how miR-149 influences the communication between breast cancer cells and macrophages, the chemotactic behavior of THP-1 MФ triggered by conditioned medium (CM) derived from MDA-MB-231 cells transfected with either miR-con or miR-149 was analyzed in Transwell assays (Figure 10A). The CM contains metabolites and growth factors secreted by the cultured breast cancer cells and thus, allows the analysis of the cellular secretome. Notably, to avoid cross-contamination with culture media components like bovine serum proteins, CM was generated by culturing breast cancer cells with serum-free media. In agreement with the suppression of CSF1 expression by miR-149, the chemotactic migration of THP-1 MФ towards CM from MDA-MB-231 cells transfected with miR-149 mimics was significantly reduced compared to that of $\mathrm{CM}$ derived from the control cells. Notably, the reduction of chemotactic 
migration by miR-149 was comparable to the one observed upon siRNA-mediated knockdown of CSF1 (Figure 10B, C).

A
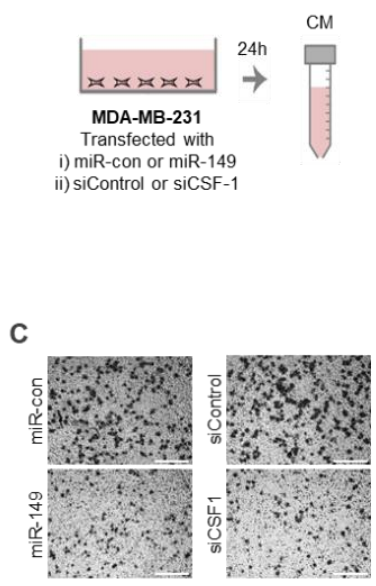

B

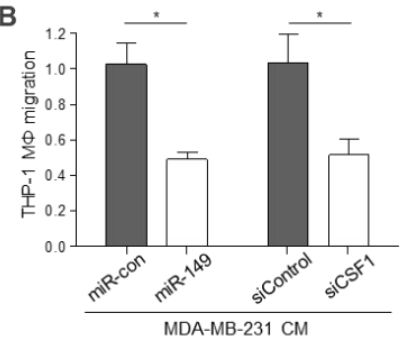

D

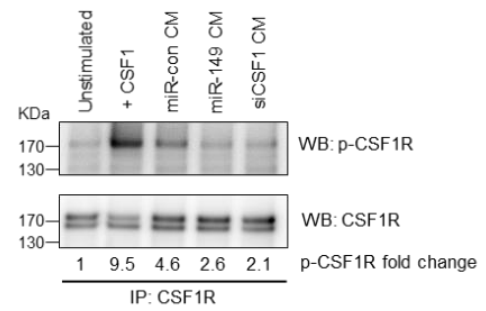

Figure 10: miR-149 suppresses CSF1-dependent THP-1 macrophage migration.

(A) Scheme of the workflow: MDA-MB-231 cells were transiently transfected with miR-con or miR-149 mimics, a nontargeting siRNA control (siControl) or CSF1-specific siRNA (siCSF1). (B) Conditioned medium (CM) was used as a chemoattractant for THP-1 MФ in a Transwell migration assay or (D) to stimulate THP-1 MФ followed by CSF1R immunoprecipitation from cell lysates and immunoblotting. The membrane was probed with a phosphotyrosine-specific antibody (pTyr99) and then reprobed with a CSF1R-specific antibody. Western blots of three independent experiments were quantified using ImageJ, the fold change (mean) in CSF1R phosphorylation was determined by normalizing the $\mathrm{p}$ - 
CSFR1/CSFR1 ratios to that of unstimulated samples. (E) Double conditioned medium (DCM) was used as a chemoattractant for MDA-MB-231 cells in a Transwell invasion assay. Representative images of (C) THP-1 MФ migration and (D) MDA-MB-231 invasion assays (scale bar, $200 \mu \mathrm{m}$ ). Data is presented as mean $\pm S D, n=3\left({ }^{*} p \leq 0.05\right.$; unpaired two-tailored Student's t-test).

To provide biochemical evidence for the reduced activation of THP-1 MФ in response to CM from MDA-MB-231 cells transfected with miR-149, the CSF1R was immunoprecipitated from whole cell lysates of THP-1 MФ, followed by analysis of receptor tyrosine phosphorylation (Fig. 10D). The direct stimulation of THP-1 MФ cells with CSF1 served as a positive control. Incubation of THP-1 MФ with CM derived from MDAMB-231 cells transfected with miR-con increased the phosphorylation of the CSF1R by approximately 5 -fold compared to the control macrophages stimulated with nonconditioned medium. Importantly, stimulation of macrophages with $\mathrm{CM}$ derived from MDA-MB-231 cells transfected with miR149 mimics or CSF1-specific siRNA induced a much weaker increase in CSF1R phosphorylation (Figure 10D; 2.6 and 2.1fold, respectively). These experiments demonstrate that the presence of miR-149 in MDA-MB-231 cells suppresses CSF1R activation in THP-1 MФ by a paracrine mechanism.

To assess how the presence of miR-149 in MDA-MB-231 cells in turn affects the secretome of macrophages, a so-called 
double conditioned medium (DCM) was generated (Figure 11A). Here, THP-1 M $\Phi$ were first stimulated with $C M$ derived from MDA-MB-231 cells for $24 \mathrm{~h}$, bef ore incubation of THP-1 $M \Phi$ with fresh medium for $24 \mathrm{~h}$ (DCM). This medium was then used as a chemoattractant for parental MDA-MB-231 cells in invasion assays. Compared to the miRNA control condition, the invasion of parental MDA-MB-231 cells was strongly and significantly reduced by the initial transfection of MDA-MB-231 cells with miR-149 mimics. Again, the reduction observed was similar to the one upon CSF1 knockdown (Figure 11B, C).

A

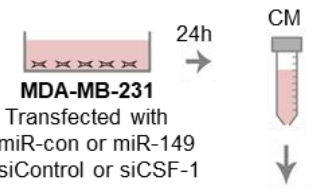

ii) siControl or siCSF-1

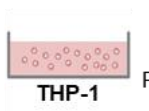
$\stackrel{24 h}{\overrightarrow{P D B u}}$
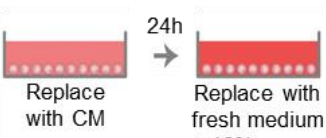
$+10 \%$ serum

B

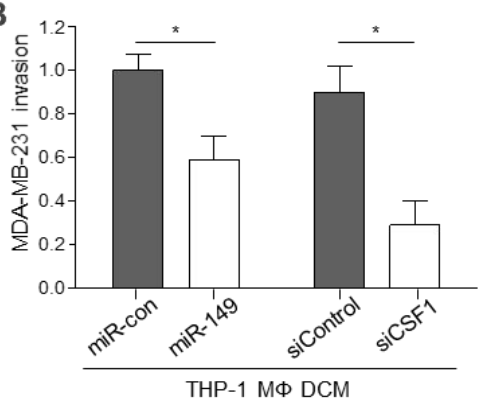

C

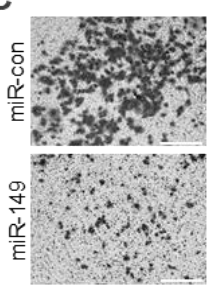

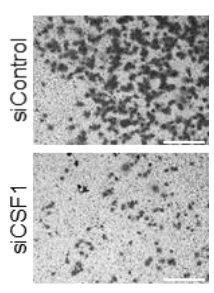

Figure 11: $\mathrm{miR}-149$ suppresses CSF1-dependent paracrine signaling between MDA-MB-231 cells and THP-1 cells. (A) 
Scheme of the workflow: MDA-MB-231 cells were transiently transfected with miR-con or miR-149 mimics, a non-targeting siRNA control (siControl) or CSF1-specific siRNA (siCSF1). Conditioned medium (CM) was used to stimulate THP-1 MФ to generate a double conditioned medium (DCM) that was further used as (B) a chemoattractant for MDA-MB-231 cells in a Transwell invasion assay. (C) Representative images of MDAMB-231 invasion assays (scale bar, $200 \mu \mathrm{m}$ ). Data is presented as mean $\pm S D, n=3$ ( ${ }^{*} p \leq 0.05$; unpaired two-tailored Student's t-test).

\subsection{MiR-149 impairs paracrine signal crosstalk of MDA-MB-231 cells with THP-1 cells}

CSF1 stimulation of macrophages has been described to promote the secretion of EGFR ligands, which in turn stimulate EGFR-expressing cancer cells. To investigate this signaling loop in dependence of miR-149 expression, a co-culture assay was established in which breast cancer cells were seed ed in the top and undifferentiated THP-1 cells in the bottom chamber of a Transwell, enabling the exchange of secreted factors while at the same time physically separating the cells (Figure 12A). 


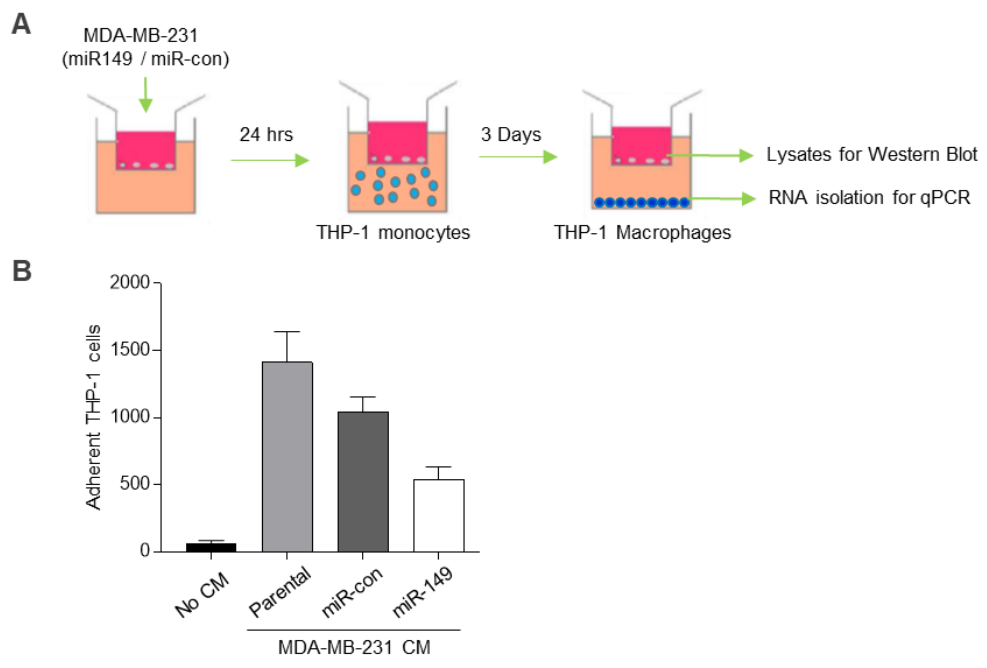

Figure 12: miR-149 impairs CSF1-dependent differentiation of THP-1 cells. (A) Scheme of the workflow:MDA-MB-231 cells transiently transfected with miR-con or miR-149 mimics were seeded in the top chamber of a Transwell and co-cultured with THP-1 monocytes contained in the bottom chamber. (B) After 3 days, adherent cells were quantified with a Neubauer chamber. Data are presented as mean $\pm S D, n=2$.

After three days of co-culture, most of the THP-1 cells cocultured with MDA-MB-231 miR-con cells became adherent. By contrast, the number of adherent THP-1 cells was reduced by $40 \%$ when co-cultured with MDA-MB- 231 cells transfected with miR-149 mimics (Figure 12B). In both cases, however, adherent THP-1 cells demonstrated increased cellular size, protrusions, and granularity, changes that reflect macrophagelike differentiation (Stewart et al. 2012). After three days, the 
adherent THP-1 cells were harvested and the expression of the EGFR ligands EGF and amphiregulin (AREG) was analyzed by quantitative RT-PCR. In THP-1 cells co-cultured with MDA-MB231 cells transfected with miR-149 mimics, the levels of EGF and $A R E G$ were strongly reduced compared to those measured in THP-1 cells co-cultured with the MDA-MB-231 control cells (Figure 13A). In parallel, the EGFR phosphorylation levels ( $p$ Y1086) in the co-cultured MDA-MB-231 cells were analyzed. In MDA-MB-231 cells transfected with miR-149, the EGFR phosphorylation level was much lower than the one observed in the MDA-MB-231 control cells in co-culture (Figure 13B). Importantly, the presence of miR-149 in MDA-MB-231 cells grown in mono-culture did not affect EGFR or phospho-EGFR levels (Figure 13B), suggesting that the reduction of EGFR phosphorylation in these cells can be ascribed to the reduced EGF and AREG production by the co-cultured THP-1 cells.

A

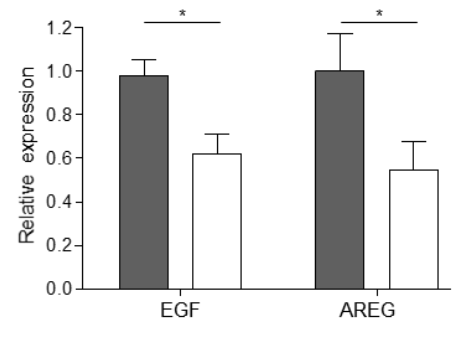

$\square+$ MDA-MB-231 miR-con

$\square+$ MDA-MB-231 miR-149
B

MDA-MB-231 MDA-MB-231

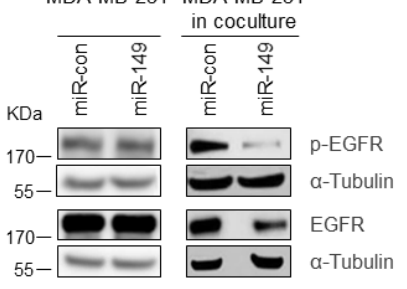

Figure 13: miR-149 impairs paracrine signal crosstalk of 
MDA-MB-231 cells with THP-1 cells. After 3 days of cocultures shown in Figure 12, (A) RNA was extracted from adherent THP-1 cells and EGF and AREG transcriptlevels were determined by qRT-PCR. PPIA and glyceraldehyde-3Phosphate dehydrogenase (GAPDH) were used as reference genes. Data is presented as mean $\pm S D, n=3\left({ }^{*} p \leq 0.05\right.$; unpaired two-tailored Student's t-test). (B) After three days, MDA-MB-231 cells were lysed and EGFR protein and phosphorylation ( $p Y 1086$ ) were detected by immunoblotting. The membranes were reprobed with tubulin-specific antibody as a loading control.

\subsection{MiR-149 suppresses EGFR ligand production by and $\mathrm{M} 2$ polarization of primary human macrophages}

To validate the results obtained with the THP-1 cell line, primary human macrophages (hMФ) derived from CD14-positive monocytes isolated from peripheral blood of healthy donors were used. In full agreement with the data obtained with THP-1 cells, the migration of $\mathrm{hM} \Phi$ was also significantly reduced when CM was derived from MDA-MB-231 or BT-549 cells transfected with miR-149 mimics rather than control miRNA(Figure 14A-D). Furthermore, compared to the basal expression levels in $\mathrm{hM}$, EGF and AREG were significantly upregulated after one day of co-culture with MDA-MB-231 miR-con cells (Figure 14E). Importantly, in the presence of MDA-MB-231 miR-149 cells, $\mathrm{hM} \Phi$ failed to increase the expression of EGF and AREG (Figure 14E). 
A

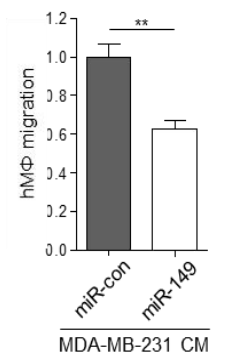

C

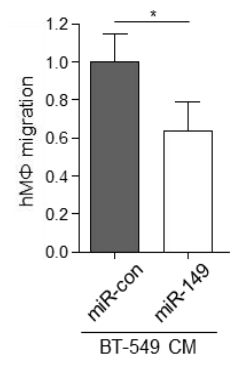

E

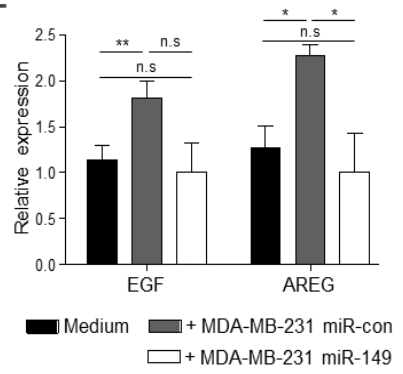

B miR-149

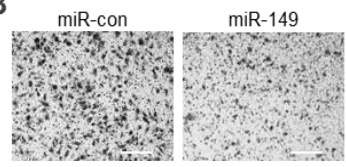

D

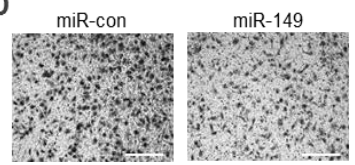

Figure 14: miR-149 impairs breast cancer cell-induced migration of primary human macrophages and suppresses EGFR ligand expression. (A) Conditioned medium (CM) of MDA-MB-231 or BT-549 cells transiently transfected with miRcon or miR-149 mimics was used as a chemoattractant for primary human macrophages ( $\mathrm{hM} \Phi)$ in a Transwell migration assay. (B, D) Representative images of the Transwell migration assay (scale bar, $200 \mu \mathrm{m}$ ). (B) hMФ were co-cultured in a Transwell system with MDA-MB-231 cells transfected with miRcon or miR-149 mimics. After $24 \mathrm{~h}$, RNA from hMФ was extracted and transcript levels of (B) EGF and AREG were determined by $q R T-P C R$. Data is presented as mean $\pm S D, n=3$. $\left({ }^{*} p \leq 0.05,{ }^{* *} p \leq 0.01\right.$; unpaired two-tailored Student's t-test (A, C) and one-way ANOVA (E)).

Next, to explore if the expression of miR-149 in MDA-MB-231 cells influences macrophage polarization, the expression of M1 and M2 macrophage markers were analyzed by qRT-PCR. 
Compared to $\mathrm{hM} \Phi$ in mono-culture, the M2 marker genes mannose receptor C-type 1 (MRC1) and arginase-1 (ARG1) were strongly upregulated in $\mathrm{hM} \Phi$ co-cultured with MDA-MB231 control cells (Figure 15B). The expression of these genes was only modestly induced in $\mathrm{hM} \Phi$ co-cultured with MDA-MB231 cells transfected with miR-149 mimics (Figure 15B), whereas the M1 markers tumor necrosis factor alpha and indoleamine 2,3-dioxygenase were not significantly different between the groups (Figure 15A). Taken together, this data suggests that miR-149 expression in the breast cancer cells not only suppresses the CSF1/EGF crosstalk with primary human macrophages but also impairs M2 macrophage polarization.

A

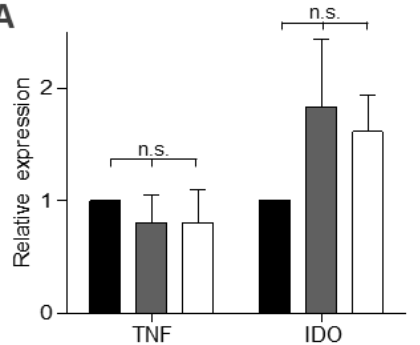

B

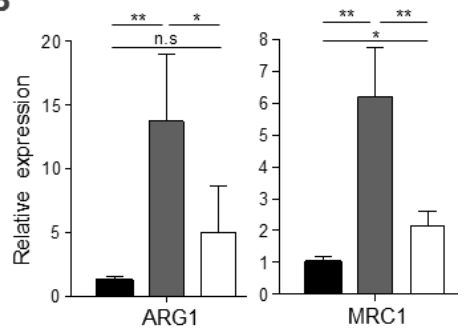

Figure 15: miR-149 impairs breast cancer cell-induced M2marker expression in primary human macrophages. $\mathrm{hM} \Phi$ were co-cultured in a Transwell system with MDA-MB-231 cells transfected with miR-con or miR-149 mimics. After $24 \mathrm{~h}$, RNA from $\mathrm{hM} \Phi$ was extracted and transcript levels of $(\mathrm{A}) \mathrm{TNF}$ and IDO or (B) MRC1 and ARG1 were determined by qRT-PCR. PPIA and GAPDH were used as reference genes. Data is 
presented as mean $\pm S D, n=3 .\left({ }^{*} p \leq 0.05,{ }^{* *} p \leq 0.01\right.$; one-way ANOVA).

\subsection{Characterization of MDA-MB-231 cells stably expressing miR-149}

To investigate the suppression of macrophage recruitment by miR-149 in vivo, MDA-MB-231 cells stably expressing a control miRNA or miR-149 were generated. In the stable MDA-MB-231miR-149 cells, the levels of mature miR-149 were twice as high as the levels in the stable control cells, concomitant with strongly reduced CSF1 mRNA and protein levels (Figure 16A, B).

In full agreement with previous results ob tained, $C M$ derived from MDA-MB-231-miR-149 cells attracted fewer THP-1 MФ than the CM from the stable MDA-MB-231 control cells, whereas the proliferation rates of the two stable cell lines was comparable (Figure 16C and D). Overall, these results are consistent with those observed in transiently transfected cells, and thus validate the reproducibility and functionality of the generated stable cells expressing either miR-con or miR-149. 
A

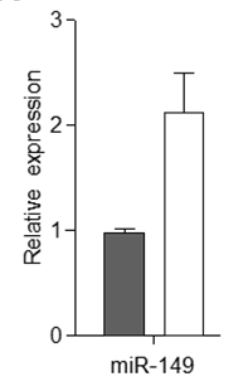

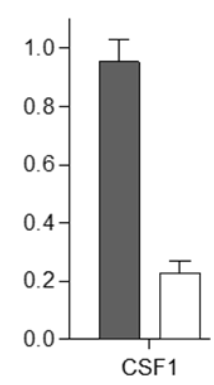

MDA-MB-231 miR-con

C

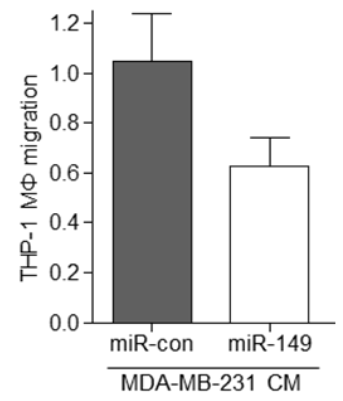

B

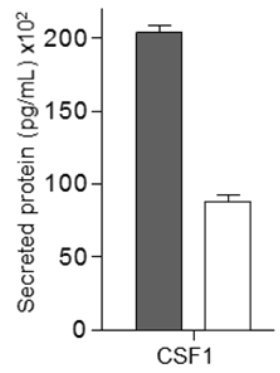

$\square$ MDA-MB-231 miR-149

D

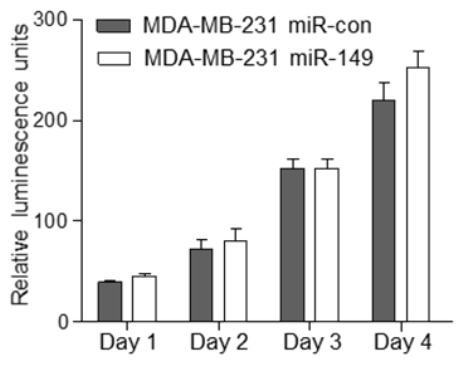

Figure 16: Characterization of MDA-MB-231 cells stably expressing miR-149. (A) RNA of MDA-MB-231 cells stably expressing a control miRNA or miR-149 was isolated and expression levels of miR-149 and CSF1 were determined by qRT-PCR. (B) The CSF1 protein concentration in the conditioned medium of MDA-MB-231 cells stably expressing a control miRNA or miR-149 was measured by ELISA. (C) Conditioned medium $(\mathrm{CM})$ derived fro $m$ the stable cell lines was used as a chemoattractant for THP-1 MФ in a Transwell migration assay. (D) Cell growth of the stable cell lines was determined by Cell TiterGlo assay. Data are presented as relative luminescence units. Data are presented as mean $\pm S D$, $\mathrm{n}=2$. 


\subsection{MiR-149 inhibits macrophage recruitment and lung metastasis of breast cancer cells in vivo}

The growing demand for in vivo cancer models that recapitulate human cancers more accurately has led to the development of so-called orthotopic tumor models. Here, tumor cells are engrafted into the relevant organ of tumor origin, allowing to assess tumor development in the appropriate microenvironment and to evaluate primary tumor growth and metastatic activity (Gengenbacher, Singhal, and Augustin 2017). The stable MDA-MB-231 cell lines were injected into the fourth mammary fat pad of severe combined immunodeficient (SCID) mice and tumor growth was monitored over 6 weeks. All mice developed tumors and no differences in tumor size were observed between the two groups (Figure 17A). Afterwards, the tumors were collected and the abundance of miR-149 and its target gene CSF1 was measured in three individual tumors from each group. qRT-PCR analysis revealed that the suppression of CSF1 was maintained in the tumors formed by MDA-MB-231miR-149 cells and inversely correlated with miR-149 expression (Figure 17B). 
A

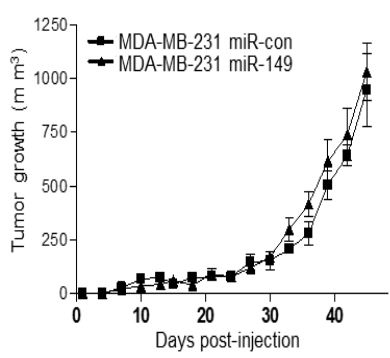

B

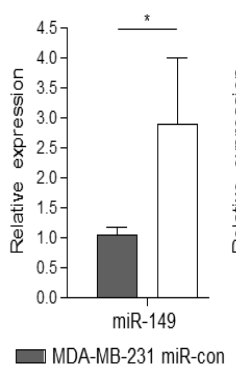

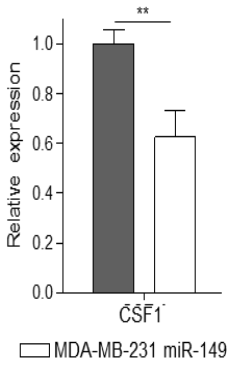

Figure 17: Ectopic miR-149 expression in MDA-MB-231 cells inhibits macrophage recruitment and lung metastasis in vivo. $M D A-M B-231$ cells stably expressing a control miRNA or miR-149 were injected into the fourth mammary fat pad of SCID mice. (A) Tumor growth was quantified every 3 days and mice were sacrificed when the tumor reached $1.2 \mathrm{~mm}^{3}$. (B) RNA was extracted from tumor tissue and miR-149 and CSF1 transcript levels were quantified by qRT-PCR. RNU6B and PPIA were used as reference genes.

To analyze the degree of macrophage infiltration, the primary tumors were transversally cryosectioned and stained by immunofluorescence for the general macrophage marker $F 4 / 80$. To ensure that the analysis was not flawed by local differences in tumor heterogeneity, entire cryosections were imaged, resulting in approximately 600 images (20x) per cryosection, followed by software-based reconstruction of the cryosections and quantification of total F4/80 staining. 


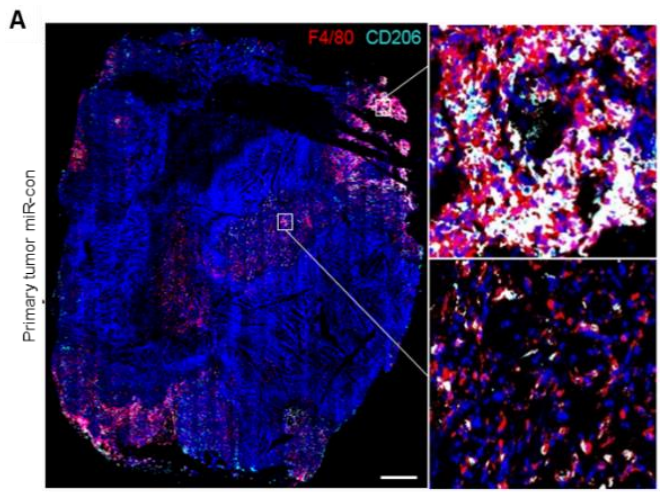

B
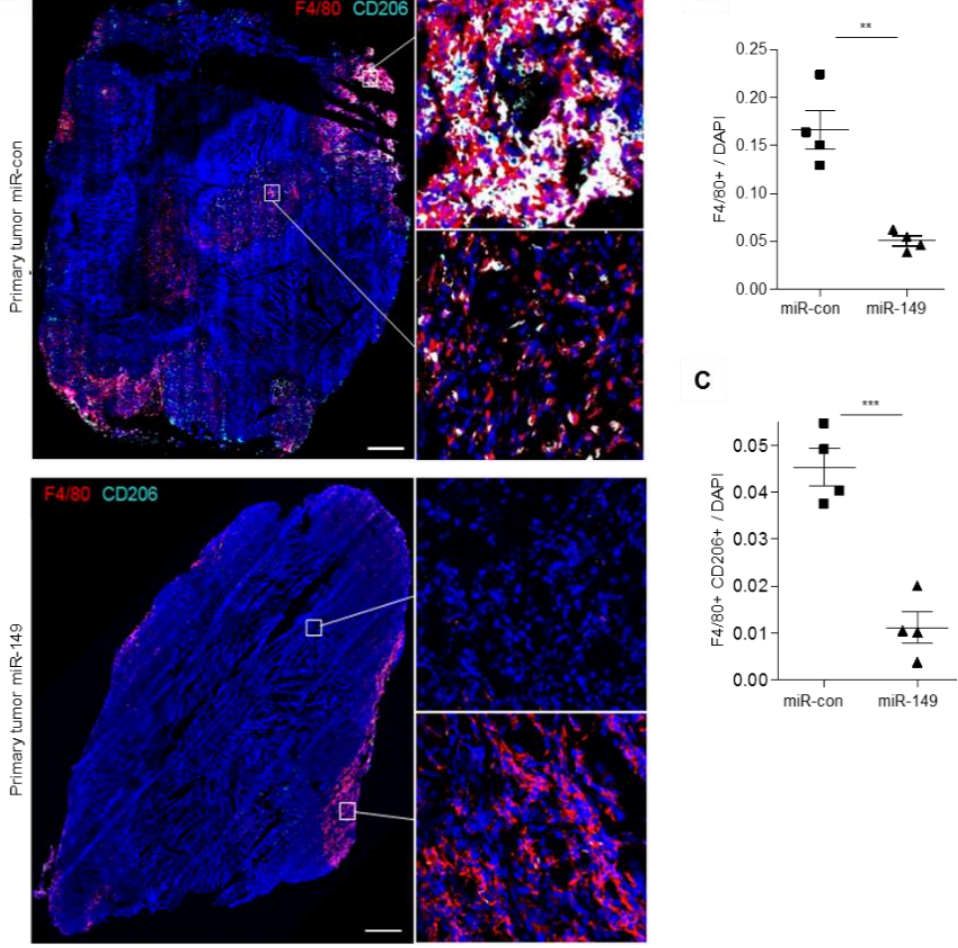

Figure 18: Ectopic miR-149 expression in MDA-MB-231 cells inhibits macrophage recruitment and lung metastasis in vivo. (A) Transversal cryosections of primary tumors were co-stained for F4/80 (red), CD206 (turquoise) and DAPI followed by imaging using a spinning disk confocal microscope equipped with a Plan-Apochromat 20x/0.8. The images shown correspond to the assembly of approximately 600 individual images per cryosection (scale bar, $1 \mathrm{~mm}$ ). Zoom-in images show representative central and peripheral regions, respectively. (B) F4/80+ and (C) F4/80+CD206+ areas were quantified and normalized to the DAPI+ areas (each value represents the analysis of 3 independent cryosections per 
tumor). ( $B, C)$ Data is presented as mean \pm SEM ( $n=4$ mice per group, ${ }^{*} p \leq 0.05,{ }^{* *} p \leq 0.01$ and ${ }^{* * *} p \leq 0.001$; unpaired twotailored Student's t-test).

In the control tumors, areas staining positively for $\mathrm{F} 4 / 80$ were frequently observed both in the periphery and central parts of the tumors. By contrast, only few F4/80-positive regions were detected in the tumors expressing miR-149 and these were restricted to the tumor periphery (Figure 18A and B). To identify M2-polarized macrophages, the tumor sections were co-stained for $F 4 / 80$ (red) and MRC1, corresponding to the CD206 antigen (turquoise). Quantification of F4/80 and CD206 double-positive areas revealed extensive infiltration of $\mathrm{M} 2$ macrophages in the miR-con tumors (red and turquoise), whereas, hardly any M2 macrophages were detected in the tumors formed by MDA-MB231 cells stably expressing miR-149 (Figure 18C).

Finally, to investigate whether miR-149 controlled metastasis development, lungs of tumor-bearing mice were longitudinally cryosectioned and stained with an anti-human vimentin antibody. The intermediate filament protein Vimentin was stained as it is highly expressed in TNBC cells and is involved in cancer metastasis (Yamashita et al. 2013). Whole samples were imaged and analyzed as described for the primary tumors. As shown in the representative pictures (Figure 19A), vimentin staining of primary tumors expressing miR-149 was similar to that of control tumors, indicating that vimentin expression was 
not altered by miR-149 expression and thus, supporting that vimentin staining can identify metastasized cells in lung cryosections.

A

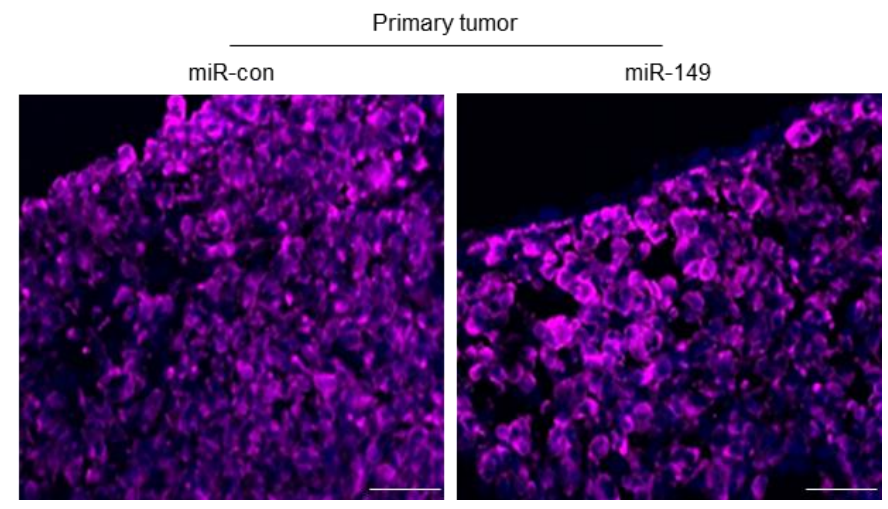

Figure 19: Vimentin expression is not altered in MDA-MB231-miR-149 stable cells. Representative images of primary tumor cryosections stained for vimentin (violet) and DAPI (blue). Scale bar, $50 \mu \mathrm{m}$.

In comparison to the control, lung micrometastasis formation, as determined by vimentin staining, was significantly reduced in mice harboring primary tumors expressing miR-149 (Figure 220A, B). Taken together, these findings provide evidence that miR-149 functions as a metastasis-suppressing miRNA in breast cancer cells by limiting CSF1-dependent recruitment and M2 polarization of macrophages. 
A

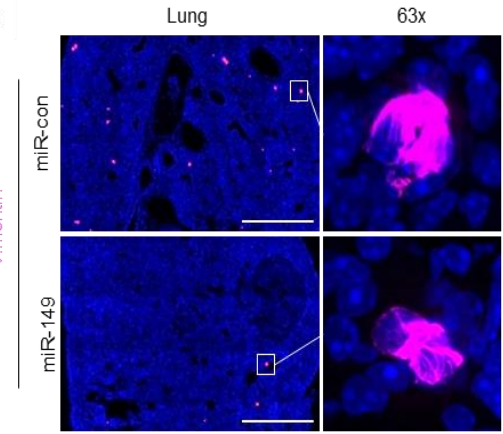

B

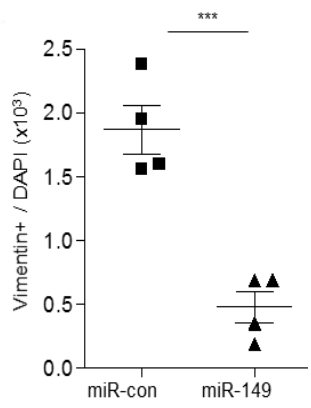

Figure 20: Ectopic miR-149 expression in MDA-MB-231 cells inhibits lung metastasis in vivo. (A) Lung metastases were detected by staining for human vimentin followed by imaging entire longitudinal lung cryosections using a spinning disk confocal microscope equipped with a Plan-Apochromat 10x/0.45 (scale bar, $0.5 \mathrm{~mm}$ ). Images of representative micrometastases were acquired with a Plan-Apochromat $63 x / 1.40$. (B) Vimentin+ areas were quantified and normalized to the $\mathrm{DAPI}+$ areas (each value represents the analysis of 4 independent cryosections per lung). Data is presented as mean \pm SEM ( $n=4$ mice per group, ${ }^{*} p \leq 0.05,{ }^{* *} p \leq 0.01$ and ${ }^{* * *} p \leq$ 0.001; unpaired two-tailored Student's t-test).

\subsection{MiR-149 is epigenetically silenced in TNBC}

To gain insight into the mechanism by which miR-149 expression is downregulated in TNBC cells, MDA-MB-231 and BT-549 cells were treated with the demethylating agent 5-aza2'-deoxycytidine (AZA). This treatment reproducibly increased miR-149 expression, suggesting that miR-149 is epigenetically silenced by DNA methylation in these cell lines (Figure 21A). The miR-149 locus is contained within the first intron of the 
glypican gene, both of which share a common transcriptional start site, although the expression of glypican and miR-149 are regulated independently (Chamorro-Jorganes et al., 2014). The candidate $\mathrm{CpG}$ islands potentially involved in miR-149 regulation are the ones downstream of the transcriptional start site and the one located intragenically, overlapping with the miR-149 coding sequence (Figure 22A). Intriguingly, in primary breast cancers, the methylation of the $\mathrm{CpG}$ sites in direct proximity of the miR-149 locus is inversely correlated with miR149 expression, which is not the case for the $\mathrm{CpG}$ sites located further upstream and downstream on chromosome 2 (Figure 22A). Interestingly, the CpG sites cg15144453 and cg12561497 contained in the $\mathrm{CpG}$ island overlapping with the miR-149 locus show a sig nificantly elevated methylation status in TNBC versus non-TNBC breast cancers (Figure 22B). Together, these preliminary data provide support for the silencing of miR-149 expression by DNA methylation in TNBC.

A

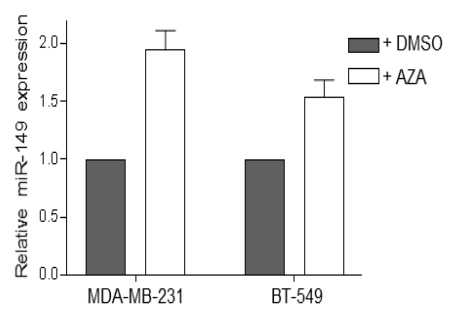

B

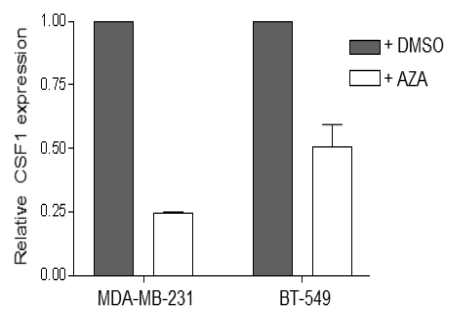

Figure 21: $\mathrm{miR}-149$ is epigenetically silenced in TNBC cell lines. MDA-MB-231 and BT-549 cell lines were treated with 
DMSO or $10 \mu \mathrm{M} 5$-aza-2'd eoxycytidine(AZA) for 48 h. RNA was isolated and (A) miR-149 or (B) CSF1 levels were determined by $q R T-P C R$. Data are presented as mean $\pm S D, n=2$.

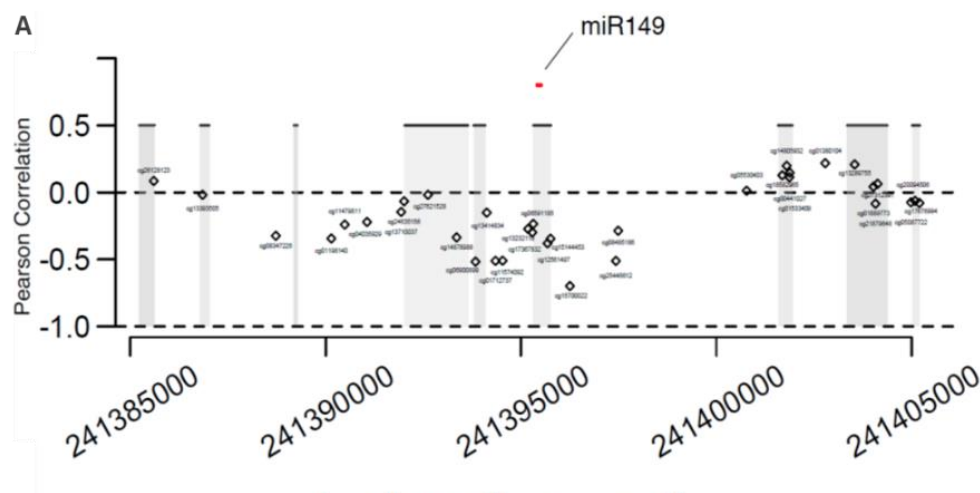

Location on Chromosome 2

B
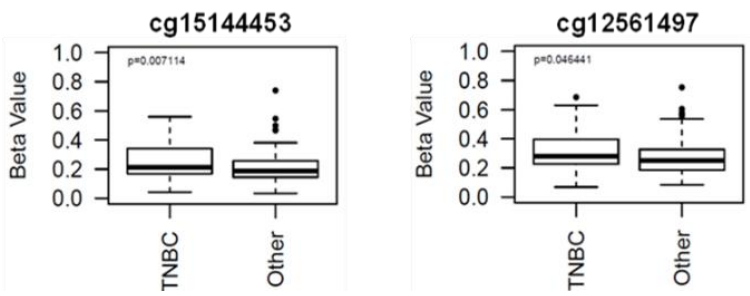

Figure 22: CpG sites of miR-149 are hypermethylated in TNBC patients. (A) Location of the $\mathrm{CpG}$ islands (shaded in grey) within $10 \mathrm{kB}$ of the miR-149 locus (highlighted in red) on chromosome 2. CpG islands were identified using a Hidden Markov model according to http://www.haowulab.org/software/makeCGl/index.html. The Pearson correlation coefficient for the methylation status of 
individual CpG sites and miR-149 expression is plotted for 674 breast cancer samples. (B) Comparison of the methylation status of the two $\mathrm{CpG}$ sites contained in the $\mathrm{CpG}$ island overlapping the miR-149 locus (red circle in B) for TNBC versus all other breast cancer samples. The data presented in this figure was provided by Hauke Busch.

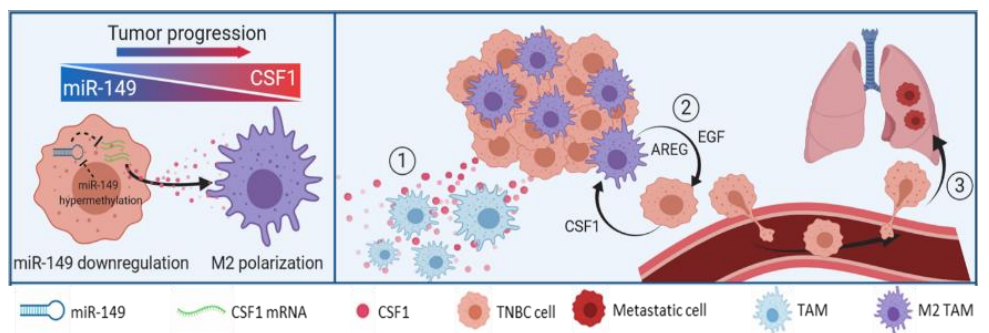

Figure 23: Regulatory role of $\mathrm{miR}-149$ in the crosstalk between triple-negative breast cancer cells and macrophages. Model describing that miR-149 downregulation in TNBC results in an increased CSF1-dependent recruitment and M2 polarization of TAMs (1). CSF1R stimulation of TAMs induces the secretion of factors such as epidermal growth factor (EGF) and amphiregulin (AREG) that bind to EGF receptor on breast cancer cells (2), thereby engaging TAMs in a paracrine signaling loop with breast cancer cells that is essential for the progression and migration of breast cancer cells to distant sites of metastasis (3). 


\section{Discussion}

Aberrant miRNA expression in cancer cells induces the altered secretion of diverse cytokines, chemokines, and growth factors that actively shapes and reprograms the surrounding nontumoral cells, eventually creating a supportive tumor microenvironment for tumor progression and metastasis. Thus, understanding the underlying molecular mechanisms goveming the crosstalk between cancer cells and the TME can allow for the development of novel therapeutic strategies that internupt the cancer cell interplay with the multiple components of the TME.

Previous studies from our group and others have demonstrated that miR-149 overexpression suppresses migration and invasion of breast cancer cells by regulating integ rin signaling through the targeting of the Ras-related GTPases Rap1a/b (Bischoff et al. 2014) and the Arf GTPase-activating protein GIT1 (Chan et al. 2014). By tracking single cells, Bishoff et al. demonstrated that the general cell motility of MDA-MB-231 cells overexpressing miR-149 has no defects, but that the directionality of cell motility is impaired. Notably, re-expression of either active Rac1 (a small GTPase downstream of Rap1 activation) or GIT1 could not completely restore the miR-149 suppression on migration and invasion; based on this observation, Chan et al. suggested that other potential targets of miR-149 regulating cell migration and invasion may exist. 
A major difference between the present work and previous reports that analyzed the role of miR-149 in breast cancer metastasis relies on the experimental metastasis mouse model used. Independent studies by Bishoff et al. and Chang et al. have shown that intravenous (IV) injection of breast cancer cells overexpressing miR-149 decreases lung colonization. The advantage of the orthotopic model used in the present study over the IV model, is that orthotopic models recapitulate the biological steps and stages from malignant breast cancer progression, including primary tumor formation, lymph node metastasis, and distant organ metastasis (Gengenbacher, Singhal, and Augustin 2017; O. M. Rashid, Takabe, and Moffitt 2015). Importantly, these characteristics of orthotopic models allow studying the contribution of the TME to malignant tumor progression. Furthermore, although gene expression profiling of lung metastases derived from orthotopic and IV breast cancer models are indistinguishable (O. Rashid et al. 2013), it has been recently reported that these models significantly differ in their miRNA signature, implying that significant differences in gene regulation mechanisms exist between the two models (Pillar et al. 2018). The present study provides additional insight into miR-149 functions as a metastasis-suppressing miRNA in breast cancer and identifies another cancer hallmark to be regulated by miR-149, namely, tumor-stroma interactions involving macrophages. 


\subsection{MiR-149 as a prognostic marker in lymph node-positive TNBC}

Despite the numerous ad vances in breast cancer treatment, the prognosis for patients with metastatic disease remains poor, with a median survival of 2-3 years (Harbeck et al. 2019). Functional analysis and characterization of aberrantly expressed miRNAs in human cancer provide valuable information to the clinic as they can correlate with diagnosis, staging, progression, prognosis, and response to therapy. Here, bioinformatic analyses demonstrated that low miR-149 expression significantly correlates with poor clinical outcomes in TNBC patients with lymph node-positive disease. This is in line with previous reports from our group and others, showing that in breast cancer, low levels of miR-149 correlate with higher tumor stage as well as with lymph node metastasis (Bischoff et al. 2014; Chan et al. 2014). Surprisingly, no evidence for low miR-149 levels affecting the survival outcome of lymph nodenegative TNBC patients was found. This apparent lack of correlation can be attributed to additional factors that differ between the LN-negative and LN-positive groups, such as tumor size or treatment. However, the lack of information on these variables for the analyzed cohort samples made it impossible to establish further associations. MiR-149 has been reported as a prognostic marker in some cancers. For example, in patients with non-small cell lung cancer, low levels of miR149 predict poor survival and a limited response to cisplatin and vinorelbine treatment (Berghmans et al. 2013). Also, low miR- 
149 correlates with reduced patient survival in hepatocellular carcinoma (L. Lin et al. 2016) and upper tract urothelial carcinoma (Izquierdo et al. 2014). Furthermore, Perez-Rivas et al. reported in breast cancer patients that downregulation of a 5-miRNA signature, including miR-149, identifies patients that will likely develop metastasis early after primary breast surgery (Jerez et al. 2014). Although numerous miRNAs have been asso ciated with reduced prognosis in TNBC (Tang et al. 2019), only limited comparison of the published data is possible due to differences in multiple factors including the methodology for miRNA detection, the selected miRNAs, sample source, and limited number of patients. Nevertheless, our observations prompted us to further investigate and elucidate miR-149 target genes that could allow the establishment of a permissive microenvironment for tumor growth and metastasis.

\subsection{MiR-149 regulates macrophage recruitment and M2-polarization by targeting CSF1}

Using bioinformatic analysis, CSF1 was identified as a target gene of miR-149 and was further confirmed and validated by dual-luciferase reporter assays. Circulating CSF1 has been a useful tumor biomarker for the detection and monitoring of response to therapy in patients with ovarian, breast, and endometrial carcinoma (Barry M. Kacinski 1995). Moreover, CSF1 has been shown to play a key role in recruiting macrophages to the tumors and its overexpression in breast 
cancer patients correlates with high-grade tumors and poor prognosis (E. Y. Lin et al. 2002). Recently, Sossey-Alaoui et al. reported that TGF $\beta$ autocrine signaling induced by the integrinregulatory protein kindlin-2 leads to CSF1 production in MDAMB-231 cells (Sossey-alaoui et al. 2017). In contrast, using multiple TNBC cell lines Patsialou et al. reported that TGF $\beta$ does not alter the mRNA expression of CSF1 (Patsialou et al. 2010, 2015). In this work, I reveal a novel mechanism by which CSF1 is dysregulated in TNBC and show that low-level miR149 re-expression in MDA-MB-231 cells suffices to suppress high CSF1 production by these cells, concomitant with the reduction of macrophage recruitment in vitro and in vivo. These findings are further strengthened by clinical data analysis of primary breast cancers that demonstrated an inverse correlation between the expression of miR-149 and CSF1 as well as macrophage markers.

Macrophage infiltration in cancer tissues is strongly associated with high vascular grade, poor prognosis, and resistance to therapy (Obeid et al. 2013; Quig ley and Kristensen 2015). Apart from CSF1, additional chemokines such as C-C motif chemokine ligand (CCL)-2, CCL-5, and CCL-20 have been shown to participate in monocyte and macrophage recruitment in breast cancer (Mantovani et al. 2017; Argyle and Kitamura 2018). Although siRNA-mediated downregulation of CSF1 mimicked the effects of miR-149 expression, it cannot be ruled out that additional factors involved in macrophage recruitment 
contribute to the significantly reduced numbers of macrophages in the primary tumors expressing miR-149. Notably, the largefield imaging method used for quantification of macrophage infiltration into primary tumors has a clear advantage over that of random or selected representative tumor areas, as the imaging of entire tumor specimens without compromising resolution or quality allows to obtain unbiased and comprehensive results on inf iltrating macrophages across the tumor. Several experimental studies in mice have demonstrated that TAMs exhibit different functions depending on their location within tumors, due to the ability of distinct tumor compartments, broadly referred as invasive, stromal, and hypoxic/necrotic areas, to differentially regulate TAMs phenotypes (M. Yang et al. 2018). For instance, under hypoxic conditions, TAMs activate the transcription factor HIF-2 $\alpha$ involved in the expression of proangiogenic factors like VEGFA and MMP7 (Burke et al. 2003). Imtiyaz et al. reported that HIF-2 $\alpha$ activation in TAMs induces the expression of CSF1R and that HIF-2 $\alpha$ deficient TAMs migrate into hepatocellular carcinomas less efficiently (Imtiyaz et al. 2010). Furthermore, it has been reported that hypoxia induces the expression of the angiopoietin receptor TIE2 on macrophages (Chen et al. 2016) and that TIE2-TAMs are responsible for blood vessel formation that facilitates metastasis in MMTV-PyMT mammary carcinomas (Mazzieri et al. 2011).

It is interesting to note that primary tumors expressing miR-149 strongly prevented macrophage accumulation in defined 
central, possibly hypoxic, regions of the tumor. Although the different compartments in the tumor samples cannot be strictly defined, it would seem that miR-149 expression in breast cancer does not only reduce overall macrophage tumor recruitment but also may influence the spatial heterogeneity and thus the function of specific TAMs subsets (e.g., TIE2TAMs) within tumors.

It is well known that intra-tumoral M2 macrophages provide essential support for breast cancer progression and metastasis by establishing an immunosuppressive microenvironment and by directly stimulating cancer cell invasion. Several reports have shown that signals originating from cancer and stroma cells regulate macrophage $\mathrm{M} 1 / \mathrm{M} 2$ polarization balance (Mantovani et al. 2017). The results from this work are consistent with previous findings (Roudnicky et al. 2015) showing that TNBC cells educate primary human macrophages into an M2 phenotype through soluble factors. To understand if miR-149 re-expression in breast cancer cells modulated macrophage function, the effect of ectopic miR-149 expression in MDA-MB-231 cells was evaluated on the capacity of breast cancer cell secretome to modulate macrophage polarization. In qRT-PCR analyses of the M2 markers, CD206 and ARG1, it was observed that miR-149 re-expression in breastcancer cells significantly impaired M2 macrophage polarization. Although this result fits well with previous reports in the literature showing that CSF1 induces M2 macrophage polarization (Laoui et al. 
2014), in gastric cancer, for example, miR-149 has been reported to target interleukin IL-6 (P. Li et al. 2015), and IL-6 is known to promote macrophage M2 activation by inducing IL-4 receptor expression (Mauer et al. 2012). Interestingly, increased expression of IL-6 has been associated with poor prognosis, advanced pathological grades, and metastases in breast cancer patients (Weng et al. 2019). Considering that IL6 is highly expressed in TNBC (Hartman et al. 2013), the suppression of M2-macrophage polarization by miR-149 might result from the synergistic co-regulation of CSF1 and IL-6. Even though the TME constitutes a complex network of cytokines, chemokines, and growth factors between multiple different cell types, in full agreement with the obtained in vitro data, a strong suppression of M2 macrophage polarization was observed in primary tumors expressing miR-149. Thus, the findings from the current study are in line with the concept that the TME is shaped and dominated by molecular signals derived from cancer cells.

As discussed above, IL- 6 is a direct target of miR-149 and in diverse human cancers has been shown that activation of signal transducer and activator of transcription 3 (STAT3) by IL-6, results in cancer cell proliferation, survival, angiogenesis, and metastasis (Yu, Pardoll, and Jove 2009). In TNBC for example, it has been demonstrated that IL- 6 supports the maintenance of cancer stem cells (Marotta et al. 2011), induces LN angiogenesis and lung metastasis by upregulating VEGF and CCL-5 in lymphatic endothelial cells (Jin, Pandey, and Popel 
2018). Although numerous stromal cells within the TME provide a paracrine source of IL-6 for breast cancer cells (Heo, Wahler, and Suh 2016), it is possible that the decreased tumor progression observed in breast cancer cells expressing miR149 may result in part, from inhibiting IL-6 cancer cell expression.

A second target identified by in silico analysis as a potential target of miR-149 was SEMA4D. Moreover, qRT-PCR analysis revealed a significant suppression of SEMA4D mRNA levels by miR-149. It has been reported that SEMA4D mRNA and protein levels are highly expressed in squamous carcinoma of head and neck cancer (Basile et al. 2004) whereas, in breast cancer mouse models, SEMA4D is mainly expressed by macrophages (Sierra et al. 2008). However, SEMA4D silencing in MDA-MB231 cells has shown to decrease bone metastases in vivo $(\mathrm{H}$. Yang et al. 2016). Furthermore, SEMA4D engagement with plexin-B1 receptors has been shown to promote angiogenesis (Basile et al. 2004) and to inhibit migration of immune cells including monocytic and B-lymphoid cells (Delaire et al. 2001). Recently, in mouse colon tumors SEMA4D was reported to stimulate IL-10 expression in TAMs resulting in the suppression of CD8+ T-cell activity (Evans et al. 2015). Despite the implication of SEMA4D in breast cancer progression, the underlying mechanism by which SEMA4D is dysregulated remains unknown. Thus, it seems possible that SEMA4D might represent another layer by which miR-149 downregulation 
supports tumor progression.

\subsection{MiR-149 regulates the EGF/CSF1 crosstalk between breast cancer cells and macrophages}

In response to CSF1 stimulation, TAMs have been shown to produce EGF, an EGFR ligand that augments the invasive properties and egress of breast cancer cells into blood vessels (Goswami et al. 2005). Moreover, Vlacicu et al. reported that primary human macrophages respond to TNBC cell-derived factors by secreting alternative EGFR ligands including, amphiregulin, epiregulin, and heparin-binding EGF-like growth factor (Vlaicu et al. 2013). The obtained results confirm that macrophages can stimulate breast cancer cell invasion through mechanisms that do not require direct cell contact, but rather via secreted factors (See Fig. 14B) and led to explore the possible role of miR-149 in regulating the CSF1/EGF paracine loop. Experimental data analysis corroborated the importance of this paracrine pathway and showed that miR-149 regulates the production of the EGFR ligands EGF and AREG by macrophages, ultimately determining EGFR activation levels in the breast cancer cells. EGFR is overexpressed in at least $50 \%$ of TNBC cases and its levels are associated with large tumor size and poor outcomes (Ali and Wendt 2017). It is well known that EGFR activation in cancer cells by EGF results in 
downstream signaling that leads to proliferation, migration, and invasion. Recently, Kedmi and colleagues reported that EGF stimulation in TNBC cells induces miRNAs that target suppressors of cell migration, including miR-15b, which promotes EGF-induced migration and invasion by targeting metastasis suppressor protein-1, a protein required for the maintenance of cell-cell junctions (Kedmi et al. 2015). Consequently, it can be assumed that by regulating EGF secretion in macrophages, miR-149 may indirectly impact further miRNAs, including miR-15b, that are involved in breast cancer progression.

AREG is upregulated in numerous cancer malignancies including breast cancer and its implication in cancer development as a pro-oncogenic factor by inducing cancer cell proliferation and survival signals has been well-described (Berasain and Avila 2014). Moreover, high AREG expression is associated with resistance to chemotherapeutic agents and breast cancer lymph node positivity (Eckstein et al. 2008; Berasain and Avila 2014). This concurs well with our previous findings of low miR-149 expression as a negative prognosis factor in lymph node-positive TNBC patients.

Lymph node metastases in patients are associated with higher tumor aggressiveness and worse prognosis. Although the hypothesis that cancer cells metastasize via the lymph nodes dates back to the late 1800 s, only recently, a causal link between lymph-node colonization and distant metastasis has 
been established. Pereira and colleagues demonstrated in a mouse breast cancer model that $70 \%$ of the mammary cancer cells in lung metastases had come from ly mph nodes (Pereira et al. 2018). The migration of cancer cells into the lymphatic circulation with the subsequent entry into ly mph no des is greatly facilitated by tumor lymphangiogenesis. Recently, a study described a podoplanin-positive M2-TAM subpopulation to be crucial for lymphangiogenesis. In breast cancer patients, association of these TAMs with tumor lymphatic vessels correlated with lymph node and distant metastasis (BieniaszKrzywiec et al. 2019). This might provide an explanation why low miR-149 levels and high macrophage infiltration correlate with poor prognosis, particularly in patients with lymph nodepositive disease. Given that TAMs are essential for cancer cell dissemination through blood and lymph vessels (Condeelis and Pollard 2006; Bieniasz-Krzywiec et al. 2019), it is likely that the reduced lung metastasis observed upon miR-149 re-expression in MDA-MB-231 cells results from blocking metastasis via both hematogenous and lymphatic routes.

It is important to mention that neither CSF1R nor EGFR is exclusively expressed on macrophages or breast cancer cells, respectively. For example, CSF1R has been reported to be expressed in most solid tumors, including b reast cancer (B. M. Kacinski et al. 1991). Furthermore, it has been shown that in MDA-MB-231-derived mammary mouse tumors, autocrine CSF1R signaling is directly involved in breast cancer cell 
invasion and dissemination and that this autocrine loop is enhanced in vivo due to CSF1R upregulation mediated by TGF $\beta$ (Patsialou et al. 2010). This suggests that, in addition to Rap1a/b and GIT1 regulation by miR-149, inhibition of the CSF1/CSF1R autocrine signaling may represent another cellintrinsic mechanism by which miR-149 regulates breast cancer invasion and metastasis.

The fact that EGFR is also expressed in leukocytes populations such as monocytes, macrophages, and lymphocytes, suggests that EGFR signaling plays a role in the immune system. For instance, Zaiss et al. reported that Tregs found in peritumoral regions express EGFR and that their function is directly enhanced by AREG produced by tumor-associated mast cells (Zaiss et al. 2013). In macrophages, it is known that deletion the of EGFR leads to a global defect in macrophage activation and an increase in $\mathrm{IL}-10$ in response to inflammatory stimuli (Hardbower et al. 2016; Lu et al. 2014) and that IL-4 induces the transactivation and downregulation of EGFR resulting in M2 polarization inhibition (Zhao et al. 2016). Although the understanding of the role of EGFR in regulating the immune function is very limited, it can be implied that the reduced EGFR ligands secreted by macrophages in response to miR-149 expression in breast cancer cells, can further contribute to the immune modulation in the tumor microenvironment.

For the in vivo breast cancer model, severe combined immunodeficient (SCID) mice were used. SCID mice are homozygous for the Prkdc $c^{\text {sid }}$ allele, which results in the lack of 
functional B and T lymphocytes, of which especially T-cells play a central role in controlling tumor growth and progression. This represents a limitation in the SCID mouse model used as the adaptive immune response in relation to miR-149 could not be analyzed. However, considering that macrophages orchestrate multiple aspects of T-cell functions, it is plausible that miR-149 dysregulation in breast cancer cells can indirectly subvert $\mathrm{T}$-cell anti-tumor immunity (suppressing CD8+ T-cells and inducing Tregs) by educating macrophages into an M2 tumor-promoting phenotype.

M2-macrophage infiltration represents a negative prognosis factor in several advanced cancers, including gastric, thyroid, and glioblastoma (Zhang et al. 2012; Hambardzumyan, Gutmann, and Kettenmann 2015), where miR-149 has been reported to be downregulated. The regulation of tumormacrophage interaction by miR-149 as uncovered in this study (see Fig. 23) may thus not be limited to TNBC. In glioblastoma, for example, the CSF1/EGF paracrine loop with macrophages has been associated with microglia-induced glioblastoma invasion (Coniglio et al. 2012).

\subsection{MiR-149 is epigenetically silenced in TNBC}

It has been shown that DNA methylation contributes to tumor progression by silencing numerous tumor suppressor genes. Treatment of two independent TNBC cell lines with the methyltransferase inhibitor AZA revealed a significant increase 
in miR-149 levels. Consequently, it is likely that DNA hypermethylation occurring at $\mathrm{CpG}$ sites in direct proximity of the miR-149 locus might prevent transcription factors or RNA polymerase from binding to DNA. These results are further supported by the clinical dataanalysis of primary breast cancers in which CpG sites in the miR-149 locus of TNBC patients had higher methylation levels than those in non-TNBC patients. This is in line with previous studies in drug-resistant MCF7/ADM breast cancer cells reporting the silencing of the miR-149 locus by DNA methylation of the neighboring CpG islands (He et al. 2014). Furthermore, multiple reports in gastric, colorectal, glioblastoma multiforme, and cervical carcinomas have shown that miR-149 is downregulated by DNA hypermethylation (Zhi et al. 2018). For example, Li et al. validated that in CAFs from gastric tissues, prostaglandin E2 induces DNA methylation of a GC-rich region upstream of the miR-149 transcriptional start site resulting in miR-149 silencing (P. Li et al. 2015). However, other reports have shown alternative mechanisms that contribute to miR-149 dysregulation in cancer. For instance, the long non-coding RNA LINC00460 is overexpressed in nasopharyngeal carcinoma and has been shown to support tumorigenesis through sponging miR-149 (Kong et al. 2018). Moreover, two single-nucleotide polymorphisms in pre-miR-149 have been shown to affect miR-149 maturation and to correlate with unf avorable patient survival in gastric and head and neck squamous cell carcinoma (L. Li et al. 2013; Tu et al. 2012). Overall, based in our results it can be assumed that miR-149 
dysregulation in TNBC is mediated at least in part by DNA methylation.

\subsection{Conclusions and outlook}

Metastasis development depends on cancer cell auto nomous signaling and cancer cell interactions with the tumor microenvironment. The aim of this thesis was to gain deeper knowledge of the mechanisms through which breast cancer cells communicate with their microenvironment to modulate tumor progression. Specifically, I focused on the role of miR149 in regulating breast cancer cell paracrine interactions with macrophages to exploit cancer cell invasiveness and metastasis.

The present work has presented evidence that CSF1 is a bona fide target of miR-149. Furthermore, miR-149 was identified as a poor prognosis marker in TNBC that orchestrates the EGFR/CSF1R signaling axis between breast cancer cells and macrophages. In an orthotopic xenograft model of breast cancer, a metastasis-suppressing function for miR-149 in vivo was revealed, which is mediated at least in part by limiting CSF1-dependent recruitment of macrophages to the primary tumor. This conclusion is supported by clinical data analysis of primary breast cancers showing an inverse correlation between the expression of miR-149 and CSF1 as well as M2 macrophage markers. 
Moreover, in silico and qRT-PCR data suggests that the tumorsuppressive function of miR-149 might additionally extend to the regulation of SEMA4D. In the future, further experiments will be necessary to validate SEMA4D as a target of miR-149 and to demonstrate the role of SEMA4D derived from breast cancer cells in tumor progression. Regarding miR-149 dysregulation, the evidence from clinical data sets and in vitro experiments implies that miR-149 is silenced in TNBC by DNA hypermethylation of the $\mathrm{CpG}$ islands in the miR-149 locus. Future work should concentrate on determining by bisulfite sequencing the sites and extent by which the candidate CpG islands are methylated in TNBC. Taking together with previous studies, it suggests that miR-149 prevents metastatic dissemination of breast cancer cells by co-regulating multiple interconnected signaling networks in both intrinsic and extrinsic pathways, i.e. controlling integrin signaling and cytoskeletal reorganization through regulating Rap $1 \mathrm{a} / \mathrm{b}$ and GIT1, as well as the auto crine CSFR signaling through CSF1 on the one hand and the communication with macrophages along with their polarization through regulating CSF1 and IL-6 on the other hand. This is in accordance with the idea of miRNAs regulating a biological process by simultaneously regulating multiple targets in interconnected pathways. For example, miR-148b was shown to control breast cancer progression and relapse by coordinating multiple genes involved in cell invasion and survival, including CSF1 (Cimino et al. 2013). The findings of this thesis establish a new interplay between miR-149 and the 
TME by providing new insights into the molecular crosstalk established between breast cancer cells and macrophages. Considering the recent advances in RNA chemistry and delivery technologies, the potential use of miRNAs as a strategy to remodel the TME in cancer therapy to prevent metastasis might become a reality sooner than later. 


\section{List of Figures}

Figure 1: Role of the tumor microenviro nment................... 24

Figure 2: M2 Tumor-associated macrophages in cancer...... 35

Figure 3: MicroRNA biogenesis and mechanism of action.... 40 Figure 4: Low miR-149 expression in lymph node-positive TNBC patients co rrelates with poor prognosis.................... 74

Figure 5: Low miR-149 expression in lymph node-positive TNBC tissues correlates with macrophage infiltration.......... 76 Figure 6: Model of macrophage migration towards TNBC spheroids in 3D co-cultures........................................... 77 Figure 7: miR-149 reduces THP-1 macrophage recruitment to MDA-MB-231 spheroids....................................... 79

Figure 8: miR-149 directly targets CSF1........................ 81 Figure 9: miR-149 regulates CSF1 expression and inversely correlates with CSF1 expression in TNBC tissues 82 Figure 10: miR-149 suppresses CSF1-dependent THP-1 macrop hage migration. ............................................. 84 Figure 11: miR-149 suppresses CSF1-dependent paracrine signaling between MDA-MB-231 cells and THP-1 cells....... 86 Figure 12: miR-149 impairs CSF1-dependent differentiation of THP-1 cells. 88 Figure 13: miR-149 impairs paracrine signal crosstalk of MDAMB-231 cells with THP-1 cells. 89 
Figure 14: miR-149 impairs breast cancer cell-induced migration of primary human macrophages and suppresses EGFR ligand expression 91

Figure 15: miR-149 impairs breast cancer cell-induced M2marker expression in primary human macrophages ............92 Figure 16: Characterization of MDA-MB-231 cells stably expressing miR-149........................................... 94 Figure 17: Ectopic miR-149 expression in MDA-MB-231 cells inhibits macrophage recruitment and lung metastasis

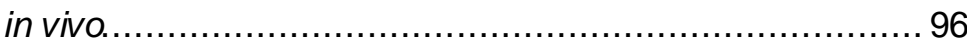

Figure 18. Ectopic miR-149 expression in MDA-MB-231 cells inhibits macrophage recruitment and lung metastasis in vivo. 97

Figure 19. Vimentin expression is not altered in MDA-MB-231miR-149 stable cells. 99 Figure 20. Ectopic miR-149 expression in MDA-MB-231 cells inhibits lung metastasis in vivo 100

Figure 21: miR-149 is epigenetically silenced in TNBC cell lines 101 Figure 22: $\mathrm{CpG}$ sites of miR-149 are hypermethylated in TNBC patients 102 Figure 23: Regulatory role of miR-149 in the crosstalk between triple-negative breast cancer cells and macrophages. 103 


\section{List of Tables}

Table 1: List of equipment used in this thesis.................. 48

Table 2: List of chemicals used in this thesis .................. 49

Table 3: List of consumables used in this thesis ............... 52

Table 4: List of buffers and solutions used in this thesis ......53

Table 5: List of cell lines used in this thesis ................... 56

Table 6: List of cell culture reagents used in this thesis .......56

Table 7: List of oligonucleotides used in this thesis ............ 57

Table 8: List of plasmids and vectors used in this thesis..... 59

Table 9: List of primary antibodies used in this thesis .......... 59

Table 10: List of secondary antibodies used in this thesis ....60

Table 10: List of kits and enzymes used in this thesis ........60 60 


\section{References}

Ali, Remah, and Michael K. Wendt. 2017. "The Paradoxical Functions of EGFR during Breast Cancer Progression." Signal Transduction and Targeted Therapy 2 (December 2016): 1-7. https://doi.org/10.1038/sigtrans.2016.42.

Alluri, Prasanna, and Lisa Newman. 2015. "Basal-like and Triple Negative Breast Cancers: Searching For Positives Among Many Negatives." Surgical Oncology Clinics of North America 23 (3): 567-77.

https://doi.org/10.1016/j.soc.2014.03.003.Basal-like.

Anaya, Jordan. 2016. "OncoLnc: Linking TCGA Survival Data to MRNAs, MiRNAs, and LncRNAs." PeerJ Computer Science 2: e67. https://doi.org/10.7717/peerj-cs.67.

Anderson, Kristin G, Ingunn M Stromnes, and Philip D Greenberg. 2018. "Obstacles Posed by the Tumor Microenvironment to T Cell Activity: A Case for Synergistic Therapies" 31 (3): 311-25. https://doi.org/10.1016/j.ccell.2017.02.008.Obstacles.

Aran, Dvir, Zicheng Hu, and Atul J Butte. 2017. "XCell: Digitally Portraying the Tissue Cellular Heterogeneity Landscape." Genome Biology 18 (1): 220. https://doi.org/10.1186/s13059-017-1349-1.

Argyle, David, and Takanori Kitamura. 2018. "Targeting Macrophage-Recruiting Chemokines as a Novel Therapeutic Strategy to Prevent the Progression of Solid Tumors." Frontiers in Immunology 9 (NOV): 1-15. https://doi.org/10.3389/fimmu.2018.02629. 
Auffray, Cedric, Darin Fogg, Meriem Garfa, Gaelle Elain, Olivier Join-Lambert, Samer Kayal, Sabine Sarnacki, Ana Cumano, Gregoire Lauvau, and Frederic Geissmann. 2007. "Monitoring of Blood Vessels and Tissues by a Population of Monocytes with Patrolling Behavior." Science 317 (5838): 666-70. https://doi.org/10.1126/science.1142883.

Basile, John R., Ana Barac, Tianqing Zhu, Kun Liang Guan, and J. Silvio Gutkind. 2004. "Class IV Semaphorins Promote Angiogenesis by Stimulating Rho-Initiated Pathways through Plexin-B." Cancer Research64 (15): 5212-24. https://doi.org/10.1158/0008-5472.CAN-040126.

Ben-Hamo, Rotem, and Sol Efroni. 2015. "MicroRNA Regulation of Molecular Pathways as a Generic Mechanism and as a Core Disease Phenotype." Oncotarget 6 (3). https://doi.org/10.18632/oncotarget.2734.

Berasain, Carmen, and Matías A. Avila. 2014. "Amphiregulin." Seminars in Cell and Developmental Biology 28: 31-41. https://doi.org/10.1016/j.semcdb.2014.01.005.

Berghmans, T, L Ameye, L Willems, M Paesmans, C Mascaux, J J Lafitte, N Leclercq, J P Sculier, European Lung, and Cancer Working. 2013. "Lung Cancer Identification of MicroRNA-Based Signatures for Response and Survival for Non-Small Cell Lung Cancer Treated with Cisplatin-Vinorelbine A ELCWP Prospective Study \&." Lung Cancer 82 (2): 340-45. https://doi.org/10.1016/j.lungcan.2013.07.020. 
Bieniasz-Krzywiec, Paweł, Rosa Martín-Pérez, Manuel Ehling, Melissa García-Caballero, Sotiria Pinioti, Samantha Pretto, Roel Kroes, et al. 2019. "Podoplanin-Expressing Macrophages Promote Lymphangiogenesis and Lymphoinvasion in Breast Cancer." Cell Metabolism 30: 1-20. https://doi.org/10.1016/j.cmet.2019.07.015.

Bischoff, Annabell, Bettina Huck, Bettina Keller, Michaela Strotbek, Simone Schmid, Melanie Boerries, Hauke Busch, Dafne Müller, and Monilola A. Olayioye. 2014. "MiR149 Functions as a Tumor Suppressor by Controlling Breast Epithelial Cell Migration and Invasion." Cancer Research 74 (18): 5256-65. https://doi.org/10.1158/0008-5472.CAN-13-3319.

Blake, J. A., K. R. Christie, M. E. Dolan, H. J. Drabkin, D. P. Hill, L. Ni, D. Sitnikov, et al. 2015. "Gene Ontology Consortium: Going Forward." Nucleic Acids Research 43 (D1): D1049-56. https://doi.org/10.1093/nar/gku1179.

Burke, Bernard, Athina Giannoudis, Kevin P. Corke, Dalvir Gill, Michael Wells, Loems Ziegler-Heitbrock, and Claire E. Lewis. 2003. "Hypoxia-Induced Gene Expression in Human Macrophages: Implications for Ischemic Tissues and Hypoxia-Regulated Gene Therapy." American Journal of Pathology 163 (4): 1233-43. https://doi.org/10.1016/S0002-9440(10)63483-9.

Calin, George A, Amelia Cimmino, Muller Fabbri, Manuela Ferracin, Sylwia E Wojcik, Masayoshi Shimizu, Cristian Taccioli, et al. 2008. "MiR-15a and MiR-16-1 Cluster Functions in Human Leukemia" 105 (13): 1-6.

Carmeliet, Peter, and Rakesh K Jain. 2011. "Molecular Mechanisms and Clinical Applications of Angiogenesis." 
https://doi.org/10.1038/nature10144.

Chan, S. H., W. C. Huang, J. W. Chang, K. J. Chang, W. H.

Kuo, M. Y. Wang, K. Y. Lin, et al. 2014. "MicroRNA-149

Targets GIT1 to Suppress Integrin Signaling and Breast

Cancer Metastasis." Oncogene 33 (36): 4496-4507.

https://doi.org/10.1038/onc.2014.10.

Chen, Lin, Jie Li, Fei Wang, Chengliang Dai, Fan Wu,

Xiao man Liu, Taotao Li, et al. 2016. "Tie2 Expression on Macrophages Is Required for Blood Vessel

Reconstruction and Tumor Relapse after

Chemotherapy." Cancer Research 76 (23): 6828-38.

https://doi.org/10.1158/0008-5472.CAN-16-1114.

Cimino, Daniela, Cristiano De Pittà, Francesca Orso, Matteo Zampini, Silvia Casara, Elisa Penna, Elena Quaglino, et al. 2013. "MiR148b Is a Major Coordinator of Breast Cancer Progression in a Relapse-Associated MicroRNA Signature by Targeting ITGA5, ROCK1, PIK3CA, NRAS, and CSF1." FASEB Journal 27 (3): 1223-35.

https://doi.org/10.1096/fj.12-214692.

Condeelis, John, and Jeffrey W Pollard. 2006. "Macrophages:

Obligate Partners for Tumor Cell Migration, Invasion, and Metastasis." Cell 124 (2): 263-66.

https://doi.org/10.1016/j.cell.2006.01.007.

Coniglio, Salvatore J, Eliseo Eugenin, Kostantin Dobrenis, E Richard Stanley, Brian L West, Marc H Symons, and Jeffrey E Segall. 2012. "Microglial Stimulation of Glioblastoma Invasion Involves Epidermal Growth Factor Receptor (EGFR) and Colony Stimulating Factor 1 Receptor (CSF-1R) Signaling." Molecular Medicine 18 (3): 519-27. https://doi.org/10.2119/molmed.2011.00217. 
Delaire, Stéphanie, Christian Billard, Rafaèle Tordjman, Alain Chédotal, Abdellah Elhabazi, Armand Bensussan, Laurence Boumsell, and Christian Billard. 2001. "Biological Activity of Soluble CD100. II. Soluble CD100, Similarly to H-Semalll, Inhibits Immune Cell Migration." J Immunology, no. 166: 4348-4354;

https://doi.org/10.4049/jimmunol.166.7.4348.

Dweep, Harsh, and Norbert Gretz. 2015. "MiRWalk2.0: A Comprehensive Atlas of MicroRNA-Target Interactions." Nature Methods 12 (8): 697-697. https://doi.org/10.1038/nmeth.3485.

Dyer, B. W., F. A. Ferrer, D. K. Klinedinst, and R. Rodriguez. 2000. "A Noncommercial Dual Luciferase Enzyme Assay System for Reporter Gene Analysis." Analytical Biochemistry 282 (1): 158-61. https://doi.org/10.1006/abio.2000.4605.

Eckstein, Niels, Kati Servan, Luc Girard, Di Cai, Georg Von Jonquieres, Ulrich Jaehde, Matthias U. Kassack, Adi F. Gazdar, John D. Minna, and Hans Dieter Royer. 2008. "Epidermal Growth Factor Receptor Pathway Analysis Identifies Amphiregulin as a Key Factor for Cisplatin Resistance of Human Breast Cancer Cells." Journal of Biological Chemistry 283 (2): 739-50. https://doi.org/10.1074/jbc.M706287200.

Edin, Sofia, Maria L Wikberg, Anna M Dahlin, Arne Oldenborg, and Richard Palmqvist. 2012. "The Distribution of Macrophages with a M1 or M2 Phenotype in Relation to Prognosis and the Molecular Characteristics of Colorectal Cancer" 7 (10). https://doi.org/10.1371/journal.pone.0047045. 
Enerly, Espen, Israel Steinfeld, Kristine Kleivi, Suvi Katri Leivonen, Miriam R. Aure, Hege G. Russnes, Jo Anders Rønneberg, et al. 2011. "MiRNA-MRNA Integrated Analysis Reveals Roles for Mirnas in Primary Breast Tumors." PLOS ONE 6 (2). https://doi.org/10.1371/journal.pone.0016915.

Evans, Elizabeth E, Alan S Jonason Jr, Holm Bussler, Sebold Torno, Janaki Veerarag havan, Christine Reilly, Michael A Doherty, et al. 2015. "Antibody Blockade of Semaphorin 4D Promotes Immune In Fi Ltration into Tumor and Enhances Response to Other Immunomodulatory Therapies," no. 19: 689-702.

https://doi.org/10.1158/2326-6066.CIR-14-0171.

Frank, Filipp, Nahum Sonenberg, and Bhushan Nagar. 2010. "Structural Basis for 5'-Nucleotide Base-Specific Recognition of Guide RNA by Human AGO2." Nature 465 (7299): 818-22. https://doi.org/10.1038/nature09039.

Fridman, Wolf Herman, Franck Pagès, and Catherine Sautèsfridman. 2012. "The Immune Contexture in Human Tumours : Impact on Clinical Outcome." Nature Publishing Group 12 (4): 298-306. https://doi.org/10.1038/nrc3245.

Gene Ontology Consortium. 2000. "Gene Ontology : Tool for The." Nature Genetics 25 (may): 25-29. https://doi.org/10.1038/75556.

Gengenbacher, Nicolas, Mahak Singhal, and Hellmut Augustin. 2017. "Preclinical Mouse Solid Tumour Models: Status Quo, Challenges and Perspectives." Nature Publishing Group 17: 751-765. 
https://doi.org/10.1038/nrc.2017.92.

Goswami, Sumanta, Erik Sahai, Jeffrey B Wyckoff, Michael

Cammer, Dianne Cox, Fiona J Pixley, E Richard Stanley, Jeffrey E Segall, and John S Condeelis. 2005. "Macro phages Promote the Invasion of Breast Carcinoma Cells via a Colony-Stimulating Factor-1/ Epidermal Growth Factor Paracrine Loop." Cancer Research, no. 12: 5278-84.

Gwak, Jae Moon, Min Hye Jang, Dong II Kim, An Na Seo, and So Yeon Park. 2015. "Prognostic Value of TumorAssociated Macrophages According to Histologic Locations and Hormone Receptor Status in Breast Cancer,"1-14. https://doi.org/10.1371/journal.pone.0125728.

Hambardzumyan, Dolores, David H. Gutmann, and Helmut Kettenmann. 2015. "The Role of Microglia and Macrophages in Glioma Maintenance and Progression." Nature Neuroscience 19 (1): 20-27. https://doi.org/10.1038/nn.4185.

Harbeck, Nadia, Frédérique Penault-Llorca, Javier Cortes, Michael Gnant, Nehmat Houssami, Philip Poortmans, Kathryn Ruddy, Janice Tsang, and Fatima Cardoso. 2019. Breast Cancer. Nature Reviews. Disease Primers. Vol. 5. https://doi.org/10.1038/s41572-019-0111-2.

Hardbower, Dana M, M Blanca Piazuelo, T Keith, Dana M Hardbower, Kshipra Singh, Mohammad Asim, Thomas G Verriere, et al. 2016. "EGFR Regulates Macrophage Activation and Function in Bacterial Infection Find the Latest Version: The Journal of Clinical Investigation EGFR Regulates Macrophage Activation and Function in 
Bacterial Infection" 126 (9): 3296-3312. https://doi.org/10.1172/JCl83585.of.

Hartman, Zachary C, Graham M Poage, Petra Den Hollander, Anna Tsimelzon, Jamal Hill, Yun Zhang, Abhijit Mazumdar, Susan G Hilsenbeck, Gordon B Mills, and Powel H Brown. 2013. "Growth of Triple-Negative Breast Cancer Cells Relies upon Coordinate Autocrine Expression of the Proin FI Ammatory Cytokines IL-6 and IL-8" 73 (11): 3470-81. https://doi.org/10.1158/00085472.CAN-12-4524-T.

He, Dong Xu, Xiao Ting Gu, You Ran Li, Li Jiang, Jian Jin, and Xin Ma. 2014. "Methylation-Regulated MiR-149 Modulates Chemoresistance by Targeting GlcNAc NDeacetylase/N-Sulfotransferase-1 in Human Breast Cancer." FEBS Journal 281 (20): 4718-30. https://doi.org/10.1111/febs. 13012.

Heo, Tae-hwe, Joseph Wahler, and Nanjoo Suh. 2016. "Potential Therapeutic Implications of IL-6/IL-6R/Gp130Targeting Agents in Breast Cancer." Oncotarget, 7 (13).

Humphries, Brock, Zhishan Wang, and Chengfeng Yang. 2019. "MicroRNA Regulation of Epigenetic Modifiers in Breast Cancer." Cancers Review 11 (897).

Imtiyaz, Hongxia Z, Brian Keith, M Celeste Simon, Hongxia Z Imtiyaz, Emily P Williams, Michele M Hickey, Shetal A Patel, and Amy C Durham. 2010. "Hypoxia-Inducible Factor 2 a Regulates Macrophage Function in Mouse Models of Acute and Tumor Inf lammation Find the Latest Version : Hypoxia-Inducible Factor $2 \alpha$ Regulates Macrophage Function in Mouse Models of Acute and Tumor Inflammation" 120 (8): 2699-2714. 
https://doi.org/10.1172/JCl39506.phages.

Izquierdo, Laura, Mercedes Ingelmo-torres, Carmen Mallofré, Juan José Lozano, Marie Verhasselt-crinquette, Xavier Leroy, Pierre Colin, et al. 2014. "Prognostic Value of MicroRNA Expression Pattern in Upper Tract Urothelial Carcinoma," 813-21. https://doi.org/10.1111/bju.12551.

Jerez, M, Rosario Carmona, Vanessa De Luque, Luis Vicioso, Luis G Pe, Nuria Ribelles, M Gonzalo Claros, et al. 2014. "A MicroRNA Signature Associated with Early Recurrence in Breast Cancer" 9 (3): 1-14. https://doi.org/10.1371/journal.pone.0091884.

Jin, Kideok, Niranjan Pandey, and Aleksander Popel. 2018. "Simultaneous Blockade of IL-6 and CCL5 Signaling for Synergistic Inhibition of Triple-Negative Breast Cancer Growth and Metastasis," 1-10.

Kacinski, B. M., K. A. Scata, D. Carter, L. D. Yee, E. Sapi, B. L. King, S. K.M. A. Chambers Jones, M. H. Pirro, E. R. Stanley, and L. R. Rohrscneider. 1991. "FMS (CSF-1 Receptor) and CSF-1 Transcripts and Protein Are Expressed by Human Breast Carcinomas in Vivo and in Vitro." Oncogene6 (6): 941-52.

Kacinski, Barry M. 1995. "CSF-1 and Its Receptor in Ovarian, Endometrial and Breast Cancer." Annals of Medicine 27 (1): 79-85. https://doi.org/10.3109/07853899509031941.

Kedmi, Merav, Nir Ben-Chetrit, Cindy Körner, Maicol Mancini, Noa Bossel Ben-Moshe, Mattia Lauriola, Sara Lavi, et al. 2015. "EGF Induces MicroRNAs That Target Suppressors of Cell Migration: MiR-15b Targets MTSS1 
in Breast Cancer." Science Signaling 8 (368): ra29. https://doi.org/10.1126/scisignal.2005866.

Kong, Yong-gang, Min Cui, Shi-ming Chen, YuXu, Yong Xu, and Ze-zhang Tao. 2018. "LncRNA-LINC00460 Facilitates Nasopharyngeal Carcinoma Tumorigenesis through Sponging MiR-149-5p to up-Regulate IL6" 639 (October 2017): 77-84. https://doi.org/10.1016/j.gene.2017.10.006.

Laoui, Damya, Eva van Overmeire, Patrick de Baetselier, Jo A. van Ginderachter, and Geert Raes. 2014. "Functional Relationship between Tumor-Associated Macrophages and Macrophage Colony-Stimulating Factor as Contributors to Cancer Progression." Frontiers in Immunology 5 (OCT): 1-15. https://doi.org/10.3389/fimmu.2014.00489.

Li, Li, Yunjian Sheng, Lin Lv, and Jian Gao. 2013. "The Association between Two MicroRNA Variants (MiR-499, MiR-149) and Gastrointestinal Cancer Risk: A MetaAnalysis." PLOS ONE 8 (11): 1-10.

https://doi.org/10.1371/journal.pone.0081967.

Li, Pu, Jing Xuan Shan, Xue Hua Chen, Di Zhang, Li Ping Su, Xiu Ying Huang, Bei Qin Yu, et al. 2015. "Epigenetic Silencing of MicroRNA-149 in Cancer-Associated Fibroblasts Mediates Prostaglandin E2/Interleukin-6 Signaling in the Tumor Microenvironment." Cell Research 25 (5): 588-603.

https://doi.org/10.1038/cr.2015.51.

Lin, Elaine Y, Valerie Gouon-Evans, Andrew V Nguyen, and Jeffrey W Pollard. 2002. "The Macrophage Growth Factor CSF-1 in Mammary Gland Development and 
Tumor Progression." Journal of Mammary Gland Biology and Neoplasia 7 (2): 147-62.

https://doi.org/10.1023/A:1020399802795.

Lin, Ling, Yang-de Zhang, Zi-yu Chen, Yuxiang Chen, and Cai-ping Ren. 2016. "The Clinicopathological Significance of MiR-149 and PARP-2 in Hepatocellular Carcinoma and Their Roles in Chemo / Radiotherapy." Tumor Biology. https://doi.org/10.1007/s 13277-0165106-y.

Linder, S., D. Nelson, , M. Weiss, and M. Aepfelbacher. 2002. "Wiskott-Aldrich Syndrome Protein Regulates Podosomes in Primary Human Macrophages." Proceedings of the National Academy of Sciences 96 (17): 9648-53. https://doi.org/10.1073/pnas.96.17.9648.

Lu, Ning, Lihong Wang, Hailong Cao, Liping Liu, Luc Van Kaer, Mary K. Washington, Michael J. Rosen, et al. 2014. "Activation of the Epidermal Growth Factor Receptor in Macrophages Regulates Cytokine Production and Experimental Colitis." The Journal of Immunology 192 (3): 1013-23.

https://doi.org/10.4049/jimmunol.1300133.

Mantovani, Alberto, Federica Marchesi, Alberto Malesci, Luigi Laghi, and Paola Allavena. 2017. "Tumour-Associated Macrophages as Treatment Targets in Oncology." Nature Reviews Clinical Oncology 14 (7): 399-416. https://doi.org/10.1038/nrclinonc.2016.217.

Marotta, Lauren L C, Vanessa Almendro, Andriy Marusyk, Michail Shipitsin, Janina Schemme, Sarah R Walker, Noga Bloushtain-qimron, et al. 2011. "The JAK2 / STAT3 Signaling Pathway Is Required for Growth of CD44 + 
CD24 - Stem Cell - like Breast Cancer Cells in Human Tumors" 121 (7): 2723-35.

https://doi.org/10.1172/JCl44745DS1.

Mauer, Jan, Bhagirath Chaurasia, Julia Goldau, Merly C. Vogt, Joan Ruud, Khoa D. Nguyen, Sebastan Theurich, et al. 2012. "Interleukin-6 Signaling Promotes Alternative Macrophage Activation to Limit Obesity-Associated Insulin Resistance and Endotoxemia." Nature Immunology 29 (6): 997-1003.

https://doi.org/10.1038/ni.2865.Interleukin-6.

Mazzieri, Roberta, Ferdinando Pucci, Davide Moi, Erika Zonari, Anna Rang hetti, Alvise Berti, Letterio S. Politi, et al. 2011. "Targeting the ANG2/TIE2 Axis Inhibits Tumor Growth and Metastasis by Impairing Angiogenesis and Disabling Rebounds of Proangiogenic Myeloid Cells." Cancer Cell 19 (4): 512-26. https://doi.org/10.1016/j.ccr.2011.02.005.

Nguyen, Don X, Paula D Bos, and Joan Massagué. 2009. "Metastasis: From Dissemination to Organ-Specific Colonization." Nature Reviews Cancer 9 (4): 274-84. https://doi.org/10.1038/nrc2622.

Nieman, Kristin M., Hilary A. Kenny, Carla V. Penicka, Andras Ladanyi, Rebecca Buell-Gutbrod, Marion R. Zillhardt, Iris L. Romero, et al. 2011. "Adipocytes Promote Ovarian Cancer Metastasis and Provide Energy for Rapid Tumor Growth." Nature Medicine 17 (11): 1498-1503. https://doi.org/10.1038/nm.2492.

Obeid, Elias, Rita Nanda, Yang Xin Fu, and Olufunmilayo I. Olopade. 2013. "The Role of Tumor-Associated Macrophages in Breast Cancer Progression." 
International Journal of Oncology 43 (1): 5-12. https://doi.org/10.3892/ijo.2013.1938.

Paget, Stephen. 1889. "The Distribution of Secondary Growths in Cancer of the Breast." The Lancet 1 (21): 1-4.

Patsialou, Antonia, Y Wang, J Pignatelli, X Chen, D Entenberg, M Oktay, and J S Condeelis. 2015. "Auto crine CSF1R Signaling Mediates Switching between Invasion and Proliferation Downstream of TGF $\beta$ in Claudin-Low Breast Tumor Cells," no. June 2014: 2721-31. https://doi.org/10.1038/onc.2014.226.

Patsialou, Antonia, Jeffrey Wyckoff, Yarong Wang, Sumanta Goswami, E Richard, and John S Condeelis. 2010. "Invasion of Human Breast Cancer Cells in Vivo Requires Both Paracrine and Autocrine Loops Involving the Colony Stimulating Factor-1 Receptor" 69 (24): 9498-9506. https://doi.org/10.1158/0008-5472.CAN-091868. Invasion.

Pereira, Ethel R., Dmitriy Kedrin, Giorgio Seano, Olivia Gautier, Eelco F.J. Meijer, Dennis Jones, Shan Min Chin, et al. 2018. "Lymph Node Metastases Can Invade Local Blood Vessels, Exit the Node, and Colonize Distant Organs in Mice." Science 359 (6382): 1403-7. https://doi.org/10.1126/science.aal3622.

Pillar, Nir, Avital Luba Polsky, Daphna Weissglas-volkov, and Noam Shomron. 2018. "Comparison of Breast Cancer Metastasis Models Reveals a Possible Mechanism of Tumor Aggressiveness." Cell Death and Disease. https://doi.org/10.1038/s41419-018-1094-8. 
Poh, Ashleigh R., and Matthias Ernst. 2018. "Targeting Macrophages in Cancer: From Bench to Bedside." Frontiers in Oncology 8 (MAR): 1-16. https://doi.org/10.3389/fonc.2018.00049.

Quigley, David A., and Vessela Kristensen. 2015. "Predicting Prognosis and Therapeutic Response from Interactions between Lymphocytes and Tumor Cells." Molecular Oncology 9 (10): 2054-62. https://doi.org/10.1016/j.molonc.2015.10.003.

Rahman, Mumtahena, Laurie K. Jackson, W. Evan Johnson, Dean Y. Li, Andrea H. Bild, and Stephen R. Piccolo. 2015. "Alternative Preprocessing of RNA-Sequencing Data in the Cancer Genome Atlas Leads to Improved Analysis Results." Bioinformatics 31 (22): 3666-72. https://doi.org/10.1093/bioinformatics/btv377.

Rashid, Omar M, Kazuaki Takabe, and Lee Moffitt. 2015. "Animal Models for Exploring the Pharmacokinetics of Breast Cancer Therapies." Expert Opinion on Drug Metabolism and Toxicology 11 (2): 221-30. https://doi.org/10.1517/17425255.2015.983073.Animal.

Rashid, Omar, Masayuki Nagahashi, Suburamaniam Ramachandran, Catherine Dumur, Julia C Schaum, Akimitsu Yamada, Tomoyoshi Aoyagi, Sheldon Milstien, Sarah Spiegel, and Kazuaki Takabe. 2013. "Is Tail Vein Injection a Relevant Breast Cancer Lung Metastasis Model ?' Journal of Thoracic Disease 5 (4): 385-92. https://doi.org/10.3978/j.issn.2072-1439.2013.06.17.

Rehmsmeier, Marc. 2006. "RNAhybrid: MicroRNA Target Prediction Easy, Fast and Flexible" 34 (16): 451-54. https://doi.org/10.1093/nar/gkl243. 
Roudnicky, Filip, Sinem Karaman, Michael Detmar, and Maija Hollme. 2015. "Characterization of Macrophage Positive and Triple-Negative Breast Cancer," 1-10. https://doi.org/10.1038/srep09188.

Rupaimoole, Rajesha, and Frank J. Slack. 2017. "MicroRNA Therapeutics: Towards a New Era for the Management of Cancer and Other Diseases." Nature Reviews Drug Discovery 16 (3): 203-21. https://doi.org/10.1038/nrd.2016.246.

Sierra, Jose Rafael, Simona Corso, Luisa Caione, Virna Cepero, Paolo Conrotto, Alessandro Cignetti, Wanda Piacibello, et al. 2008. "Tumor Angiogenesis and Progression Are Enhanced by Sema4D Produced by Tumor-Associated Macrophages." The Journal of Experimental Medicine 205 (7): 1673-85. https://doi.org/10.1084/jem.20072602.

Sossey-alaoui, Khalid, Elzbieta Pluskota, Katarzyna Bialkowska, Dorota Szpak, Yvonne Parker, Chevaun D Morrison, Daniel J Lindner, William P Schiemann, and Edward F Plow. 2017. "Kindlin-2 Regulates the Growth of Breast Cancer Tumors by Activating CSF-1 - Mediated Macrophage In Fi Ltration," 5129-42. https://doi.org/10.1158/0008-5472.CAN-16-2337.

Stewart, Delisha A., Yinmeng Yang, Liza Makowski, and Melissa A. Troester. 2012. "Basal-like Breast Cancer Cells Induce Phenotypic and Genomic Changes in Macrophages." Molecular Cancer Research 10 (6): 72738. https://doi.org/10.1158/1541-7786. mcr-11-0604.

Su, Shicheng, Jianing Chen, Herui Yao, Jiang Liu, Shubin Yu, Liyan Lao, Minghui Wang, et al. 2018. "CD 10+GPR77+ 
Cancer-Associated Fibroblasts Promote Cancer Formation and Chemoresistance by Sustaining Cancer Stemness." Cell 172 (4): 841-856.e16. https://doi.org/10.1016/j.cell.2018.01.009.

Syeda, Zainab Ali, Siu Semar, Saratu Langden, Choijamts Munkhzul, and Mihye Lee. 2020. "Regulatory Mechanism of MicroRNA Expression in Cancer" 5.

Tang, Qian, Hu Ouyang, Dongxiu He, Cuiyun Yu, and Guotao Tang. 2019. "MicroRNA-Based Potential Diagnostic, Prognostic and Therapeutic Applications in TripleNegative Breast Cancer." Artificial Cells, Nanomedicine, and Biotechnology 47 (1): 2800-2809. https://doi.org/10.1080/21691401.2019.1638791.

Tu, Hsi Feng, Chung Ji Liu, Che Lun Chang, Pei Wen Wang, Shou Yen Kao, Cheng Chieh Yang, En Hao Yu, Shu Chun Lin, and Kuo Wei Chang. 2012. "The Association between Genetic Polymorphism and the Processing Efficiency of MiR-149 Affects the Prognos is of Patients with Head and Neck Squamous Cell Carcinoma." PLoS ONE 7 (12): e51606.

https://doi.org/10.1371/journal.pone.0051606.

Vlaicu, Philip, Philipp Mertins, Thomas Mayr, Peter Widschwendter, Beyhan Ataseven, Bernhard Högel, Wolfgang Eiermann, Pjotr Knyazev, and Axel Ullrich. 2013. "Monocytes/Macrophages Support Mammary Tumor Invasivity by Co-Secreting Lineage-Specific EGFR Ligands and a STAT3 Activator." BMC Cancer 13 (1): 197. https://doi.org/10.1186/1471-2407-13-197.

Weber, Barbara, Carlo Stresemann, Bodo Brueckner, Frank Lyko, Barbara Weber, Carlo Stresemann, Bodo 
Brueckner, Frank Lyko, and Frank Lyko. 2007. "Methylation of Human MicroRNA Genes in Normal and Neoplastic Cells ND ES SC Key Words RIB" 4101 (May). https://doi.org/10.4161/cc.6.9.4209.

Weng, Yueh-shan, Hong-yu Tseng, Yen-an Chen, Pei-chun Shen, Aushia Tanzih, Al Haq, Li-mei Chen, Yi-chung Tung, and Hsin-ling Hsu. 2019. "MCT-1/MiR-34a/L-6/IL6R Signaling Axis Promotes EMT Progression, Cancer Stemness and M2 Macrophage Polarization in TripleNegative Breast Cancer," 1-15.

Wu, Song, Wei Zhu, Patricia Thompson, and Yusuf A.

Hannun. 2018. "Evaluating Intrinsic and Non-Intrinsic Cancer Risk Factors." Nature Communications 9 (1). https://doi.org/10.1038/s41467-018-05467-z.

Yamashita, Nami, Eriko Tokunaga, Hiroyuki Kitao, and Yuichi Hisamatsu. 2013. "Vimentin as a Poor Prognostic Factor for Triple-Negative Breast Cancer." Journal of Cancer Research and Clinical Oncology 139: 739-46. https://doi.org/10.1007/s00432-013-1376-6.

Yang, Hua, Asma Buhamrah, Abraham Schneider, Yi Ling Lin, Hua Zhou, Amr Bugshan, and John R. Basile. 2016.

"Semaphorin 4D Promotes Skeletal Metastasis in Breast Cancer." PLOS ONE 11 (2): 1-20.

https://doi.org/10.1371/journal.pone.0150151.

Yang, Ju, Xiaojing Li, Xiuping Liu, and Yongjuan Liu. 2015. "The Role of Tumor-Associated Macrophages in Breast Carcinoma Invasion and Metastasis" 8 (6): 6656-64.

Yang, Ming, Daniel McKay, Jeffrey W. Pollard, and Claire E. 
Lewis. 2018. "Diverse Functions of Macrophages in Different Tumor Microenvironments." Cancer Research 78 (19): 5492-5503. https://doi.org/10.1158/00085472.CAN-18-1367.

Yang, Ning, Shan Zhu, Xinping Lv, Yuan Qiao, Yong Jun Liu, and Jingtao Chen. 2018. "MicroRNAs: Pleiotropic Regulators in the Tumor Microenvironment." Frontiers in Immunology 9 (NOV): 1-12. https://doi.org/10.3389/fimmu.2018.02491.

Ye, Shu-biao, Ze-lei Li, Dong-hua Luo, Bi-jun Huang, and Yusuan Chen. 2014. "Tumor-Derived Exosomes Promote Tumor Progression and T-Cell Dysfunction through the Regulation of Enriched Exosomal MicroRNAs in Human Nasopharyngeal Carcinoma." Oncotarget 5 (14).

Yin, Yuan, Xing Cai, Xi Chen, Hongwei Liang, Yujing Zhang, Jing Li, Zuoyun Wang, and Xiulan Chen. 2014. "TumorSecreted MiR-214 Induces Regulatory T Cells : A Major Link between Immune Evasion and Tumor Growth." Nature Publishing Group 24 (10): 1164-80.

https://doi.org/10.1038/cr.2014.121.

Yu, Hua, Drew Pardoll, and Richard Jove. 2009. "STATs in Cancer Inflammation and Immunity: A Leading Role for STAT3" 9 (NovEmBER). https://doi.org/10.1038/nrc2734.

Zaiss, Dietmar M.W., Jorg van Loosdregt, Andrea Gorlani, Cornelis P.J. Bekker, Andrea Gröne, Maria Sibilia, Paul M.P. van Bergen en Henegouwen, Rob C. Roovers, Paul J. Coffer, and Alice J.A.M. Sijts. 2013. "Amphiregulin Enhances Regulatory T Cell-Suppressive Function via the Epid ermal Growth Factor Receptor." Immunity 38 (2): 275-84. https://doi.org/10.1016/j.immuni.2012.09.023. 
Zhang, Qiong wen, Lei Liu, Chang yang Gong, Hua shan Shi, Yun hui Zeng, Xiao ze Wang, Yu wei Zhao, and Yu quan Wei. 2012. "Prognostic Significance of Tumor-Associated Macrophages in Solid Tumor: A Meta-Analysis of the Literature." PLoS ONE 7 (12): e50946. https://doi.org/10.1371/journal.pone.0050946.

Zhao, Gang, Liping Liu, Richard M. Peek, Xishan Hao, D. Brent Polk, Hui Li, and Fang Yan. 2016. "Activation of Epidermal Growth Factor Receptor in Macrophages Mediates Feedback Inhibition of M2 Polarization and Gastrointestinal Tumor Cell Growth." Journal of Biological Chemistry 291 (39): 20462-72. https://doi.org/10.1074/jbc.M116.750182.

Zhi, Yingru, Hao Zhou, Abudoureyimu Mubalake, Ying Chen, Bei Zhang, Kai Zhang, Xiaoyuan Chu, and Rui Wang. 2018. "Regulation and Functions of MicroRNA-149 in Human Cancers." Cell Proliferation 51 (5): 1-12. https://doi.org/10.1111/cpr.12465. 


\section{Acknowledgements}

I would like to express my deepest appreciation to my supervisor, Professor Dr. Monilola Olayioye for all the immense support, assistance, and excellent guidance she gave me since the application process to obtain my PhD-fellowship until the competition of my PhD studies. I do appreciate she was always opened to share her valuable scientific advice, knowledge, experience and along with her constructive criticism and discussions, she made not only a significant positive impact on this project but also on myself.

I would like to thank Professor Dr. Thomas Kufer for kindly accepting and taking the time to be co-examiner of my PhD thesis.

I want to thank Professor Dr. Melanie Boerries, and Professor Dr. Hauke Busch for the bioinformatical analysis support and Dr. Stephan Eisler for his assistance with imaging.

I am also grateful to Dr. Angelika Hausser for all her valuable input and discussions for this project as well for giving me the chance to participate in further interesting projects from her lab.

Thanks to all the members of the MoLab and AhaLab for the support and for the great stimulating working environment 
during my PhD, especially to Yannick Frey and David Benz, for making all the long-working nights in the lab smoother and more enjoyable.

Last but not least, I am extremely grateful to my family, especially my parents Lila González and Eduardo Sánchez, for always believing in me, encouraging me to follow my goals, and sharing with me their immense love despite the enormous distance during these years. I'd also like to extend my gratitude to my dear friends in México, especially to Erick Aguirre, that despite the enormous distance, all your continuous support and warmth were very important during these years. I also want to thank all the wonderful people I met here in Germany and those who became my German family, particularly to David Benz, Norman von der Heyden and Yannick Frey for warmly welco ming me in their lives and always making me feel at home. 


\section{Curriculum vitae}

\section{Personal details}

\begin{tabular}{l|l} 
Name: & Ismael Sánchez-González \\
Date of Bith: & 08 January, 1988 \\
Place of birth: & Mexico city, Mexico \\
Nationality: & Mexican
\end{tabular}

\section{Education and training}

Since

10/2015

$2011-2013$

$2006-2011$

$2005-2006$

$2003-2006$

$2000-2003$
PhD program at the Institute of Cell Biology and Immunology, University of Stuttgart, Germany

M. Sc. in Immunology at the National Polytechnic Institute, Mexico

BSc. in Pharmaceutical and Biological Chemistry at the National Autonomous University of Mexico, Mexico

Histopathology Technician at the National Autono mous University of Mexico, Mexico

Senior high School at the National Autono mous University of Mexico, Mexico

Junior high school at Cristobal Colón School, Mexico 
\begin{tabular}{l|l}
1994 - 2000 & $\begin{array}{l}\text { Primary school at Cristobal Colón School, } \\
\text { Mexico }\end{array}$
\end{tabular}

\section{Research activities and professional experience}

2015 - 2019 Institute of Cell Biology and Immunology, University of Stuttgart, Germany, Scientific work on the role of miR-149 in breast cancer (PhD thesis)

Title: miR-149 Suppresses Breast Cancer Metastasis by Blocking Paracrine Interactions with Macrophages

2011 - 2013 Research assistant and M. Sc. thesis at the Medical Research Unit on Immunochemistry, Specialties Hospital, National Medical Centre Siglo XXI, Mexican Social Security Institute, Mexico

Title: Evaluation of the antibody response induced by the LPPG from E. histolytica and the porin OmpC from $S$. typhi as a possible bivalent vaccine against amebic liver abscess and infection by S. typhi.

$2010-2011$ BSc. thesis at the Medical Research Unit on Immunochemistry, Specialties Hospital, National Medical Centre Siglo XXI, Mexican Social Security Institute, Mexico

Title: Effect of structural modifications in the LPS from $S$. typhimurium, in the recognition by the complex TLR4/MD2/CD14. 


\begin{tabular}{l|l}
$2009-2010$ & $\begin{array}{l}\text { Internship at the Medical Research Unit on } \\
\text { Immunochemistry, Specialties Hospital, } \\
\text { National Medical Centre Siglo XXI, Mexican } \\
\text { Social Security Institute, Mexico } \\
\text { Project: Antigen-adjuvant properties of } \\
\text { papaya mosaic virus. }\end{array}$ \\
Internship at the Psychiatric institute Juan \\
$\begin{array}{l}\text { Ramón de la Fuente, Mexico } \\
\text { Project: Anticonvulsant properties of Annon } \\
\text { diversifolia extracts }\end{array}$
\end{tabular}

\section{Fellowships}

\begin{tabular}{l|l}
$2015-2019$ & $\begin{array}{l}\text { PhD fellowship by the DAAD (German } \\
\text { Academic Exchange Service and } \\
\text { CONACYT (National Council of Science and } \\
\text { Technology) }\end{array}$ \\
2011-2013 $2010-2011$ & $\begin{array}{l}\text { M.Sc. fellowship by CONACYT (National } \\
\text { Council of Science and Technology) } \\
\text { Fellowship in Excellence in Health and } \\
\text { Nutrition by Carlos Slim Grupo Carso } \\
\text { Research assistant fellowship by CONACYT } \\
\text { (National Council of Science and } \\
\text { Technology) }\end{array}$
\end{tabular}




\section{Publications}

This work was published in part in the following publication:

Sánchez-González I, Bobien A, Molnar C, Schmid S, Strotbek M, Boerries M, Busch H, Olayioye MA. miR-149 Suppresses Breast Cancer Metastasis by Blocking Paracrine Interactions with Macro phages. Cancer Research. 2020 Jan; 80:1330-1341.

Other publications:

Pacheco-Fernandez N, Pakdel M, BlankB, Sanchez-Gonzalez I, Weber K, Tran ML, Hecht TK, Gautsch R, Beck G, Perez F, Hausser A, Linder S, von Blume J. Nucleobindin-1 regulates ECM degradation by promoting intra-Golgi trafficking of MMPs. Journal of Cell Biology. 2020 Aug; 219:e201907058.

Chen M, Urs MJ, Sánchez-González I, Olayioye MA, Herde M, Witte CP. m6A RNA Degradation Products Are Catabolized by an Evolutionarily Conserved N6-Methyl-AMP Deaminase in Plant and Mammalian Cells. Plant Cell. 2018 Jul; 30:15111522.

Strotbek M, Schmid S, Sánchez-GonzálezI, Boerries M, Busch $\mathrm{H}$, Olayioye MA. miR-181 elevates Akt signaling by co-targeting PHLPP2 and INPP4B phosphatases in luminal breast cancer. International Journal of Cancer. 2017 May; 140:2310-2320. 


\section{Conference presentations}

Sánchez-González, I. miR-149 suppresses breast cancer metastasis by blocking paracrine interactions with macrophages. Oral presentation delivered at the IZI Workshop on Molecular Mechanisms and Therapeutic Approaches in Cancer, Feldberg-Falkau, Germany, October 2019.

Sánchez-González, I. miR-149 functions as a tumor suppressor by controlling invasive motility through both cell intrinsic and paracrine signaling mechanisms. Oral presentation delivered at the International Conference on Tumor Microenvironment, Lisbon, Portugal, June 2018.

Sánchez-González, I, Kiefer J, Frey Y, Stephan I, Krautter E, and Olayioye M. Role of DLC3 in macrophages. Poster presentation delivered at the IZI Workshop on Molecular Mechanisms and Therapeutic Approaches in Cancer, Freudenstadt, Germany, October 2018.

Sánchez-González, I. MicroRNA-149 in breast carcinoma cell and macrophage communication.

Oral presentation delivered at the IZI Workshop on Molecular Mechanisms and Therapeutic Approaches in Cancer and Inflammatory Diseases, Freudenstadt, Germany. September 2017.

Sánchez-González, I. Protective activity of antibodies generated by the immunization of the mixture of LPPG from $E$. histolytica with the OmpC porin from S. typhi, as a bivalent vaccine against amebic liver abscess by $E$. histolytica and infection by $S$. typhi. Poster presentation delivered at the International Congress of Immunology, Milan, Italy, August 2013. 